LA WAE NCE LIVEAMCAE NATIONAL LABOAATORY

\title{
Detection of special nuclear material in cargo containers using neutron interrogation
}

Dennis Slaughter, Mark Accatino, Adam Bernstein, James Candy, Arden Dougan, James Hall, Alex Loshak, Doug Manatt, Alan Meyer, Bert Pohl, Stanley Prussin (UC Berkeley), Rosemary Walling, David Weirup.

\section{August 2003}


This document was prepared as an account of work sponsored by an agency of the United States Government. Neither the United States Government nor the University of California nor any of their employees, makes any warranty, express or implied, or assumes any legal liability or responsibility for the accuracy, completeness, or usefulness of any information, apparatus, product, or process disclosed, or represents that its use would not infringe privately owned rights. Reference herein to any specific commercial product, process, or service by trade name, trademark, manufacturer, or otherwise, does not necessarily constitute or imply its endorsement, recommendation, or favoring by the United States Government or the University of California. The views and opinions of authors expressed herein do not necessarily state or reflect those of the United States Government or the University of California, and shall not be used for advertising or product endorsement purposes.

This work was performed under the auspices of the U.S. Department of Energy by University of California, Lawrence Livermore National Laboratory under Contract W-7405-Eng-48. 


\section{Summary}

The goal of the work reported here is to develop a concept for an active neutron interrogation system that can detect small targets of SNM contraband in cargo containers, roughly $5 \mathrm{~kg} \mathrm{HEU}$ or $1 \mathrm{~kg} \mathrm{Pu}$, even when well shielded by a thick cargo. It is essential that the concept be reliable and have low false-positive and false-negative error rates. It also must be rapid to avoid interruption of commerce, completing the analysis in minutes.

A new radiation signature unique to $\mathrm{SNM}$ has been identified that utilizes high-energy $\left(\mathrm{E}_{\gamma}=3-7 \mathrm{MeV}\right)$ fission product $\gamma$-ray emission. Fortunately, this high-energy $\gamma$-ray signature is robust in that it is very distinct compared to normal background radiation where there is no comparable high-energy $\gamma$-ray radiation. Equally important, it has a factor of 10 higher yield than delayed neutrons that are the basis of classical interrogation technique normally used on small unshielded specimens of SNM. And it readily penetrates two meters of low- $Z$ and high- $Z$ cargo at the expected density of $\sim 0.5 \mathrm{gm} / \mathrm{cm}^{3}$. Consequently, we expect that in most cases the signature flux at the container wall is at least 2-3 decades more intense than delayed neutron signals used historically and facilitates the detection of SNM even when shielded by thick cargo.

Experiments have verified this signature and its predicted characteristics. However, they revealed an important interference due to the activation of ${ }^{16} \mathrm{O}$ by the ${ }^{16} \mathrm{O}(\mathrm{n}, \mathrm{p})^{16} \mathrm{~N}$ reaction that produces a $6 \mathrm{MeV} \gamma$-ray following a 7-sec $\beta$ decay of the ${ }^{16} \mathrm{~N}$. This interference is important when irradiating with $14 \mathrm{MeV}$ neutrons but is eliminated when lower energy neutron sources are utilized since the reaction threshold for ${ }^{16} \mathrm{O}(\mathrm{n}, \mathrm{p})^{16} \mathrm{~N}$ is $10 \mathrm{MeV}$. The signature $\gamma$-ray fluxes exiting a thick cargo can be detected in large arrays of scintillation detectors to produce useful signal count rates of $2-4 \times 10^{t} \mathrm{cps}$. That is high enough to quickly identify SNM fission by its characteristic high energy $\gamma$-ray emission and characteristic fast decay time. Fortunately, the fission product $\gamma$-radiation decays with a distinctive $\mathrm{T}_{1 / 2}=20-30 \mathrm{sec}$ lifetime that is well matched to cargo scan speeds of about one minute per container. Experimental characterization of the $\gamma$-ray fluxes exiting thick cargos has not yet been undertaken.

The work reported here leads to definite requirements for the interrogation neutron source that can be met with neutron commercially available source technology. A small (6-20 ft) deuteron accelerator producing about $\sim 1 \mathrm{~mA}, 2-5 \mathrm{MeV}$ deuteron beam on a deuterium or beryllium target is required. Neutrons produced by such an accelerator are kinematically collimated in the forward direction, reducing shielding requirements while increasing the neutron flux on target to meet the intensity requirement even when there is thick intervening cargo. In addition, this technology provides a very penetrating beam in the energy range $4-8 \mathrm{MeV}$ while remaining below the oxygen activation threshold. Maximum counting statistics and lowest error rates in the identification occur when the beam is pulsed with a $50 \%$ duty cycle. The period for this pulsing must be comparable to the half-lives of the species that make up the signature, i.e. 10-60 sec. This is readily achieved with commercially available equipment and is well suited to rapid scanning of cargo containers.

Finally, unwanted collateral effects of the interrogation such as neutron activation of the cargo have been analyzed. Even in the worst case when $14 \mathrm{MeV}$ neutrons are used and not moderated the dose rates resulting from activation are well within limits for radiation workers within minutes after the 
end of irradiation and in most cases drop to levels acceptable for exposure of the general public within minutes or hours. In all cases studied the activation levels of cargo, even under the worst case assumptions are low enough for the cargo to be considered non-radioactive for shipping by the Department of Transportation. Activation of agricultural products is very low as well. Although no applicable standards have been identified, the levels of radioactivity predicted for neutron activation in even the worst case are much lower than the naturally present ${ }^{40} \mathrm{~K}$ content of many foods widely used for human consumption.

A viable concept for cargo active neutron interrogation has been presented and its components have been evaluated experimentally. Utilization of the new $\gamma$-ray signature for SNM appears to promise a dramatic improvement in sensitivity for those cases where thick intervening cargo shields a target of interest or where the material is shielded with intentionally placed high-Z materials. Experiments and simulations are in progress to quantitatively determine the effects of cargo or intentional shielding to reduce and/or interfere with the SNM signature. These experiments will then be used to establish the scanning intervals required to reduce the error rates, i.e. false-positive and falsenegative, to acceptable levels. 


\section{Table of contents}

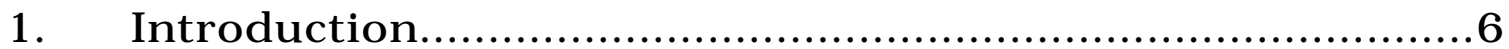

1.1 Threat description .................................................. 6

1.2 Conventional neutron interrogation to detect SNM .............8

1.3 Other active methods to detect SNM ..............................9

1.4 A new signature: Delayed high-energy $\gamma$-rays...................9

1.5 Detection of Chemical Weapons and Explosives .................10

2 Neutron interrogation concept.........................................11

2.1 Relationship to other components of container security.....11

2.2 Neutron interrogation architecture.................................12

2.3 Goal of the neutron interrogation system ......................15

3 High-energy $\gamma$-ray signature of SNM .................................. 15

3.1 Estimates of high energy $\gamma$-ray flux........................... 15

3.2 Delayed high-energy $\gamma$-rays in ${ }^{235} \mathrm{U}$ thermal fission.............17

3.3 Delayed high-energy $\gamma$-rays in ${ }^{239} \mathrm{Pu}$ thermal fission.............18

3.4 Delayed high-energy $\gamma$-rays in ${ }^{238} \mathrm{U}$ fast fission .................19

3.5 Estimating high-energy $\gamma$-ray fluxes and count rates...........20

3.6 Effect of varying enrichment.....................................22

4 Experimental validation of $\gamma$-ray signature................................ 24

4.1 Detecting the signatures of SNM .................................24

4.2 Beam filters to reduce ${ }^{16} \mathrm{~N}$ interference.........................33

5 Detector design......................................................... 34

6 Advanced signal processing to suppress background................39

$7 \quad$ Neutron source design ..................................................... 41

7.1 Neutron beam energy .............................................. 41

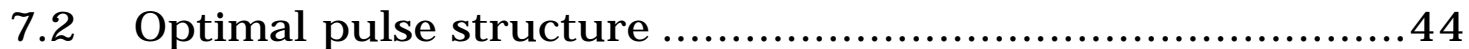

7.3 Overall neutron source requirements .........................47

8 Limitations due to activation of cargo.................................48

8.1 Context and perspective.......................................... 49

8.2 Radioactive material..............................................49

8.3 Radiation dose, a very rough thumb rule ........................49

8.4 Activation of aluminum ........................................... 51

8.5 Activation in steel ............................................... 52

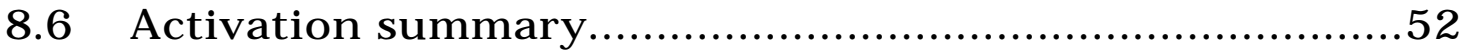

8.7 Activation of agricultural products..............................54

9 Conclusions and prospects.............................................. 57

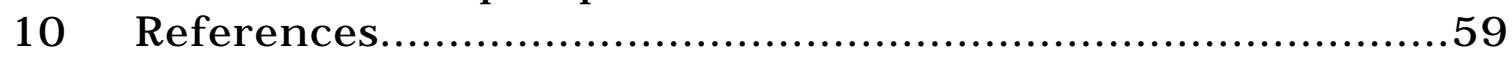




\section{Introduction}

\subsection{Threat description}

The largest volume of cargo entering the US is through the shipping ports, which receive about 6 million cargo containers each year. Today approximately $90 \%$ of the world's trade moves by cargo containers[1]. Fortunately this traffic is geographically compact where half of all the traffic bound for the US originates in the top ten foreign ports and nearly $90 \%$ of the cargo containers arrive here at the top ten US ports of entry, as shown in the table below.

Table 1.1 Ports of origin and ports of entry for US-bound cargo containers[1] in 2001.

\begin{tabular}{|l|r|r|l|r|r|}
\hline Top ten foreign ports or origin & \multicolumn{4}{l|}{ Top ten domestic ports } \\
\hline Port of origin & $\begin{array}{r}\text { Number } \\
\text { US-bound } \\
\text { containers }\end{array}$ & $\begin{array}{r}\text { \% of } \\
\text { total } \\
\text { traffic }\end{array}$ & Port of entry & $\begin{array}{r}\text { Number } \\
\text { US-bound } \\
\text { containers }\end{array}$ & $\begin{array}{r}\% \text { of } \\
\text { total } \\
\text { traffic }\end{array}$ \\
\hline Hong Kong & 558,600 & 9.8 & Los Angeles & $1,774,000$ & 24.7 \\
\hline Shanghai & 330,600 & 5.8 & Long Beach & $1,371,000$ & 19.1 \\
\hline Singapore & 330,600 & 5.8 & $\begin{array}{l}\text { New York, } \\
\text { New Jersey }\end{array}$ & $1,044,000$ & 14.6 \\
\hline $\begin{array}{l}\text { Kaohsiung, } \\
\text { Taiwan }\end{array}$ & 319,200 & 5.6 & Charleston & 376,000 & 5.2 \\
\hline Rotterdam & 290,700 & 5.1 & Savannah & 312,000 & 4.3 \\
\hline $\begin{array}{l}\text { Pusan, South } \\
\text { Korea }\end{array}$ & 285,000 & 5.0 & Norfolk & 306,000 & 4.3 \\
\hline Bremerhaven & 256,500 & 4.5 & Seattle & 284,000 & 4.0 \\
\hline Tokyo & 159,600 & 2.8 & Tacoma & 273,000 & 3.8 \\
\hline Genoa & 119,700 & 2.1 & Oakland & 268,000 & 3.7 \\
\hline Yantian, China & 114,000 & 2.0 & Houston & 233,000 & 3.3 \\
\hline Top ten total & $\mathbf{2 , 7 6 4 , 5 0 0}$ & $\mathbf{4 8 . 5}$ & Top ten total & $\mathbf{6 , 2 4 1 , 0 0 0}$ & $\mathbf{8 7 . 0}$ \\
\hline
\end{tabular}

For example, the port of Los Angeles/Long Beach is one of the busiest ports in the US and received over three million cargo containers in 2001; approximately half of the total traffic arriving at US ports. One such shipment at the Port of Oakland is shown in the figure below. 


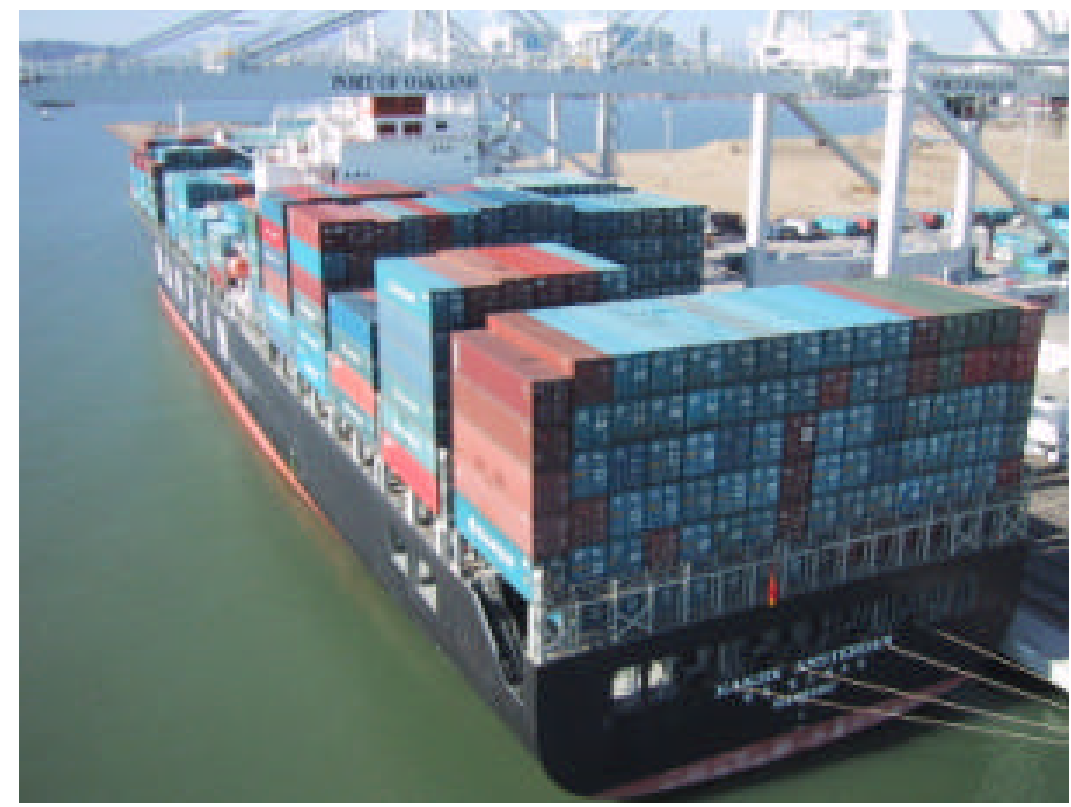

Fig 1.1

A loaded container ship at Port of Oakland

The rate of container arrivals at US ports is expected to increase dramatically over the coming decade. The West Coast ports of Los Angeles/Long Beach, Oakland, and Seattle are currently processing 11,000 containers per day, or 8 per minute on a $24 / 7$ basis. With so many containers and a large volume and mass of cargo in each one it is clear that these containers provide an attractive venue for smuggling illicit material into the US, including weapons of mass destruction (WMD). Because successful delivery of just one such weapon can have catastrophic consequences it is essential that all cargo containers entering the US be screened with an extremely high probability of detecting any WMD hidden within. The cost of failure is very high. An OECD report[2] estimates that a successful WMD attack would shutdown the entire maritime shipping system for a period up to 10 days and this would produce economic costs in the US alone of up to 58 billion dollars.

The number of cargo containers is sufficiently large that the time available to do an inspection would have to be short, about one minute. Inspecting the millions of cargo containers that enter the US by truck, rail, ship or aircraft is a daunting task. The seriousness and difficulty of the problem has been summarized a number of places including a recent report[3] of the CISAC at Stanford, a PNL report[4], a GAO report[1], and elsewhere[5-7]. Quoting from the President's announcement of the homeland security program: "The Department of Homeland Security would make defeating this threat a top priority of its research and development efforts. This nuclear denial program would develop and deploy new technologies and systems for safeguarding nuclear material stockpiles and for detecting the movement of those materials. In particular, it would focus on better detection of illicit nuclear material transport on the open seas, at U.S. ports of entry, and throughout the national transportation system."

Chemical weapons (CW) that are potentially present in cargo may or may not have distinctive chemical vapors allowing their detection, but they have no 
radiation signatures that facilitate passive detection by nuclear means. Among nuclear weapons the ${ }^{239} \mathrm{Pu}$ components have weak but sometimes detectable radioactive emissions and they may be detectable using passive nuclear techniques, though detection is not reliable. On the other hand, ${ }^{235} \mathrm{U}$ in the form of "highly enriched uranium" (HEU) components have only weak, low-energy $\gamma$ ray emissions[8], with principal emission at $185 \mathrm{keV}$, that are severely attenuated by even small cargo over-burden so that they are nearly impossible to detect using passive nuclear techniques. This problem is even more difficult because natural radioactive decay of ${ }^{235} \mathrm{U}$ produces negligible neutron emission $(\sim 0.006 \mathrm{n} / \mathrm{s}$ per $\mathrm{kg})[9]$. For these reasons the concept described below utilizes active neutron interrogation to stimulate neutron capture $\gamma$-rays for the identification of chemical weapons and to produce detectable delayed fission product neutron and $\gamma$-ray emission for the identification of fissionable material. Unfortunately, none of these techniques are capable of identifying biological weapons.

Work reported in the following sections will focus on detection of shielded HEU since that is a very difficult problem not adequately addressed in the published literature over the past several decades. The technique described here utilizes large, high-efficiency detectors that will also be useful in passively scanning cargo containers and may detect ${ }^{239} \mathrm{Pu}$ by its normal radioactive decay. Similarly, analysis of neutron-capture or neutron inelastic scattering $\gamma$-ray emission can be used as in the past to provide remote chemical assay of unshielded targets such as high explosive (HE) and chemical weapons (CW). Nevertheless, while $\mathrm{Pu}, \mathrm{HE}$, and $\mathrm{CW}$ detection may be within the capabilities to be described, the technical approach here will be optimized for the detection of shielded HEU.

\subsection{Conventional neutron interrogation to detect SNM}

Active interrogation methods are considered to be the only feasible option for the detection of HEU, because simple passive detection methods are made difficult by moderate amounts of shielding. The same methods of active interrogation can be used to detect plutonium. Intense fluxes of $\gamma$-rays or neutrons may penetrate cargo and/or shielding within which a mass of HEU is hidden and generate a characteristic signal that may be detected. There are at least four potentially viable approaches to detection of SNM and they are distinguished by the interrogation source (neutrons or $\gamma$-rays), and the induced radiation signature (neutrons or $\gamma$-rays). Passive radiation measurements and radiographs to locate high-density components buried within an otherwise lowdensity cargo may augment these four approaches.

Earlier work in detection of SNM focused on emission of delayed neutrons by fission products[10-13] following neutron-induced fission. Delayed neutrons are emitted from a fraction of a second to a few minutes after fission and have lower energies than the fast prompt fission neutrons. While delayed neutrons can be a reliable indication of SNM present, their yield is low [14], approximately 0.008 per fission in ${ }^{239} \mathrm{Pu}$ and 0.017 per fission in ${ }^{235} \mathrm{U}$. More importantly, delayed neutrons are emitted at relatively low energy $[15,16](200-$ $500 \mathrm{keV}$ ) and are rapidly attenuated in low-Z hydrogenous cargo so that SNM is difficult to detect in the presence of cargo. The energy and die-away time distributions of delayed neutrons differ from the energy and time structure of 
natural radioactive backgrounds, thus providing a distinctive signature for $\mathrm{Pu}$ or HEU. There are very few sources of delayed neutron emission other than fission products. This method has been demonstrated by VNIIA and RIPT (in collaboration with LLNL on an ISTC project) to measure HEU in luggage and at LANL to produce a package monitor. Russian work demonstrated the ability to detect $15 \mathrm{gm}$ of HEU in a 20 second measurement and detect the presence of a shield around the HEU by the anomaly in the neutron die-away. Further, they produced a directed thermal neutron beam and were able to scan luggage, with a sensitivity of $2 \mathrm{gm}$ of ${ }^{235} \mathrm{U}$ in a 100 -second measurement. However, all of this work was done with close access $(10-20 \mathrm{~cm})$ and no shielding around the targets. Results indicate that detection performance is rapidly degraded by introduction of cargo or the access restrictions imposed by the cargo container.

Delayed neutrons are uncommon in the natural radioactive background and thus generally provide a distinctive signature of fission products and thus of SNM presence. The exception to this is the case where $14 \mathrm{MeV}$ neutrons are used for the interrogation. There is a reaction in oxygen, ${ }^{17} \mathrm{O}(\mathrm{n}, \mathrm{p})^{17} \mathrm{~N}$ that produces delayed neutrons with a $4.2 \mathrm{sec}$ half-life. The threshold for that reaction is high, $10.1 \mathrm{MeV}$, so softening the neutron spectrum can reduce or eliminate this interference with detection of SNM.

\subsection{Other active methods to detect SNM}

Utilizing $\gamma$-ray radiography the object is typically irradiated by an isotopic source of ${ }^{137} \mathrm{Cs}$ or ${ }^{60} \mathrm{Co}$. Transmitted $\gamma$-rays can be detected in a detector array to provide a density image. A density image can offer another means to "see" inside a cargo container. This method has been implemented by SAIC[17-20], San Diego to radiograph the contents of cargo containers.

Some radiography systems utilizing accelerator sources have been extended to energies high enough $\left(\mathrm{E}_{\gamma}>5.6 \mathrm{MeV}\right)$ to produce fission in SNM and provide a new capability for $\gamma$-ray interrogation. At the same time neutrons from $(\gamma, n)$ reactions may be detected due to high $Z$ materials. This technique is utilized by INEEL and ARACOR[10, 11, 21]. The commonly occurring low and mid-Z elements typically have photo neutron emission thresholds above 6-7 $\mathrm{MeV}$, while high-Z elements have thresholds below 6-7 MeV. It is not known at this time how accurately $\mathrm{Z}$ can be determined using the threshold effect. However uranium may stand out in such a measurement, since the nearest high$Z$ elements in common use are $\mathrm{Pb}(\mathrm{Z}=82)$ and $\mathrm{Bi}(\mathrm{Z}=83)$. In addition to this signature, the delayed neutron signature from $(\gamma$, fission) reactions may be detectable, because cross sections for photo neutron emission and photo fission are roughly comparable for ${ }^{235} \mathrm{U}$ in the energy range of interest. Some work in this area has been done by James Jones at INEEL[10,11, 21], using a tabletop electron Linac (4-11 MeV) and by LANL using a 6, 8 and $11 \mathrm{MeV}$ Linac[22, 23]. While the method can penetrate cargo containers and detect fissile materials, a disadvantage of this approach is the inability to detect hazardous contraband and explosives signatures simultaneously.

\subsection{A new signature: Delayed high-energy $\gamma$-rays}

There are many short-lived fission products that produce abundant $\gamma$-rays following $\beta$-decay and many have half-lives are in the range 1-60 sec. Some of 
the $\beta$-decays have very high energies allowing population of highly excited states and copious emission of high-energy $\gamma$-rays that are distinct from the natural background radiation where high-energy $\gamma$-rays are almost nonexistent. Utilization of this signature for detection of SNM was first proposed recently by Norman and Prussin[24] and it is the primary tool used here to detect well shielded SNM. Details of this signature will be discussed in a later section. The advantages are:

- Delayed high-energy $\left(\mathrm{E}_{\gamma}>3 \mathrm{MeV}\right)$ fission product $\gamma$-rays are produced with total intensities approximately $\sim 10$ times larger than that of delayed neutrons in thermal neutron fission of ${ }^{235} \mathrm{U}$ or ${ }^{239} \mathrm{Pu}$.

- High-energy $\gamma$-rays suffer 10X-100X less attenuation in thick cargos than is the case for delayed neutrons.

- High-energy $\gamma$-rays are a distinctive signature of SNM. They are generally not present in the normal radioactive background and not produced in high abundance by neutron activation of cargos or cargo environments.

This signature has not been utilized in earlier reports of neutron or $\gamma$-ray interrogation of cargo. The detector technology for harvesting the substantially larger flux of $\gamma$-rays escaping a thick cargo is well developed and costs are reasonable. The details of possible interferences from background and other sources from a broad range of cargo types have not been developed and are the focus of the work reported below and to be done in the future.

\subsection{Detection of Chemical Weapons and Explosives}

Considerable work has been done by others to develop neutron interrogation technology for detection of unshielded HE. Some of the systems providing remote chemical assay for HE detection are expected to provide similar capability for CW detection. Identification of the combinations of these elements in a sample is adequate not only to distinguish the CW materials from $\mathrm{HE}$, but also to distinguish the $\mathrm{CW}$ agents from one another. Interrogation systems developed over the last three decades rely on characteristic neutroncapture or inelastic neutron scattering $\gamma$-rays for identification. The method has been applied to chemical weapons and explosives in munitions by LLNL[25] and AWRE, and for finding hazardous materials in luggage by VNIIA, using a 14 $\mathrm{MeV}$ neutron generator, and at INEEL, using a ${ }^{252} \mathrm{Cf}$ source. Thermal neutron capture $\gamma$-ray based chemical assay has been used as well[26]. Pulsed generators can provide elemental assay for drug and HE detection OSI (formerly Ancore and SAIC), and by Pulsed Fast/Thermal Neutron Analysis, PFTNA[26-34]. Similarly, fast neutrons have been used in systems such as NELIS[27] and PELAN[35-37] for explosives in munitions and utilize time-of-flight to delineate depth in the cargo and neutron capture $\gamma$-rays to provide remote chemical assay [28-30, 32, 33, 38-40] or even imaging of certain elements[39, 41]. These technologies have been reviewed by Martz \& Griffin[42], Kahn[43] and some of the technical challenges are summarized by Micklich[40] and Moss[23]. Those techniques developed earlier may be applied here to augment the capabilities of this system. But they will not be discussed in detail because the focus here is the detection of SNM. 


\section{Neutron interrogation concept}

\subsection{Relationship to other components of container security}

The basic interrogation concept is illustrated in the cartoon below.

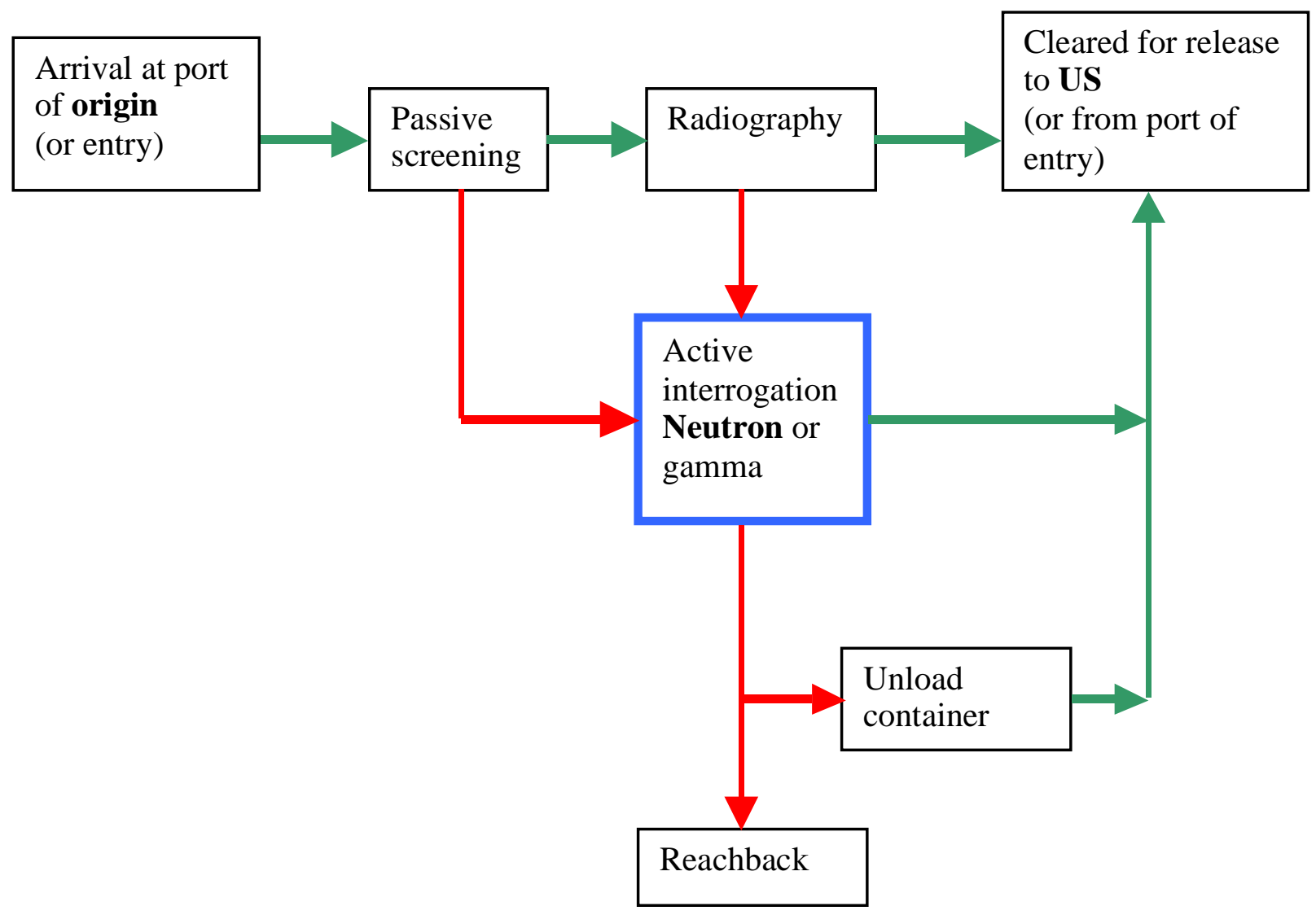

Figure 2.1.1 Architecture of a neutron interrogation system

It is planned that all cargo containers will soon be subject to document screening 24 hours prior to arrival at a port, then radiography and passive radioactivity scans will be utilized as standard screening procedures to detect the presence of SNM. Only those containers that are suspicious for some other reason or because of questions raised by these screening procedures will be subject to additional screening. Neutron interrogation is thus a secondary screening technique utilized to resolve questions. Those suspicious containers would be subject to neutron interrogation to ferret out the possible presence of SNM, large amounts of HE, or CW. Given that only a small fraction of the container traffic is likely to require neutron interrogation it is assumed that a little more time will be allowed for its completion. In the design studies described below we assume that the goal is completion of a scan in about one 
minute and some situations may allow up to a few minutes for completion of the screening process.

The figure above may be considered ambidextrous. That is, it can describe screening either at the port of origin or the port of entry. Initial implementation is expected to occur at US ports of entry because that is convenient and because necessary agreements with foreign governments for screening at their ports are not yet in place. In this configuration the figure above describes screening of containers arriving at a US port of entry before they are released for shipment by truck to other domestic destinations. However, US Customs Service (USCS) is currently implementing a plan[1] to provide USCS personnel at foreign ports of origin to oversee the screening US bound containers by port of origin personnel. Clearance of these containers prior to their departure for the US ports is obviously desirable. Thus, it is expected that neutron interrogation systems will ultimately be located at foreign ports of origin and will scan US bound containers as required. In this configuration the figure above is interpreted differently and is provided as an architecture to screen containers as they enter the port of origin and before they depart for US ports.

\subsection{Neutron interrogation architecture}

Screening of incoming cargo containers can be carried out in several locations, including the truck exit or truck entrance. An exit portal is shown below for the Port of Oakland.

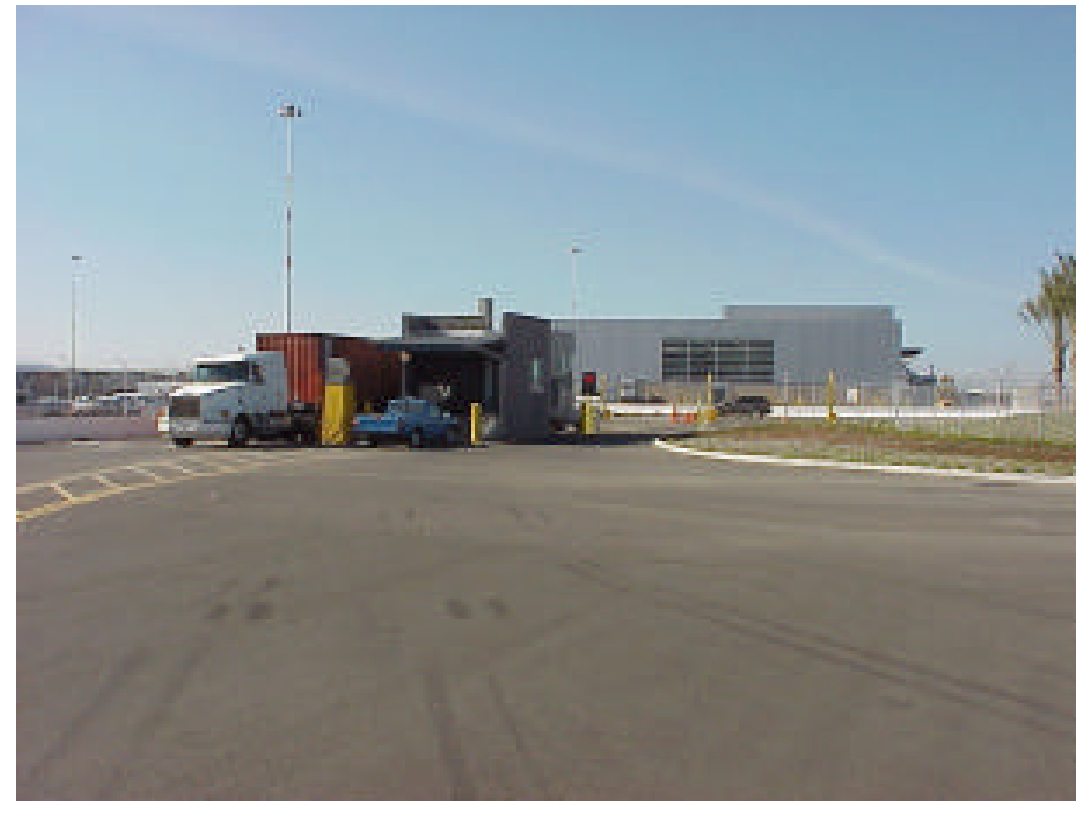

Figure 2.2.1 Truck exit for the Port of Oakland

In the proposed concept a well-collimated neutron generator is located below ground in a shielded cave. A cargo container is drawn over the collimated beam aperture as shown in the figure below. 


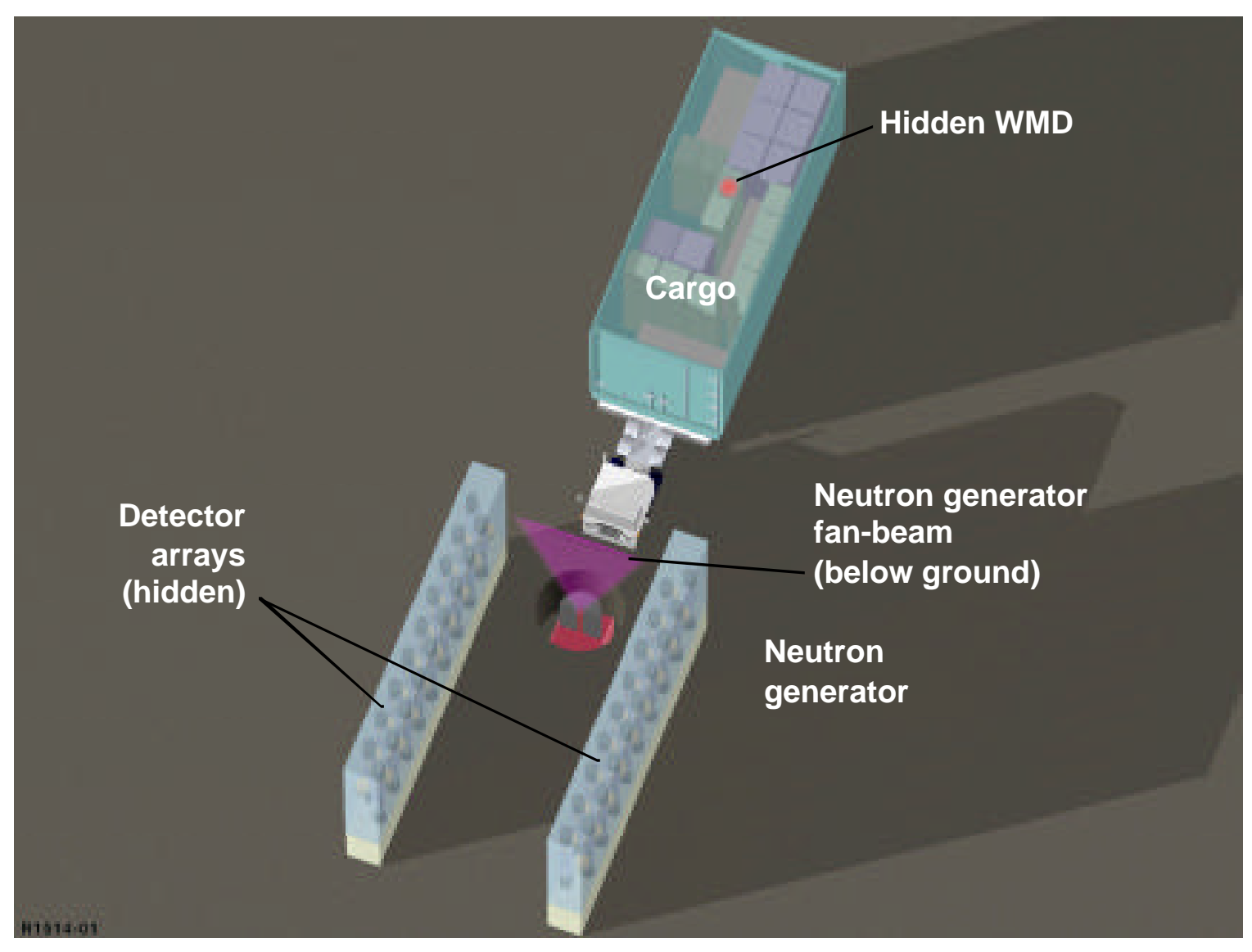

Figure 2.2.2 Essential components of a neutron interrogation system

The beam is a thin fan spanning the width of the container and passes into the cargo where it produces neutron capture and inelastic scatter $\gamma$-rays, and it produces fission in any SNM that may be present. An array of large, highefficiency $\gamma$-ray and neutron detectors covers both sides and the top and bottom of the container, some of which is shown in the figure. The neutron beam is pulsed and detector data is acquired both during the beam pulse and between beam pulses. This is illustrated in the cartoon below. 


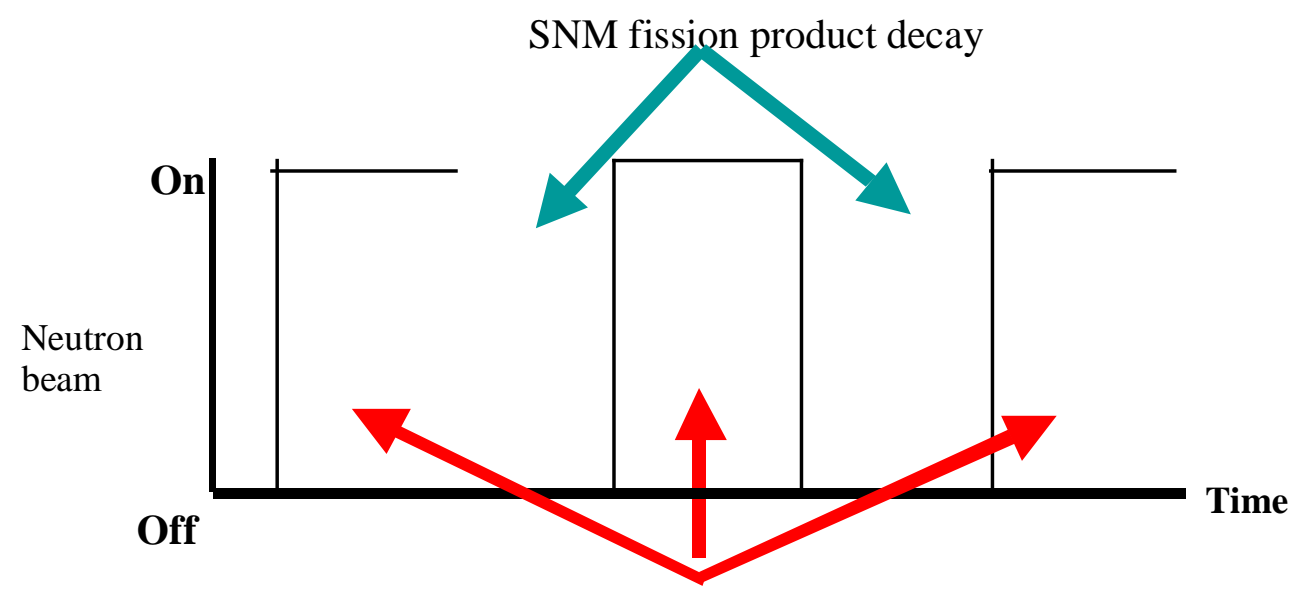

$\mathrm{HE}+\mathrm{CW}$ neutron capture and elastic scattering $\gamma$-rays

Figure 2.2.3 Pulsed beam provides both chemical assay and detection of SNM

During the beam pulse neutron capture $\gamma$-rays are detected and analyzed spectroscopically. The characteristic emission lines of each chemical element are utilized to provide a chemical assay of the cargo materials. Elemental ratios of $\mathrm{H}$, $\mathrm{C}, \mathrm{O}, \mathrm{N}, \mathrm{S}, \mathrm{F}, \mathrm{Cl}$ and other elements are used to ascertain the possible presence of $\mathrm{CW}$ or HE. If the ratios fall within bounds characteristic of WMD an alarm is triggered that leads to further investigation and analysis.

Neutron interrogation also produces fission in any SNM that may be hidden in the cargo. Some fission products decay between beam pulses emitting delayed high-energy $\gamma$-rays and delayed neutrons. The delayed high-energy $\gamma$-rays and neutrons are characterized with regard to their decay time to distinguish fission product emission from normal activation of cargo materials.

High-energy fission product $\gamma$-rays detected between beam pulses are used to identify the presence of SNM and are distinguished from activation and background sources by their high energies $\left(\mathrm{E}_{\gamma}>3 \mathrm{MeV}\right)$ and their characteristic decay times $\left(\mathrm{T}_{1 / 2} \sim 20 \mathrm{sec}\right)$. While there is expected to be some $\gamma$-radiation between beam pulses due to activation of cargo, that radiation is expected to be low energy ( $<2.5 \mathrm{MeV})$ and mostly characterized by long half-lives ( $>1 \mathrm{~min}$ ) compared to the fission product radiation. Detailed experimental evaluation of these assumptions and interferences must be conducted with real cargos to qualify this methodology for the reliable detection of HE, CW, and SNM. The present concept will be optimized for detection of SNM but will include CW and HE capability to the extent that this can be done without reducing reliability for SNM detection.

In addition, the detector arrays will routinely detect both neutrons and $\gamma$-rays emitted by any radioactive cargo whether or not interrogation is taking place. Consequently, this system provides a passive screening capability for materials emitting either neutrons or $\gamma$-rays without activating the neutron source. 


\subsection{Goal of the neutron interrogation system}

The goals of the interrogation system are:

- Reliably detect $5 \mathrm{~kg}$ HEU ( $\leq 1 \%$ error rates)

- Reliably detect $1 \mathrm{~kg}^{239} \mathrm{Pu}(\leq 1 \%$ error rates)

- Maintain reliability in cargos ranging from $0-60 \mathrm{gm} / \mathrm{cm}^{2}$

- Maintain reliability for a wide range of cargo types, including agricultural products, electronics products, and machinery.

- Maintain reliability even when time available for scanning is limited to about one minute.

- To the extent possible it should also detect CW or HE in amounts larger than $50 \mathrm{~kg}$ without compromising the ability to detect SNM

\section{$3 \quad$ High-energy $\gamma$-ray signature of SNM}

\subsection{Estimates of high energy $\gamma$-ray flux}

An alternative and untried approach is to detect SNM by its characteristic short-lived, high-energy fission product $\gamma$-rays in between beam pulses. Prior to the recent suggestion of Norman and Prussin there is only one published effort[44] to look for fission products following photo-fission reactions where delayed fission product $\gamma$-rays are utilized. $I{ }^{235} U$ thermal neutron fission there are approximately 144 fission products[45] with cumulative fission yield $>0.1 \%$ and with half-lives $<10$ minutes. Of those, 44 nuclides produce $\gamma$-rays at energies above $3 \mathrm{MeV}$ with significant intensity[8]. In the case of ${ }^{239} \mathrm{Pu}$ there are 140 fission product nuclides within the above criteria and 45 of those produce significant high-energy $\gamma$-rays. Table 3.1 below summarizes the $\gamma$-ray yields and compares them to the delayed neutron yield. Clearly, the $\gamma$-ray intensity above 3 $\mathrm{MeV}$ is roughly a decade larger than the delayed neutron yield.

Table 3.1.1 Neutrons or $\gamma$-rays per fission

\begin{tabular}{|c|c|c|c|}
\hline & ${ }^{235} \mathrm{U}$ thermal fission & $\begin{array}{c}{ }^{239} \mathrm{Pu} \text { thermal } \\
\text { fission }\end{array}$ & ${ }^{238} \mathrm{U}$ fast fission \\
\hline $\begin{array}{c}\text { Delayed } \\
\text { neutrons[14] }\end{array}$ & 0.015 & 0.0061 & 0.044 \\
\hline $\begin{array}{c}\gamma \text {-rays[8] at } \\
\mathrm{E}_{\gamma}>3 \mathrm{MeV}\end{array}$ & 0.127 & 0.065 & 0.11 \\
\hline $\begin{array}{c}\gamma \text {-rays[8] at } \\
\mathrm{E}_{\gamma}>4 \mathrm{MeV}\end{array}$ & 0.046 & 0.017 & 0.03 \\
\hline
\end{tabular}

More importantly, high-energy $\gamma$-rays suffer much less attenuation in low$\mathrm{Z}$ cargos typical of maritime container contents. The consequence is that highenergy $\gamma$-ray fluxes at the wall of the container are likely to be much larger than delayed neutron fluxes and thus potentially easier to detect. To see this in a little better detail the $\gamma$-ray flux is assumed to be attenuated exponentially where the attenuation constant is taken to be not the total cross section but the energy loss cross section, $\mu / \rho=0.022 \mathrm{~cm}^{2} / \mathrm{gm}$, from Rockwell[46] for $4 \mathrm{MeV} \gamma$-rays. That is 
because the concept described below detects and utilizes as signal the scattered photons exiting the cargo.

The attenuation of delayed neutrons is more complicated to predict. The intensity of unscattered neutrons can be predicted to fall exponential according to the total neutron cross section. For water that cross section is $\mu_{\mathrm{T}} / \rho=0.65 \mathrm{~cm}^{2} / \mathrm{gm}$. On the other hand many scattered neutrons will escape a cargo and can be detected, so the total cross section overestimates the attenuation of a useful signal. Another limit could be obtained by assuming that the lower bound on escaping neutron flux is limited by absorption that is very weak in water at $300 \mathrm{keV}$, amounting to only about $\mu_{\mathrm{a}} / \rho=3 \times 10^{-6} \mathrm{~cm}^{2} / \mathrm{gm}$. Reality falls between these two extremes. Rockwell[46] Figure 3.8 shows experimental data for neutron fluxes attenuated in water and the intensity decreases almost exponentially with distance. Analyzing that data an effective attenuation cross-section of $\mu / \rho=0.13 \mathrm{~cm}^{2} / \mathrm{gm}$ is obtained.

Using these values, the energy loss cross section for $\gamma$-ray attenuation and the empirical data for neutron attenuation, we arrive at the comparison of neutron and $\gamma$-ray fluxes shown in the figure below, where the yield per fission has been incorporated into the data.

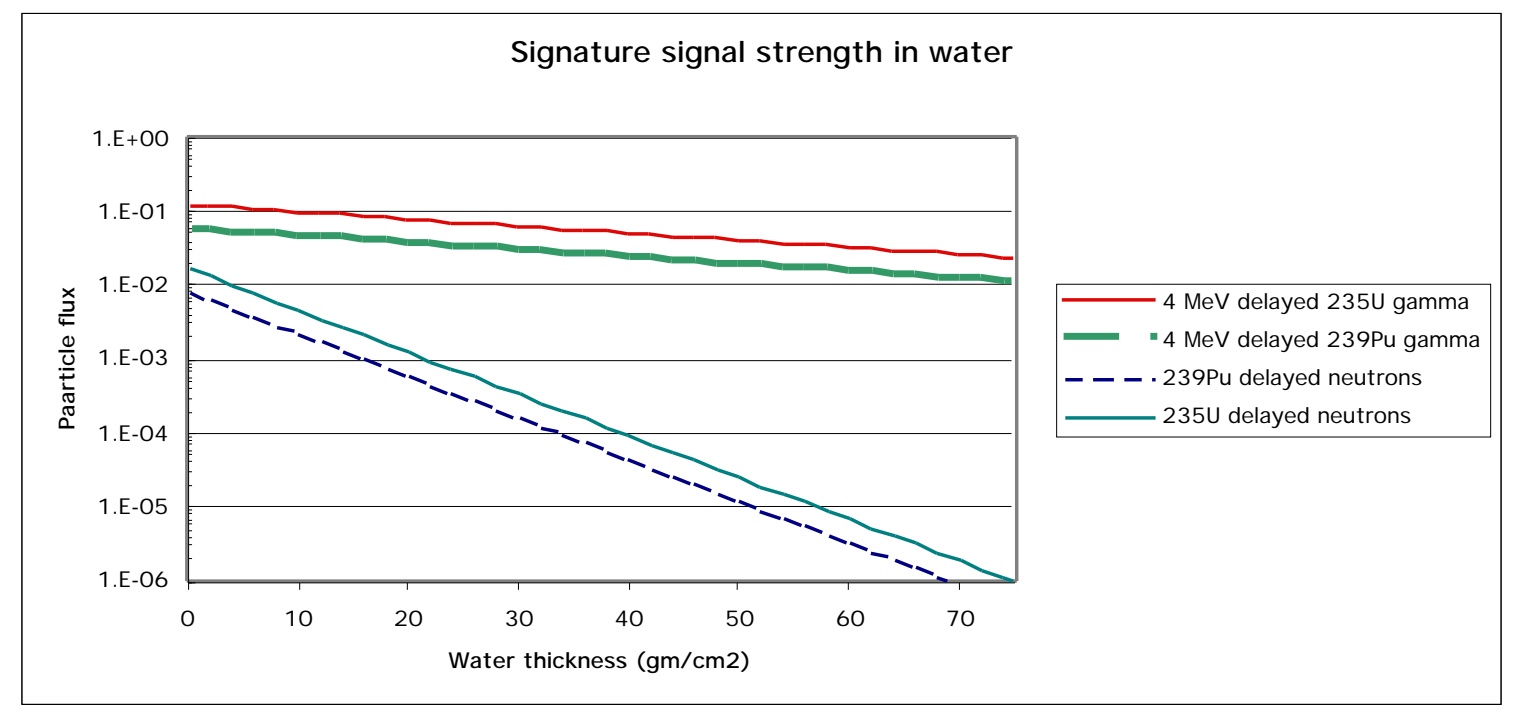

Figure 3.1.1 Attenuated delayed neutron and delayed high-energy $\gamma$-ray fluxes in water.

The figure above shows not only the roughly $\sim 10$ times higher source intensity of the delayed high-energy $\gamma$-rays, but in addition the attenuation of these $\gamma$-rays may be up to 2-3 decades less than for the delayed neutrons in a thick $\left(40-60 \mathrm{gm} / \mathrm{cm}^{2}\right)$ cargo of agricultural products. The result is that the highenergy $\gamma$-ray signal leaving the thick cargo may be as much as $10^{2}-10^{4}$ times larger than the delayed neutron flux. 


\subsection{Delayed high-energy $\gamma$-rays in ${ }^{235} U$ thermal fission}

A search of the available fission product yield data was made for ${ }^{235} \mathrm{U}$ thermal fission[8]. The sum of the total intensities above $3 \mathrm{MeV}$ and above 4 $\mathrm{MeV}$ was determined and summarized above in Table 3.1. The most intense emitters of high-energy $\gamma$-radiation are summarized in the table below.

Table 3.2.1 High-energy $\gamma$-ray yields in ${ }^{235} U$ thermal neutron fission

\begin{tabular}{|c|c|c|c|}
\hline Nuclide & Half-life[45] (sec) & $\begin{array}{l}>4 \text { MeV gammas } \\
\text { per fission[8] }\end{array}$ & $\begin{array}{l}\text { > 3 MeV gammas } \\
\text { per fission[8] }\end{array}$ \\
\hline${ }^{85} \mathrm{Se}$ & 39 & 0 & 0.0012 \\
\hline${ }^{86} \mathrm{Br}$ & 55 & 0.0013 & 0.0013 \\
\hline${ }^{87} \mathrm{Br}$ & 55. & 0.0045 & 0.0073 \\
\hline${ }^{88} \mathrm{Br}$ & 16 & 0.0045 & 0.0072 \\
\hline${ }^{89} \mathrm{Br}$ & 4.4 & 0.0016 & 0.0021 \\
\hline${ }^{89} \mathrm{Kr}$ & 189 & 0.00064 & 0.0029 \\
\hline${ }^{90-\mathrm{m}} \mathrm{Rb}$ & 258 & .00063 & .0036 \\
\hline${ }^{90} \mathrm{Rb}$ & 156 & .0089 & .016 \\
\hline${ }^{91} \mathrm{Kr}$ & 8.6 & .000047 & .0020 \\
\hline${ }^{91} \mathrm{Rb}$ & 58 & .0052 & .017 \\
\hline${ }^{92} \mathrm{Rb}$ & 4.5 & .011 & .012 \\
\hline${ }^{93} \mathrm{Rb}$ & 5.9 & .00078 & .0073 \\
\hline${ }^{94} \mathrm{Rb}$ & 2.7 & .00022 & .0015 \\
\hline${ }^{95} \mathrm{Rb}$ & 0.38 & .000027 & .0011 \\
\hline${ }^{95} \mathrm{Sr}$ & 25 & .00052 & .0031 \\
\hline${ }^{97} \mathrm{Y}$ & 3.8 & 0 & .017 \\
\hline${ }^{98-\mathrm{m}} \mathrm{Y}$ & .59 & .003 & .007 \\
\hline${ }^{136} \mathrm{Te}$ & 17.5 & 0 & .0020 \\
\hline${ }^{136} \mathrm{I}$ & 83 & .0005 & .0011 \\
\hline${ }^{138} \mathrm{I}$ & 6.5 & .00043 & .0010 \\
\hline${ }^{140} \mathrm{Cs}$ & 63 & 0 & .0038 \\
\hline${ }^{141} \mathrm{Cs}$ & 25 & 0 & .0017 \\
\hline${ }^{142} \mathrm{Cs}$ & 1.8 & .00054 & .0014 \\
\hline Total, including & Varying & 0.0458 & 0.127 \\
activities not & & & \\
\hline shown & & & \\
\hline & & & \\
\hline
\end{tabular}




\subsection{Delayed high-energy $\gamma$-rays in ${ }^{239} \mathrm{Pu}$ thermal fission}

A search of the available fission product yield data was made for ${ }^{239} \mathrm{Pu}$ thermal fission[45]. The sum of the total intensities above $3 \mathrm{MeV}$ and above 4 $\mathrm{MeV}$ was determined and summarized above in Table 3.1. The most intense emitters of high-energy $\gamma$-radiation are summarized in the table below.

Table 3.3.1 High-energy $\gamma$-ray yields in ${ }^{239} \mathrm{Pu}$ thermal fission

\begin{tabular}{|c|c|c|c|}
\hline Nuclide & $\begin{array}{l}\text { Half-life[45] } \\
\text { (sec) }\end{array}$ & $\begin{array}{l}>4 \mathrm{MeV} \\
\text { gammas per } \\
\text { fission[8] }\end{array}$ & $\begin{array}{l}>3 \mathrm{MeV} \\
\text { gammas per } \\
\text { fission[8] }\end{array}$ \\
\hline${ }^{87} \mathrm{Br}$ & 55 & .0015 & .0025 \\
\hline${ }^{88} \mathrm{Br}$ & 16 & .0013 & .0020 \\
\hline${ }^{90-\mathrm{m}} \mathrm{Rb}$ & 258 & .00038 & .0021 \\
\hline${ }^{90} \mathrm{Rb}$ & 156 & .0025 & .0046 \\
\hline${ }^{91} \mathrm{Rb}$ & 58 & .0020 & .0063 \\
\hline${ }^{92} \mathrm{Rb}$ & 4.5 & .0045 & .0049 \\
\hline${ }^{93} \mathrm{Rb}$ & 5.9 & .00031 & .0029 \\
\hline${ }^{95} \mathrm{Sr}$ & 25 & .0003 & .0017 \\
\hline${ }^{97} \mathrm{Y}$ & 3.8 & 0 & .013 \\
\hline${ }^{98} \mathrm{Y}$ & 0.59 & .0024 & .0055 \\
\hline${ }^{106} \mathrm{Tc}$ & 36 & 0 & .0066 \\
\hline${ }^{140} \mathrm{Cs}$ & 64 & 0 & .0026 \\
\hline${ }^{141} \mathrm{Cs}$ & 25 & 0 & .0014 \\
\hline${ }^{142} \mathrm{Cs}$ & 1.8 & .00037 & .0022 \\
\hline $\begin{array}{c}\text { Total including } \\
\text { activities not shown }\end{array}$ & Varying & 0.017 & 0.065 \\
\hline & & & \\
\hline
\end{tabular}




\subsection{Delayed high-energy $\gamma$-rays in ${ }^{238} U$ fast fission}

A search of the available fission product yield data was made for ${ }^{238} \mathrm{U}$ high-energy fission[45]. There were 253 fission products found with cumulative yields greater than $0.1 \%$ per fission, and with half-lives less than 10 minutes. Of those there were 59 nuclides that produced reportable $\gamma$-ray intensities at energies above $3 \mathrm{MeV}$. The sum of the total intensities above $3 \mathrm{MeV}$ and above $4 \mathrm{MeV}$ was determined and summarized above in Table 3.1. The most intense emitters of high-energy $\gamma$-radiation are summarized in the table below.

\section{Table 3.4.1 High-energy $\gamma$-ray yield in ${ }^{238} U$ high-energy fission}

\begin{tabular}{|c|c|l|c|}
\hline Nuclide & Half-life[45] (sec) & $\begin{array}{l}>4 \mathrm{MeV} \text { gammas } \\
\text { per fission[8] }\end{array}$ & $\begin{array}{c}>3 \mathrm{MeV} \text { gammas } \\
\text { per fission[8] }\end{array}$ \\
\hline${ }^{85} \mathrm{Se}$ & 39.0 & 0 & .0012 \\
\hline${ }^{87} \mathrm{Br}$ & 55.9 & .0034 & .0056 \\
\hline${ }^{88} \mathrm{Br}$ & 16.4 & .0037 & .0060 \\
\hline${ }^{89} \mathrm{Br}$ & 4.4 & .0021 & .0029 \\
\hline${ }^{89} \mathrm{Kr}$ & 189 & .00040 & .0018 \\
\hline${ }^{90} \mathrm{Br}$ & 1.9 & .00057 & .0014 \\
\hline${ }^{90 \mathrm{~m}} \mathrm{Rb}$ & 258 & .00035 & .0020 \\
\hline${ }^{91} \mathrm{Kr}$ & 8.6 & .000035 & .0015 \\
\hline${ }^{91} \mathrm{Rb}$ & 58 & .0035 & .0115 \\
\hline${ }^{92} \mathrm{Rb}$ & 4.5 & .00084 & .0091 \\
\hline${ }^{93} \mathrm{Rb}$ & 5.9 & .00075 & .0070 \\
\hline${ }^{94} \mathrm{Rb}$ & 2.7 & .00036 & .0024 \\
\hline${ }^{95} \mathrm{Rb}$ & 0.38 & .000053 & .0021 \\
\hline${ }^{95} \mathrm{Sr}$ & 25.1 & .00042 & .0025 \\
\hline${ }^{97} \mathrm{Y}$ & 3.8 & 0 & .017 \\
\hline${ }^{106} \mathrm{Tc}$ & 36 & 0 & .0040 \\
\hline${ }^{128} \mathrm{n}$ & 0.8 & .00080 & .0024 \\
\hline${ }^{136} \mathrm{Te}$ & 17.5 & 0 & .0022 \\
\hline${ }^{140} \mathrm{Cs}$ & 63.6 & 0 & .0030 \\
\hline${ }^{141} \mathrm{Cs}$ & 24.9 & 0 & .0016 \\
\hline${ }^{142} \mathrm{Cs}$ & 1.8 & .00058 & .0015 \\
\hline Total, including & Varying & 0.034 & 0.108 \\
activities not & & & \\
\hline shown & & & \\
\hline
\end{tabular}




\subsection{Estimating high-energy $\gamma$-ray fluxes and count rates}

Signals characteristic of SNM present in a cargo container are expected to be very small and hard to detect. What follows is a very simplistic analytical study of the factors that support this expectation. It is first assumed that the container is interrogated by a source of neutrons at high energy (possibly 14 $\mathrm{MeV}$ ) that is isotropic but collimated to reduce the neutron flux everywhere except for a small vertical band propagating across the width of the container. For a point isotropic neutron source of strength $I$, located distance $R_{s}$ from the target SNM and penetrating a thickness $R_{c}$ of cargo whose density is $\rho_{c}$ and neutron attenuation coefficient is $\left(\mu_{n} / \rho_{c}\right)$, the flux of neutrons at the SNM target is estimated approximately below.

$$
\Phi_{14}=\frac{I}{4 \pi R_{s}^{2}} e^{-\left(\frac{\mu_{n}}{\rho_{c}}\right) \rho_{c} R_{c}}
$$

Consider a cylindrical target of length $L$, radius $r$, density $\rho$, and mass $M$. Then, assuming a target thin enough to be considered transparent to $14 \mathrm{MeV}$ neutrons, the fast fission rate due to $14 \mathrm{MeV}$ neutrons is given by the following.

$$
F_{14}=\Phi_{14} \pi r^{2} L \frac{\rho N_{o}}{A_{o}}\left(\varepsilon \sigma_{f}^{25}(14 M e V)+(1-\varepsilon) \sigma_{f}^{28}(14 M e V)\right)
$$

In the equation $\varepsilon$ is the enrichment (fraction of ${ }^{235} \mathrm{U}$ ), superscripts 25 and 28 refer to ${ }^{235} \mathrm{U}$ and ${ }^{238} \mathrm{U}$ respectively, $\mathrm{N}_{\mathrm{o}}$ and $\mathrm{A}_{\mathrm{o}}$ are Avogadro's number and the mass number, respectively.

For thermal neutrons the target is definitely not transparent and, in fact, the thermal neutrons penetrate only a thin layer on the surface of a target. The depth of penetration depends on the enrichment, but the total mass of ${ }^{235} \mathrm{U}$ illuminated by thermal neutrons is only weakly affected by enrichment. There's considerable uncertainty regarding the actual thermal neutron flux that will exist at the target location in experiments planned for the near future. To estimate this flux in a schematic way we assume an infinite medium of moderator where all fast neutrons that scatter are in equilibrium with thermal absorption, that is they will reach thermal energies and will be absorbed as thermal neutrons. In this simple model the thermal neutron absorption rate in the moderator is equal to the fast neutron scattering rate, represented in the relation below.

$$
\Sigma_{s}^{14} \Phi_{14} \approx \Sigma_{a}^{t h} \Phi_{t h}
$$

In the above model the ratio of thermal to fast neutron flux, $\beta$, is given by the ratio of cross sections.

$$
\beta \equiv \frac{\Phi_{t h}}{\Phi_{14}} \approx \frac{\sigma_{s}^{14}}{\sigma_{a}^{t h}}
$$

For water the ratio $\beta=1.5$. 
In order to estimate the thermal fission rate it is assumed that fissions occur over the surface of the target cylinder and that the thermal neutron penetration depth is $\lambda=1 / \Sigma_{\mathrm{T}}$ where $\Sigma_{\mathrm{T}}$ is the total thermal neutron cross-section in the target material. The surface area assumed is that for a cylinder. Then the thermal fission rate is given below.

$$
F_{t h}=\Sigma_{f}^{t h} \beta \Phi_{14}\left(2 \pi r^{2}+2 \pi r L\right) \lambda=\beta \Phi_{14} 2 \pi r^{2}\left(1+\frac{L}{r}\right) \frac{\varepsilon \sigma_{f}^{25}(t h)}{\varepsilon \sigma_{T}^{25}(t h)+(1-\varepsilon) \sigma_{T}^{28}(t h)}
$$

Evaluation of Eqs. 3.5.1 thru 3.5.5 for targets consisting of solid cylinders of ${ }^{235} \mathrm{U}$ with $\mathrm{L}=2 \mathrm{r}=4 \mathrm{~cm}$ (a $1 \mathrm{~kg}$ cylinder), assuming $\mathrm{I}=10^{11} \mathrm{n} / \mathrm{s}, \mathrm{R}_{\mathrm{s}}=2 \mathrm{~m}, \mathrm{R}_{\mathrm{d}}=1.5 \mathrm{~m}$, the cargo is water at $\rho R_{c}=60 \mathrm{gm} / \mathrm{cm}^{2}$, and taking the known cross sections[14] one predicts a thermal neutron flux at the target roughly $1.5 \times 10^{5} \mathrm{n} / \mathrm{cm}^{2} / \mathrm{sec}$ and fast flux $1 \times 10^{5} \mathrm{n} / \mathrm{cm}^{2} / \mathrm{sec}$ that leads to the following fission rates.

\section{Table 3.5.1 Fission rates in cylindrical targets of ${ }^{235} U$ (fissions/sec)}

\begin{tabular}{|l|l|l|}
\hline & $1 \mathrm{~kg}$ target of ${ }^{235} \mathrm{U}$ & $200 \mathrm{gm}$ target of ${ }^{235} \mathrm{U}$ \\
\hline $14 \mathrm{MeV}$ fission rate & $4.2 \times 10^{5}$ & $8.0 \times 10^{4}$ \\
\hline Thermal fission rate & $4.4 \times 10^{6}$ & $1.6 \times 10^{6}$ \\
\hline Total fission rate & $4.8 \times 10^{6}$ & $1.7 \times 10^{6}$ \\
\hline
\end{tabular}

The above analysis can be continued to predict $\gamma$-ray fluxes exiting the cargo container. Taking the above estimate of fission rate the $\gamma$-ray flux on a detector at the cargo container wall is approximately given below.

$$
\Phi_{\gamma}=\frac{F_{t o t} Y_{\gamma} e^{-\left(\frac{\mu_{\mu c}}{\rho_{c}} \rho_{x} R_{x}\right.}}{4 \pi R_{d}^{2}}
$$

Where $F_{\text {tot }}$ is the sum of thermal and fast fission rates, $Y_{\gamma}$ the high-energy or "signal" $\gamma$-ray yield per fission, $R_{d}$ the distance from the target to the detector, and $\mu_{\gamma}$ the $\gamma$-ray attenuation coefficient. Of course a large and highly efficient detector extending over a significant length of the cargo container improves the count rates. In this case $R_{d}$ may extend over a considerable range and that variation must be corrected for. For this case we replace $1 / R^{2}$ by its mean value and neglect the effect of extending attenuation paths in the cargo. The mean value of $1 / r^{2}$ for a wall of length $L$ is given below.

$$
\left\langle\frac{1}{r^{2}}\right\rangle=\frac{1}{R^{2}}\left[\frac{2 R}{L} \tan ^{-1}\left(\frac{L}{2 R}\right)\right]
$$

Utilizing the evaluations above with $\mathrm{R}_{\mathrm{d}}=1.5 \mathrm{~m}$, the relevant attenuation coefficient for water at $\mu_{\gamma} R_{c}=60 \mathrm{gm} / \mathrm{cm}^{2}$ and the yield values from Table 3.1 the $\gamma$-ray flux at the detector is given in the table below. 
Table 3.5.2 High-energy $\gamma$-ray flux at the wall of a cargo container

\begin{tabular}{|l|l|l|}
\hline & $1 \mathrm{~kg}^{235} \mathrm{U}$ target & $1 \mathrm{~kg}{ }^{239} \mathrm{Pu}$ target \\
\hline$\Phi_{\gamma}\left(\gamma / \mathrm{cm}^{2} \mathrm{sec}\right)$ & 0.5 & 0.25 \\
\hline $\begin{array}{l}\text { Count rate in 20 ft long, } \\
\begin{array}{l}10 \% \text { efficient detector } \\
\text { (counts/sec) }\end{array}\end{array}$ & $3.7 \times 10^{4}$ & $1.8 \times 10^{4}$ \\
\hline
\end{tabular}

Note that the count rate for the $20 \mathrm{ft}$ long detector was corrected using Eq. 3.5.7, but the additional attenuation due to oblique pathways in the cargo were not corrected. The count rate predicted is adequate for reliable scanning in reasonably short duration interrogation at the assumed fast flux.

The $\gamma$-ray fluxes correspond to beam-on or beam-equilibrium conditions. Of course the flux and count rate will decay between beam pulses so the indications in Table 3.5.2 are only approximate. Effects of decay between beam pulses will be predicted in a later section and those effects will lead to an optimized beam structure that maximizes the detected signal.

\subsection{Effect of varying enrichment}

The forgoing discussion focused on targets of a single isotope. Real SNM targets are likely to include isotope mixtures of which only one is thermally fissionable. HEU, natural-U, and depleted-U are examples. Eq. 3.5.5 has been evaluated for $\mathrm{I}=1 \times 10^{11} \mathrm{n} / \mathrm{s}, \beta=1.5,2 \mathrm{r}=\mathrm{D}=10 \mathrm{~cm}$, water attenuation due to $\rho R_{c}=60$ $\mathrm{gm} / \mathrm{cm}^{2}$, and using cross sections from NDS-2000[14]. The result is shown below.

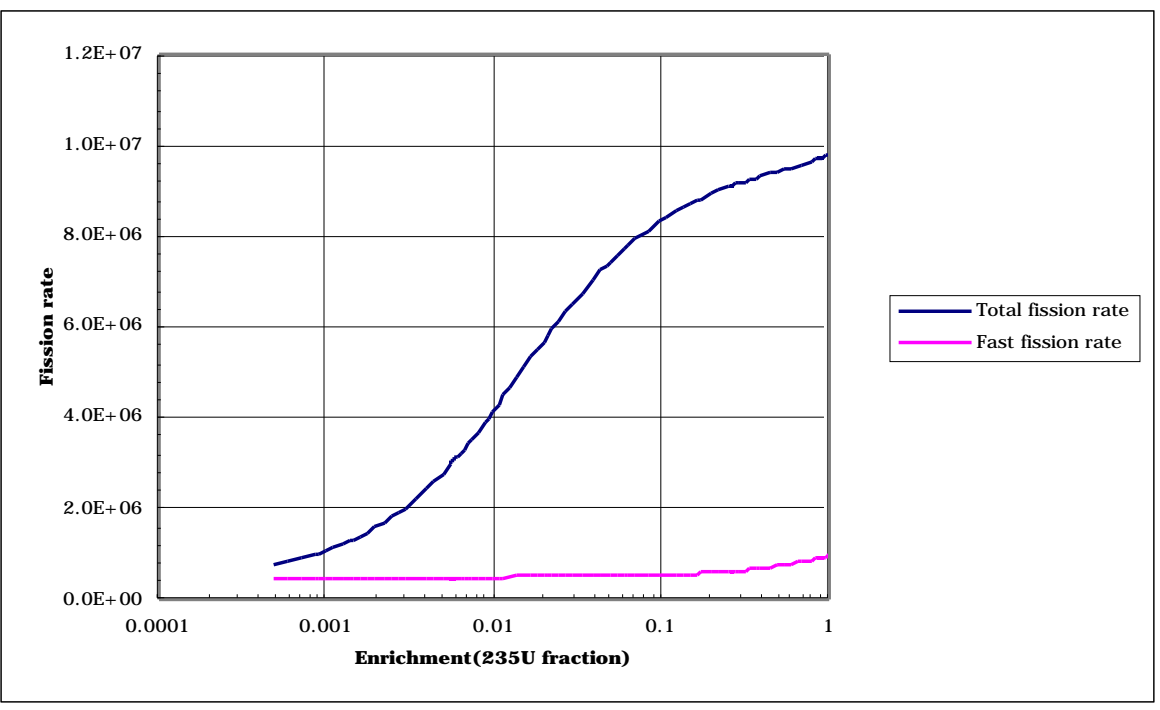

Figure 3.6.1 Fission rate dependence on enrichment.

The result shown in the figure exhibits a very weak dependence of fission rate on enrichment. When the enrichment is reduced from $100 \%$ to only $1 \%$ the fission rate drops only a factor of 2 . That is; natural uranium produces half the fission rate of HEU in this problem where the mass is fixed. That is intuitively 
clear when one considers the fate of a neutron entering the target. Thermal neutrons are lost only by fission and capture. So the fraction of neutrons entering the target that produce thermal fission is simply the ratio of crosssections as shown below.

$$
\frac{F_{\text {th }}}{\text { Absorption }}=\frac{\Sigma_{f}^{25}(t h)}{\Sigma_{n, \gamma}^{25}+\Sigma_{f}^{25}+\Sigma_{n, \gamma}^{28}}=\frac{\varepsilon \sigma_{f}^{25}}{\varepsilon\left(\sigma_{n, \gamma}^{25}+\sigma_{f}^{25}\right)+(1-\varepsilon) \sigma_{a}^{28}}
$$

Given that $\sigma_{\mathrm{f}}^{25}>>\sigma_{\mathrm{a}}{ }^{28}$ the ratio is nearly constant until $\varepsilon$ is reduced to $\sim 1 \%$. At lower enrichment the thermal neutron penetration depth increases so that more ${ }^{235} \mathrm{U}$ is accessed and produces fission over a larger volume. At enrichments $>1 \%$ the target is essentially opaque to thermal neutrons. This is reflected in the figure below.

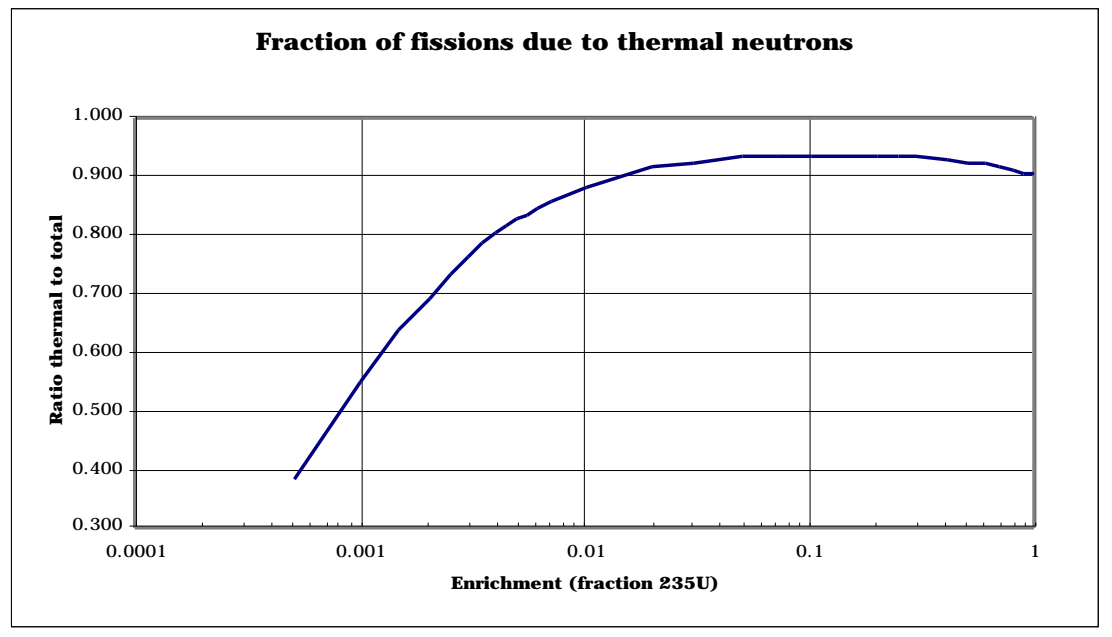

Figure 3.6.2 Thermal fission fraction ws. enrichment

Even for depleted uranium, i.e. D-38 at $\varepsilon=.003$, the fissions are predominantly due to thermal neutrons. Of course, these conclusions are sensitive to the target dimensions since the ratio of fast to thermal fissions is higher in a very thick target and thus the total is more sensitive to enrichment than in the case of a thin target where essentially all fissions are due to thermal neutrons.

The findings of this section including the several sub-sections above are summarized in the table below. 
Table 3.6.1 Summary of flux and count rate estimates

\begin{tabular}{|l|l|}
\hline Assumptions & Parameter range studied \\
\hline Target characteristics & $\begin{array}{l}1 \mathrm{~kg} 93 \% \text { enriched uranium } \\
\mathrm{r}=2 \mathrm{~cm}, \mathrm{~L}=4 \mathrm{~cm}\end{array}$ \\
\hline Source characteristics & $\begin{array}{l}\mathrm{I}=1 \times 10^{11} \mathrm{n} / \mathrm{s} \text { at } 14 \mathrm{MeV} \\
\mathrm{R}_{\mathrm{s}}=2 \mathrm{~m}\end{array}$ \\
\hline Cargo characteristics & Water $\mathrm{cargo}, \rho \mathrm{R}_{\mathrm{c}}=60 \mathrm{gm} / \mathrm{cm}^{2}$ \\
\hline Detector characteristics & $\mathrm{R}_{\mathrm{d}}=1.5 \mathrm{~m}, \mathrm{~L}=6.1 \mathrm{~m} \times \mathrm{H}=3 \mathrm{~m}$, efficiency $=10 \%$ \\
\hline Fast neutron flux at target & $\Phi_{14}=8.9 \times 10^{4} \mathrm{n} / \mathrm{cm}^{2} / \mathrm{sec}$ \\
\hline Thermal neutron flux at target & $\Phi_{\mathrm{th}}=1.3 \times 10^{5} \mathrm{n} / \mathrm{cm}^{2} / \mathrm{sec}$ \\
\hline Total fission rate & $4.4 \times 10^{6} \mathrm{fission} / \mathrm{sec}$ \\
\hline Signature $\gamma$-ray flux at detector & $\Phi_{\gamma}=0.5 \gamma / \mathrm{cm}^{2} / \mathrm{sec}$ \\
\hline Detector count rate & $4.6 \times 10^{3} \mathrm{cps}$ \\
\hline
\end{tabular}

This table summarizes the results from previous analyses. It shows that a $1 \times 10^{11} \mathrm{n} / \mathrm{s}$ D-T neutron source can adequately penetrate the maximum cargo thickness considered reasonable; then produce a substantial fission rate from which the predicted signature $\gamma$-radiation above $3 \mathrm{MeV}$ escapes that maximum thickness to produce a useful count rate in the proposed detector of $\sim 5,000 \mathrm{cps}$. This is a strong signal and should prove amenable for discrimination from background and characterization of the unique decay time signature of fission products.

\section{Experimental validation of $\gamma$-ray signature}

Some of the concepts presented in previous sections have been evaluated experimentally to assess their performance and illuminate technical difficulties. The technical challenges are substantially different for chemical assay to detect CW or HE than they are for detection of SNM. The former is based on analysis of neutron capture $\gamma$-rays with the beam on while the latter is based on analysis of high-energy delayed fission product $\gamma$-rays observed between beam pulses. Chemical assay is readily tractable for unshielded targets but is rapidly complicated by the presence of intervening cargo. Detection of SNM is based on a new signature introduced here for the first time and will be addressed in detail below.

\subsection{Detecting the signatures of SNM}

The new $\gamma$-ray signature was first suggested by Norman and Prussin and they recently undertook experiments to verify its presence and intensity. The first of these experiments was carried out using a deuteron beam on a Be target at the LBNL 88" cyclotron[24]. In those experiments the high yield predicted for these $\gamma$-rays was verified both for ${ }^{235} \mathrm{U}$ and ${ }^{239} \mathrm{Pu}$, using very small samples, good detection geometry, and a well-shielded analysis cell. Intense $\gamma$-radiation in the 2.5-6 MeV range was observed from small samples of HEU and $\mathrm{Pu}$ and there was negligible intensity when the SNM samples were removed and/or replaced by other materials such as iron, wood, or polyethylene. Decay curves were 
obtained there indicating that the high-energy $\gamma$-ray component decayed with a half-life of approximately $20 \mathrm{sec}$.

Subsequently, signature verification experiments have been conducted at LLNL using a collimated $14 \mathrm{MeV}$ neutron source $\left(2 \times 10^{10} \mathrm{n} / \mathrm{s}\right)$ irradiating a $22 \mathrm{~kg}$ target of natural uranium located within a standard $20 \mathrm{ft}$ long cargo container. A picture of the lab with the shielded neutron generator on the right and cargo container in the center is shown below.

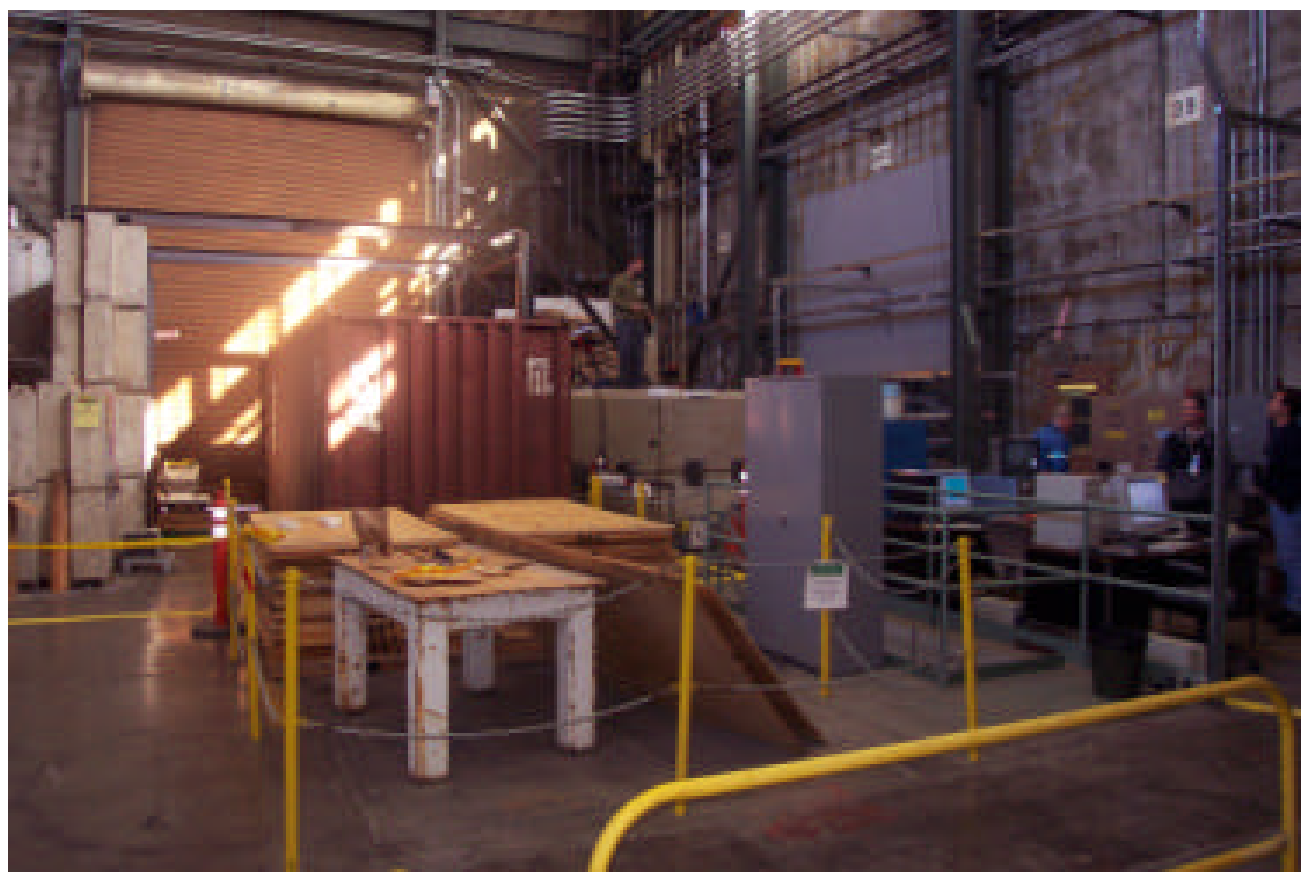

Figure 4.1.1 Cargo container lab at LLNL containing a collimated $14 \mathrm{MeV}$ neutron source, a $20 \mathrm{ft}$ cargo container.

The neutron source was located approximately $2.5 \mathrm{~m}$ from the target on the side of the cargo container (behind it in the figure) and produced a neutron flux of $\sim 2 \times 10^{4} \mathrm{n} / \mathrm{cm}^{2} / \mathrm{sec}$ at the target without shielding or intervening cargo. The target was a cylindrical container of metallic uranium beads making up a cylinder approximately $8 \mathrm{~cm}$ diameter by $15 \mathrm{~cm}$ long, at reduced density. A picture of it is shown below. 


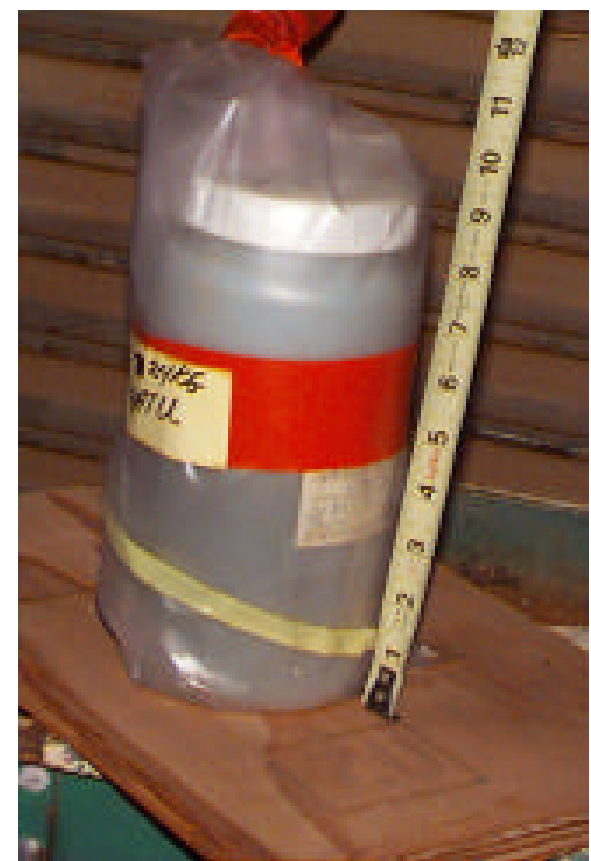

Figure 4.1.2 Natural uranium target used in foreground experiments. The ruler scale is in inches.

This target was normally centered in a 113-liter drum that was filled with polyethylene beads for moderation. On a few occasions the target was separated into two containers within the drum as shown below.

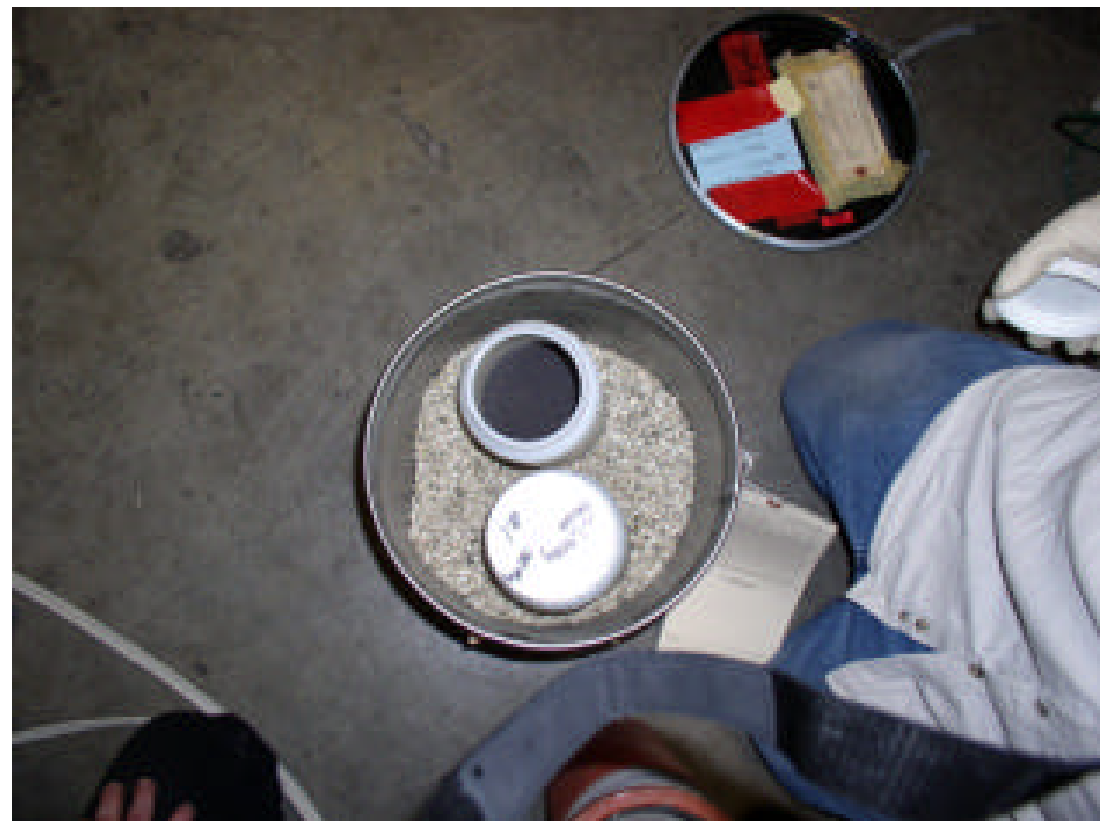

Figure 4.1.3 Close up view of target and target drum

The target was installed in the drum, and was subsequently filled with polyethylene beads and sealed. The drum was then placed in the beam with additional polyethylene pieces. It was positioned in the beam approximately $1.5 \mathrm{~m}$ from a collimated HPGe spectrometer as shown below. 


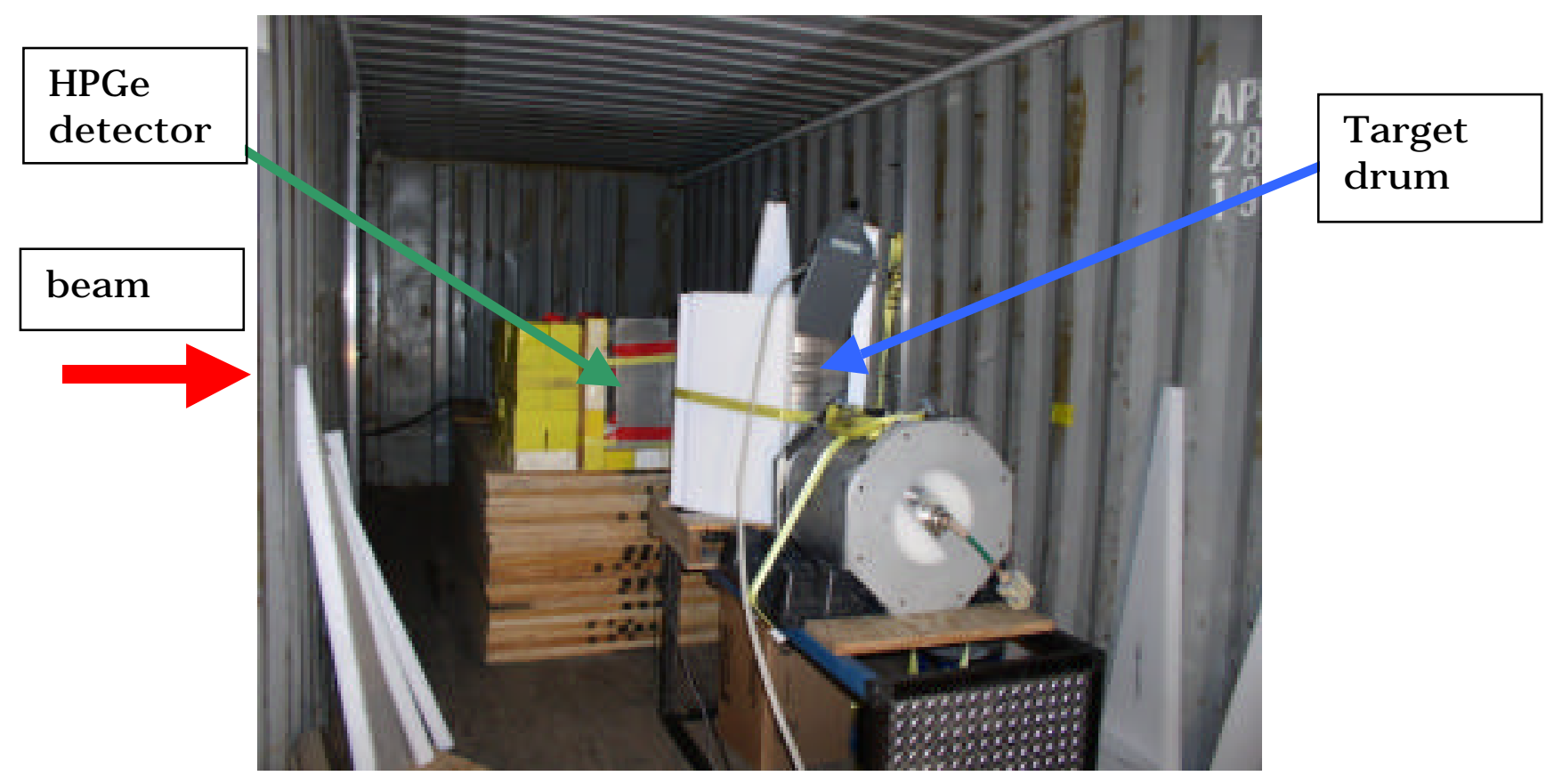

Figure 4.1.4 Experimental configuration inside the cargo container showing HPGe detector in read inside Pb shield, target in steel drum in the center. Neutron beam enters through the wall at left.

The HPGe detector is collimated by lead and borated polyethylene bricks seen stacked on top of a pile of plywood, behind the target. The emitted $\gamma$-rays were analyzed in a relatively small $(50 \%)$ HPGe spectrometer located approximately $1.5 \mathrm{~m}$ from the target. The detector location is temporary and chosen to provide high sensitivity for detection and characterization of the SNM signature radiation. Of course, in a practical implementation all detectors must be located outside the cargo container.

Studies to determine the attenuation and thermalization effects due to cargo are just beginning. For these studies sheets of plywood, aluminum, or steel are stacked into the container between the beam and target, as well as behind the target. A typical setup is shown in the figure below. 


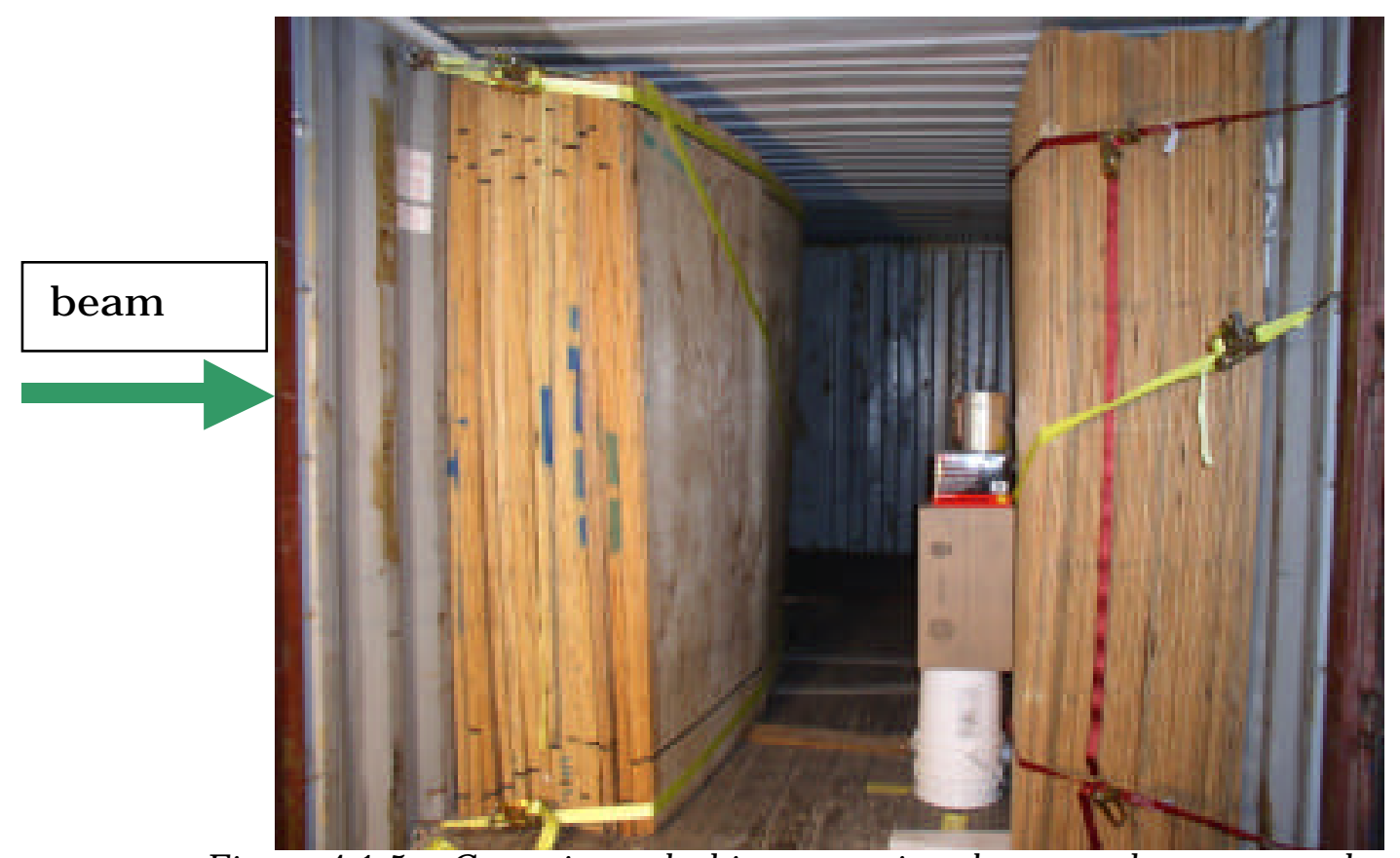

Figure 4.1.5 Cargo is stacked into container between the source and target

The neutron generator was pulsed with a period of 60 seconds, operated at $50 \%$ duty cycle, i.e. beam was on $30 \mathrm{sec}$ and then $\gamma$-ray counting extended for 30 seconds between beam pulses. Due to the very small size of the HPGe $\gamma$-ray detector the count rates were low and data was obtained by accumulating pulse height data over several hundred pulses. Following each pulse the data was acquired in 1-sec intervals up to $30 \mathrm{sec}$. At the end of a measurement the pulse height spectra corresponding to a single interval, cf. the interval 3-4 sec after beam-off, were summed together to produce a final set of 30 pulse height spectra. These measurements were repeated with the natural uranium present (foreground) and with the natural uranium replaced by an empty container (background), with the polyethylene beads still present.

Below are two superimposed spectra corresponding to foreground and background where the data has been accumulated over all pulses for the intervals corresponding to the first 10-sec of decay following beam-off. 


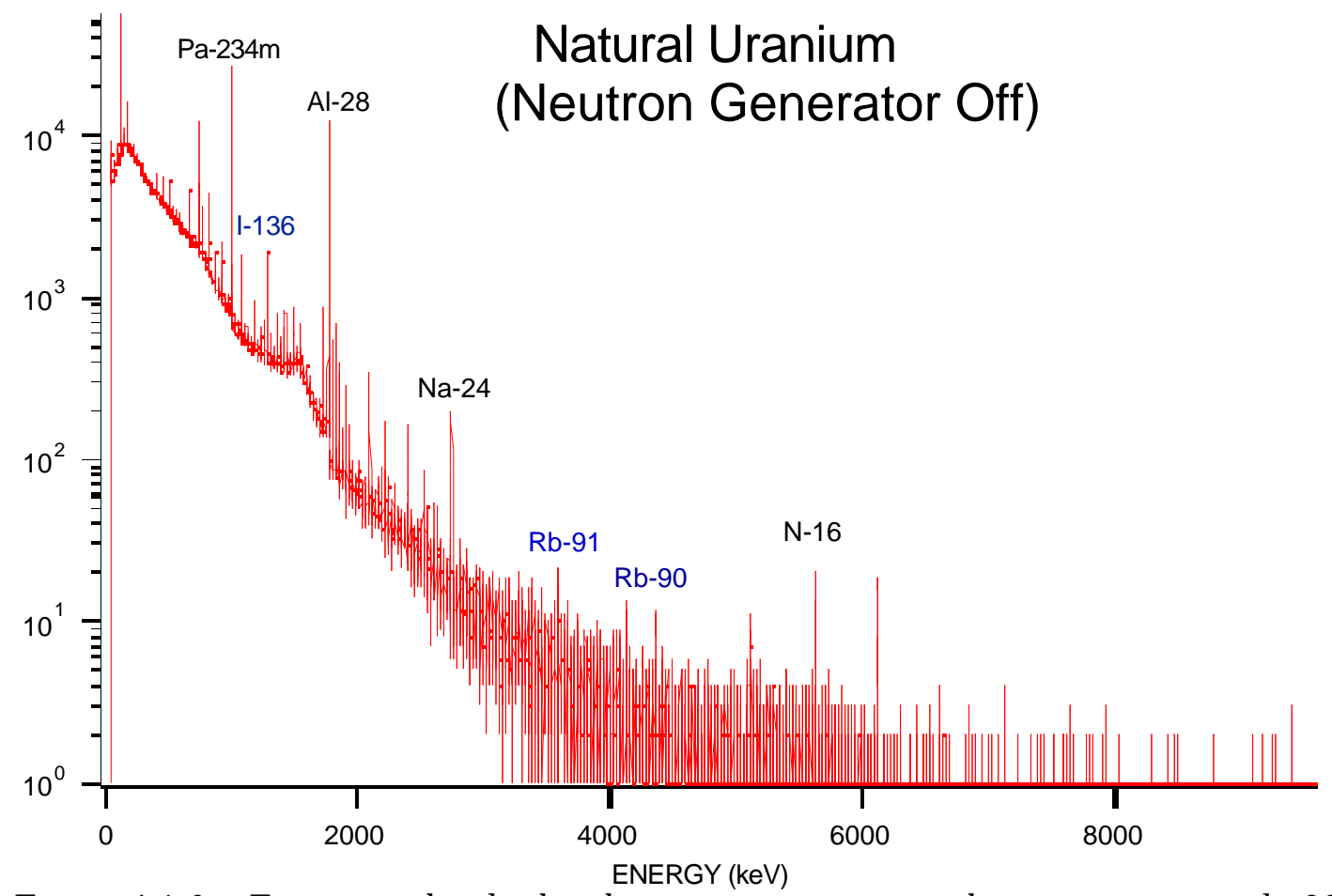

Figure 4.1.6a Foreground pulse height spectrum, integrated over approximately 300 neutron pulses $\left(2 x 10^{10} \mathrm{n} / \mathrm{s}\right.$ at $\left.R_{\mathrm{s}}=3 \mathrm{~m}\right)$ illuminating a $22 \mathrm{~kg}$ natural uranium target. The detector was low efficiency ( $50 \%$ relative to $3 \times 3 \mathrm{NAI}(\mathrm{Tl})$ located at $R_{d}=1.5 \mathrm{~m}$.

The pulse height spectrum exhibits a broad continuum due to thousands of fission product $\gamma$-ray lines that are not resolved by the detector. Nevertheless, a few particularly strong lines stand above the continuum. They include prominent $\gamma$-ray lines due to ${ }^{136} \mathrm{I},{ }^{91} \mathrm{Rb}$, and ${ }^{90} \mathrm{Rb}$. At low energy lines of the uranium decay chain are observed. At intermediate energies activation products in aluminum are observed due to ${ }^{27} \mathrm{Al}(\mathrm{n}, \gamma)$ and ${ }^{27} \mathrm{Al}(\mathrm{n}, \alpha)$ reactions. At the highest energy a $6 \mathrm{MeV} \gamma$-ray is observed following the $7.1 \mathrm{sec} \beta$-decay of ${ }^{16} \mathrm{~N}$ that is produced by the ${ }^{16} \mathrm{O}(\mathrm{n}, \mathrm{p})^{16} \mathrm{~N}$ in oxygen in the experimental environment. The strong lines at high energy are the full energy peak, single escape peak, and double escape peak for this emission. 


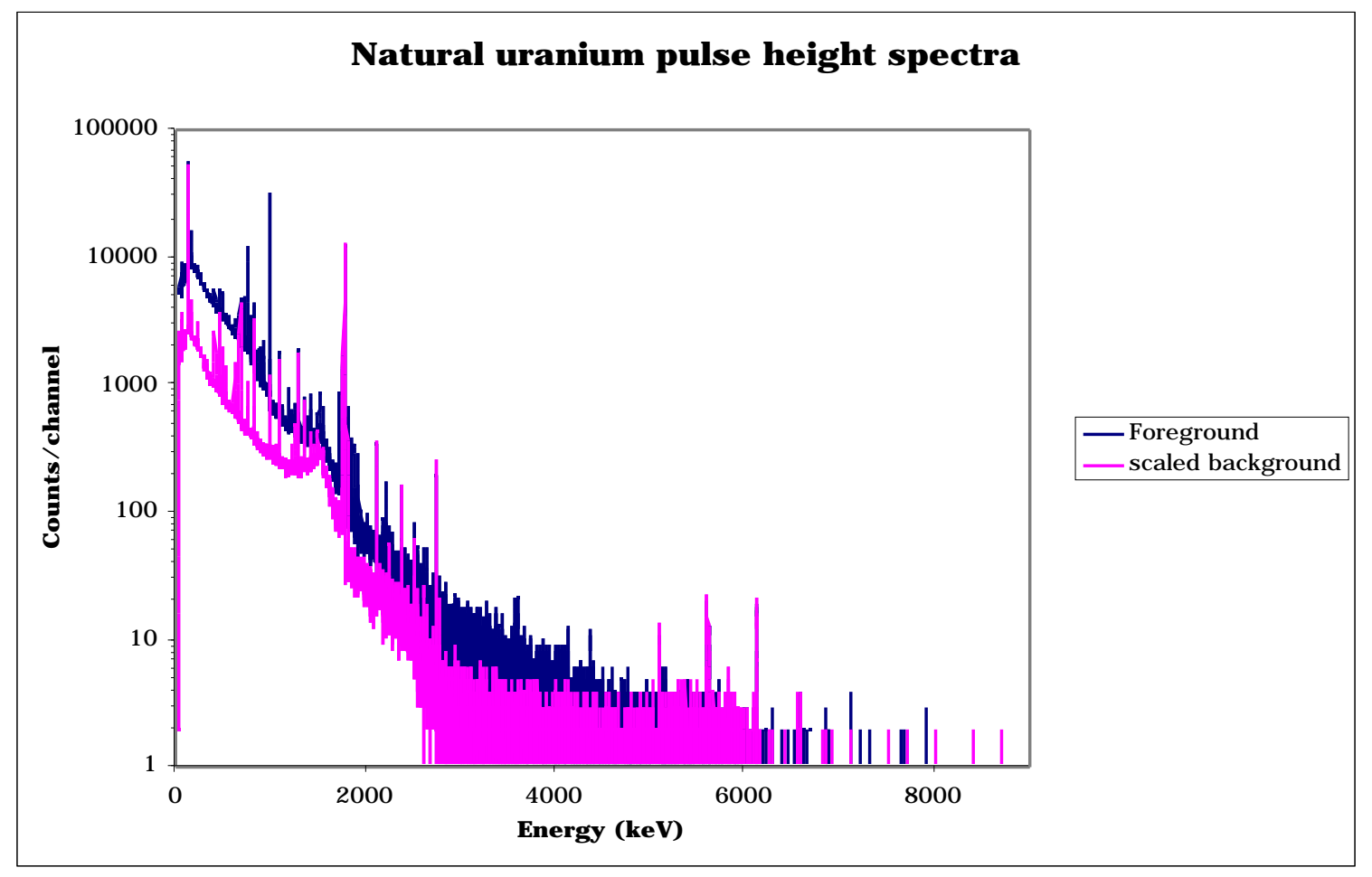

Figure 4.1.6b Superimposed foreground and background pulse height spectra

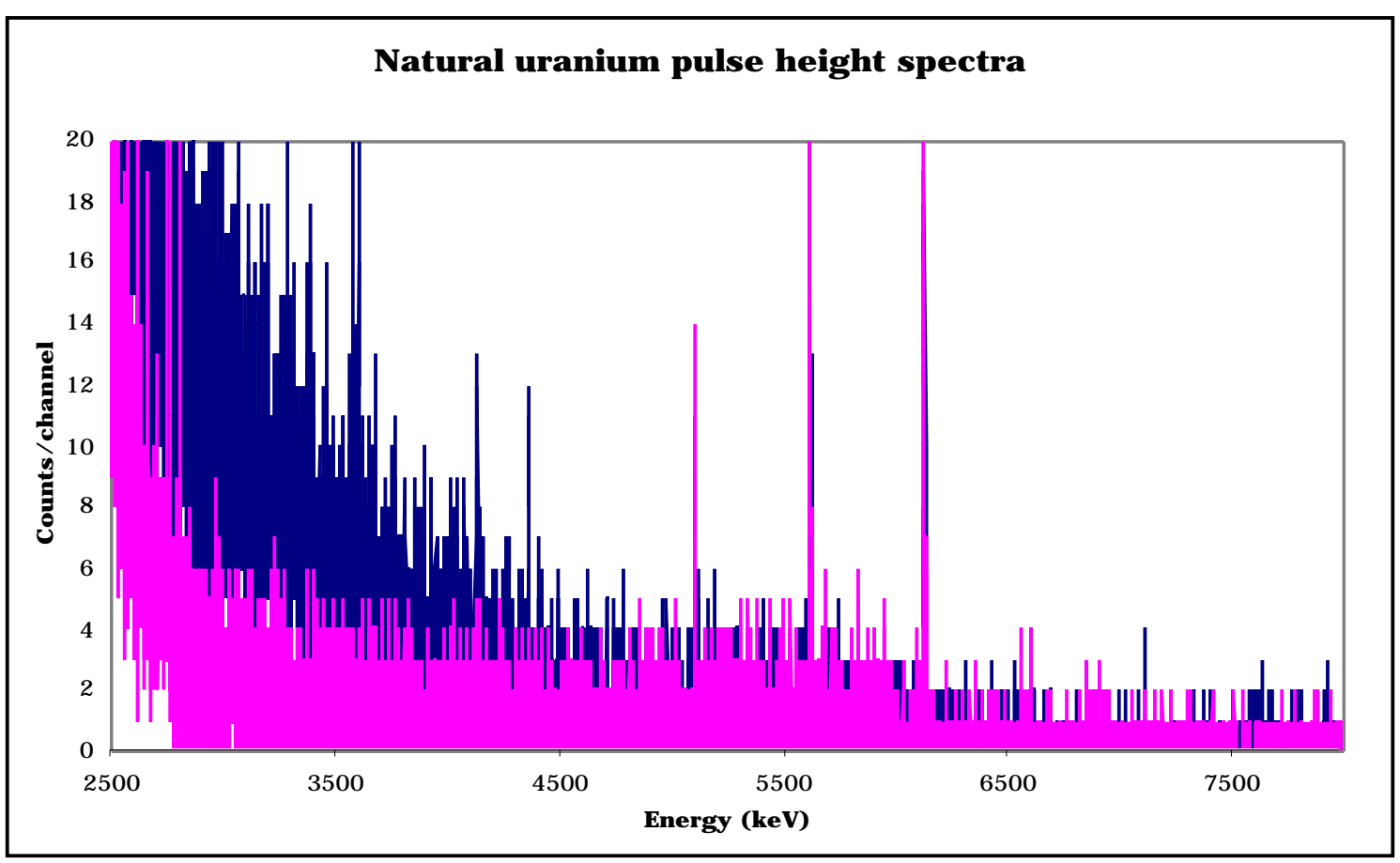

Figure 4.1.6c Expanded view of pulse height data showing both background and foreground data. Dark blue data is foreground and magenta data is background. 
Examination of the figures shows that there is a substantial intensity due to fission product $\gamma$-radiation in the foreground spectrum at all energies. Specifically, foreground intensity in the $\mathrm{E}_{\gamma}=3-4 \mathrm{MeV}$ range where most of the high-energy fission product $\gamma$-rays fall, is at least a factor of five larger than background. In spite of the strong interference due to the ${ }^{16} \mathrm{~N}$, the fission product radiation stands out clearly in the data. It is important to note that the reaction producing the ${ }^{16} \mathrm{~N}$ has threshold energy of $10 \mathrm{MeV}$ and can be reduced or even eliminated by lowering the neutron beam energy. In that case the ratio of signal to background will be a great deal larger than five.

Integrating the total $\gamma$-ray intensity at high energy, once for $\mathrm{E}_{\gamma}>3 \mathrm{MeV}$, and again for $\mathrm{E}_{\gamma}>4 \mathrm{MeV}$ we find two principal decay modes. They are shown in the figures below.

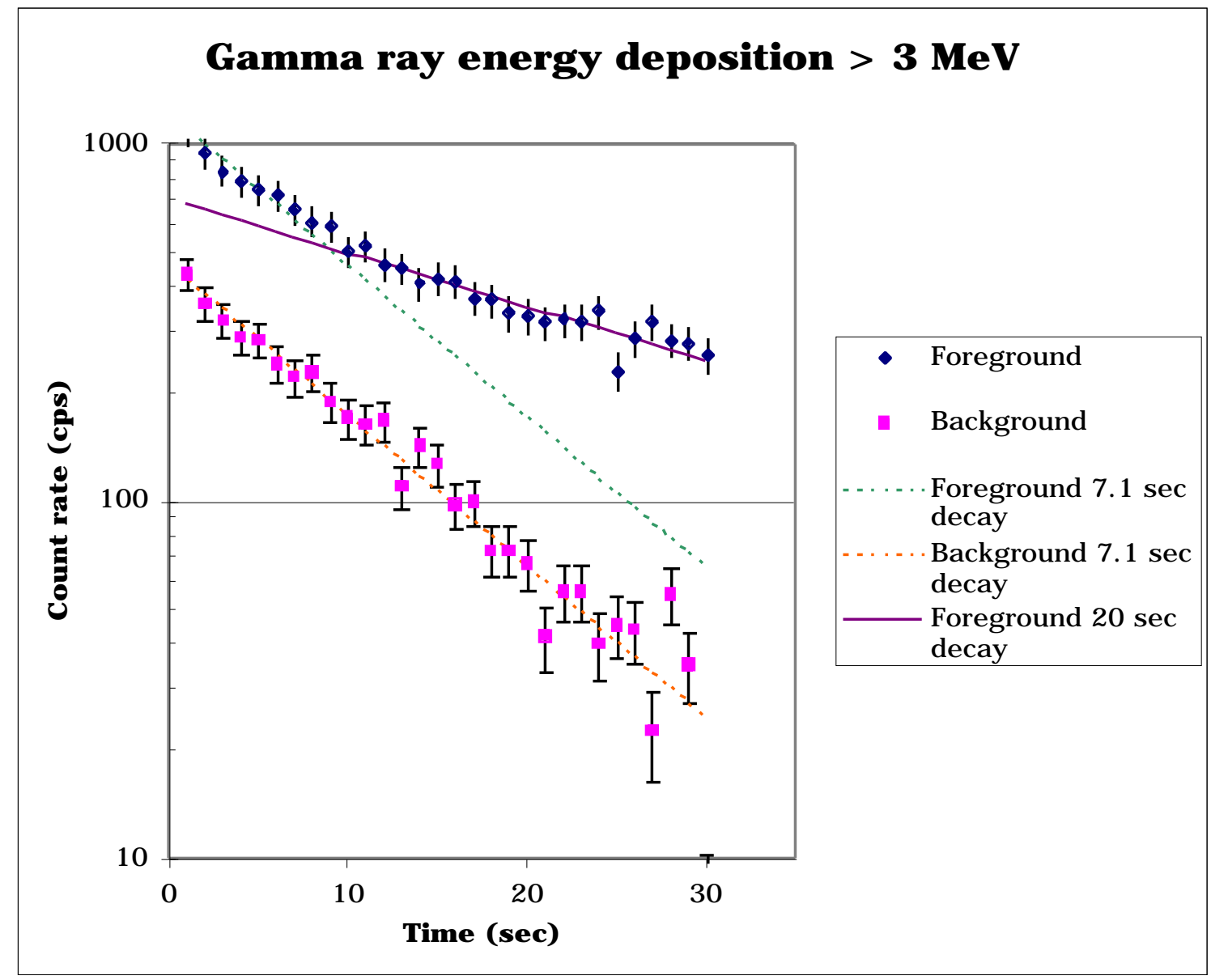

Figure 4.1.7 Decay of total $\gamma$-ray intensity at $E_{\gamma}>3 \mathrm{MeV}$.

The above figure shows the decay of $\gamma$-radiation that deposits more than $3 \mathrm{MeV}$ in the HPGe spectrometer. In the foreground data there are two, and only two, components in the decay, one due to the ${ }^{16} \mathrm{~N} \gamma$-ray at $6.1 \mathrm{MeV}$, and the remainder due to a longer-lived activity attributed to fission products. Shown for comparison (solid lines) is an exponential with $\mathrm{T}_{1 / 2}=7.1 \mathrm{sec}$ and the early decay falls on this line in both the foreground and background. The background data 
continues to fall on the $7.1 \mathrm{sec}$ decay to the maximum extent of the data indicating that ${ }^{16} \mathrm{~N}$ is the dominant background radiation source at high energy for as long as this observation was continued. In the foreground data the ${ }^{16} \mathrm{~N}$ decay accounts for $\sim 39 \%$ of the count rate at $\mathrm{t}=0$ but is negligible at late times. Shown for comparison is an exponential decay with $\mathrm{T}_{1 / 2}=20 \mathrm{sec}$ (dotted line). The late decay falls on this line within errors and indicates that its contribution, presumably due to fission products, accounts for $61 \%$ of the initial count rate.

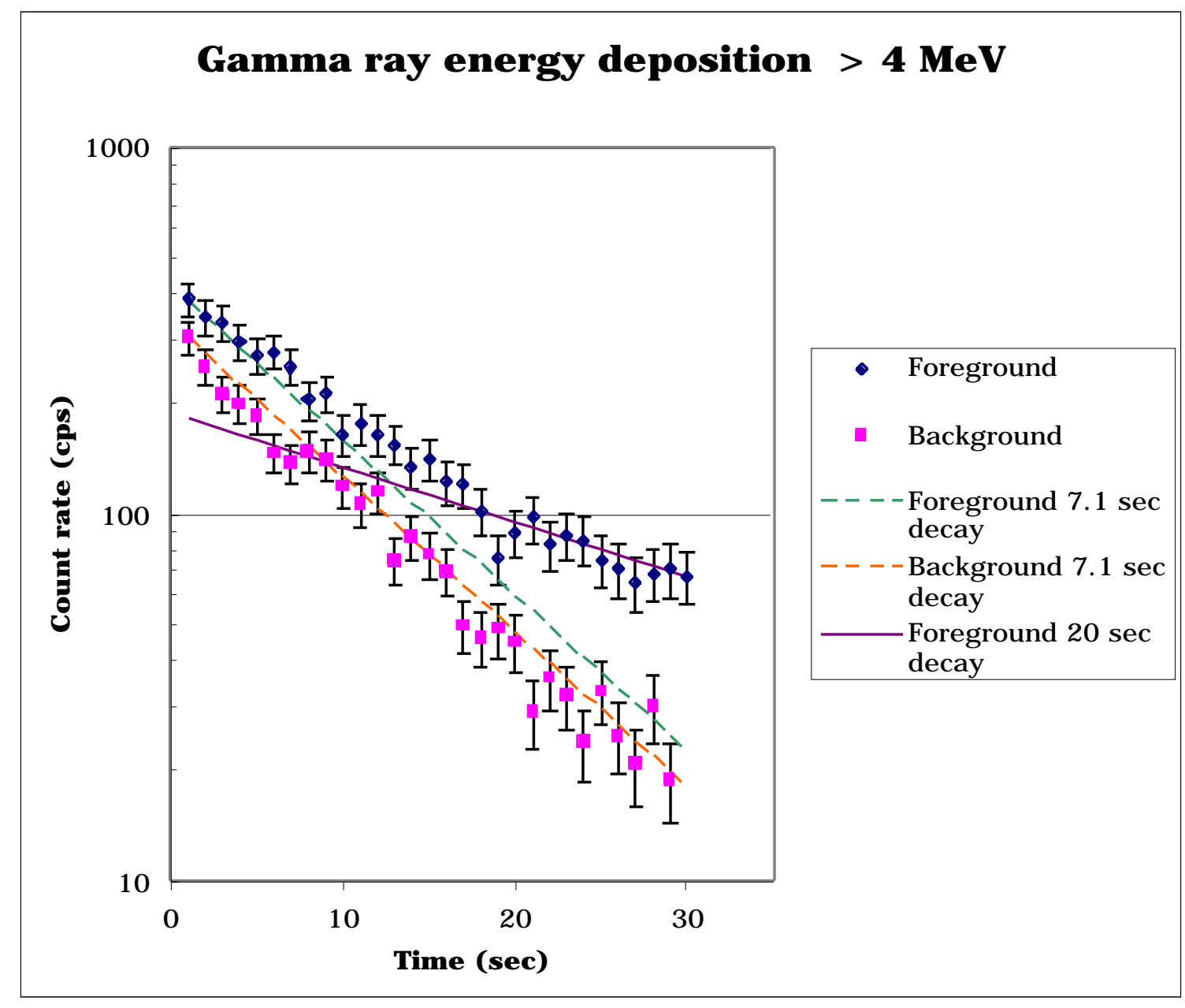

Figure 4.1.8 Decay of total $\gamma$-ray intensity at $E_{\gamma}>4 \mathrm{MeV}$

At higher energy deposition, $\mathrm{E}>4 \mathrm{MeV}$, similar conclusions may be drawn. Early decay is due to ${ }^{16} \mathrm{~N}$ background radiation while late decay falls on the $T_{1 / 2}=20$ sec decay attributed to fission products. For this energy range the fission products account for $\sim 46 \%$ of the initial count rate and dominate at late times.

Examination of both the spectral data and the decay curves indicates no interferences with detection of fission product $\gamma$-rays other than the ${ }^{16} \mathrm{~N}$ decay noted here. The count rates observed in these measurements are consistent with the predictions made earlier, when properly scaled for the detector distance and efficiency as used in these measurements. At this point we conclude that the 
early analysis provides a valid prediction of the high-energy fission product $\gamma$-radiation and that this signature is robust and provides detectable radiation fluxes that exceed those due to delayed neutrons by a few decades. While there is an important interference due to activation of ${ }^{16} \mathrm{O}$, this can be suppressed by reducing the interrogating neutrons to energies below the activation threshold, i.e. $\mathrm{E}_{\mathrm{n}}<10 \mathrm{MeV}$.

\subsection{Beam filters to reduce ${ }^{16} \mathrm{~N}$ interference}

When the neutron generator produces a $14 \mathrm{MeV}$ beam, the spectrum on-target can be softened by inelastic scattering in a beam filter. Passing the beam through a thick window of lead or steel reduces the beam energy rapidly and can reduce the activation of oxygen or other materials in the cargo or target. Simulations have been carried out to determine the effect of a lead filter on the beam, both as it reduces the mean neutron energy and as it scatters the beam, reducing the flux on target. In the simulations the $14 \mathrm{MeV}$ beam passed through the filter to illuminate a $5 \mathrm{~kg}$ HEU target that was immersed in a large block of wood to simulate cargo. The cargo simulant thermalizes the beam to produce fission in the HEU, and it also contains oxygen that activates. The fission rate and ${ }^{16} \mathrm{~N}$ production were predicted and the results scaled for comparison with earlier results (described above). Below is a plot of the results after scaling for comparison.

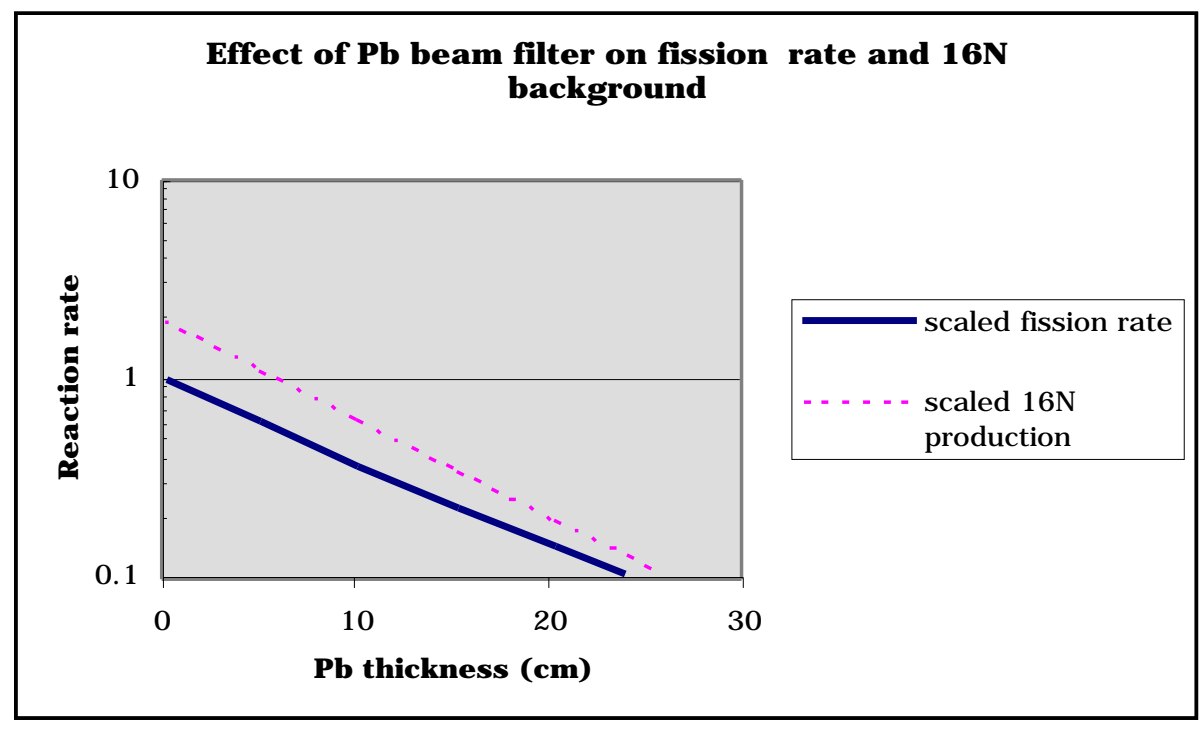

Figure 4.2.1 Target fission rate and oxygen activation when $14 \mathrm{MeV}$ beam passes through various thicknesses of lead 
The figure shows that the filter attenuates the beam and consequently reduces the fission rate in the target. However, activation of the oxygen is reduced even further so that there is some net benefit in utilization of the beam filter. The magnitude of that improvement is shown in the plot below where the ratio of nitrogen production to the fission rate is compared after scaling.

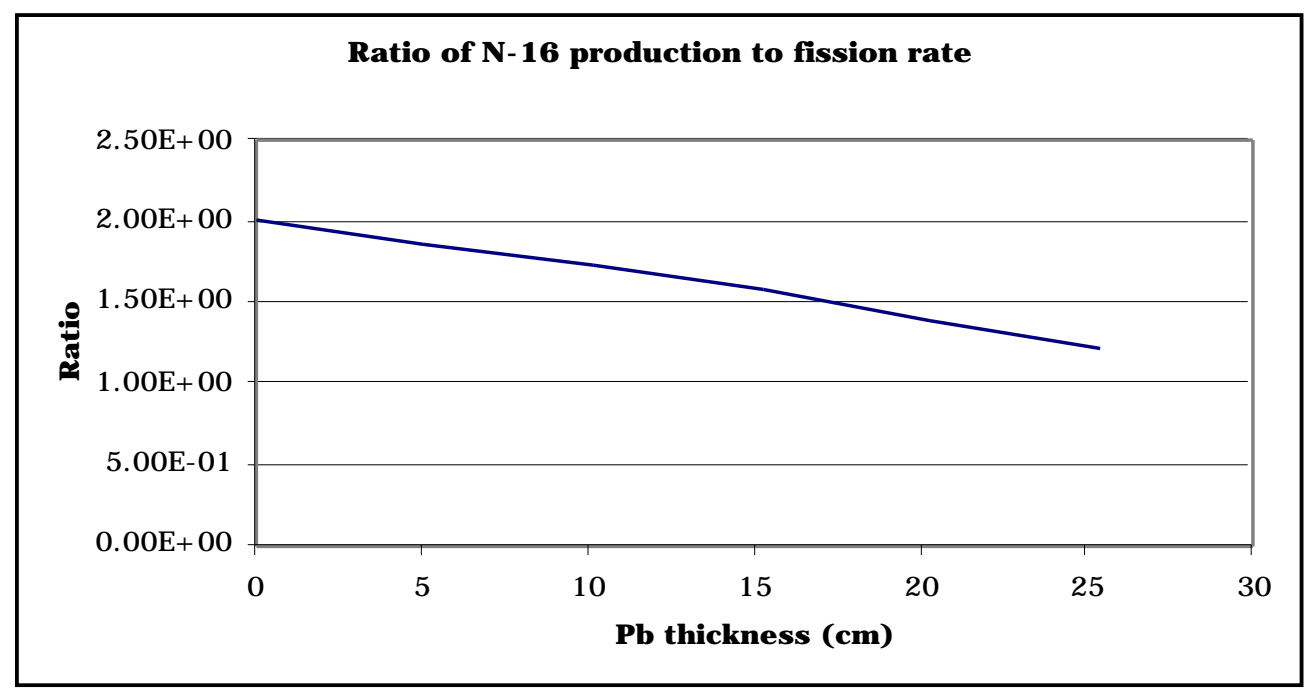

Figure 4.2.2 Relative improvement in oxygen activation compared to fission rate as $\mathrm{Pb}$ filter thickness is increased.

Examination of the results show that while $25 \mathrm{~cm}$ of lead reduces the neutron flux at the target $\sim 10 \mathrm{X}$, the oxygen activation is reduced $\sim 20 \mathrm{X}$ so that there is a net gain in the ratio of SNM signal to oxygen interference by about $2 X$. Further analyses of predicted error rates will be carried out to determine whether the improvement in signal to background ratio offsets the loss of nearly a decade in signal strength.

\section{Detector design}

Rapid assessment of cargo container contents requires very high-count rates for the desired signal. Earlier sections showed that this signal is weak even with strong interrogation source strength. It is essential to have very high detector efficiency in order to detect the unique signals due to SNM fission product emission. As described in Section 3 there are far too many $\gamma$-ray lines among the 40 or so prominent fission products to be resolved even by a highenergy resolution spectrometer. A low-resolution detector will prove adequate for reliable detection of the SNM signature. In addition, the signature $\gamma$-rays are likely to scatter in thick cargos several times before escape. Consequently, although absorption is very weak and the total intensity is only moderately attenuated as $\gamma$-radiation transits the cargo, the photons are scattered in a way that decreases the intensity of the full energy peaks and increases the intensity of the underlying continuum spectrum due to Compton scattering in the cargo. Because of this high resolution spectroscopy is not useful or warranted. High efficiency, low-resolution $\gamma$-ray detectors are available, appropriate, and relatively inexpensive. 
The concept studied here invokes 2-4 very large detector arrays sensitive to both neutrons and $\gamma$-rays, and able to distinguish the two radiation sources. They consist of a bank of liquid-scintillator-filled tubes spanning the full length and height of each container sidewall. These tubes are nominally $30 \mathrm{~cm}$ diameter by $3 \mathrm{~m}$ length and are aligned with their axis vertical. Two offset rows are emplaced to provide total coverage of each container sidewall. A total of 20 tubes are sufficient to cover one sidewall of the cargo container. A subset of 4 tubes has been assembled for evaluation and its schematic is shown below.

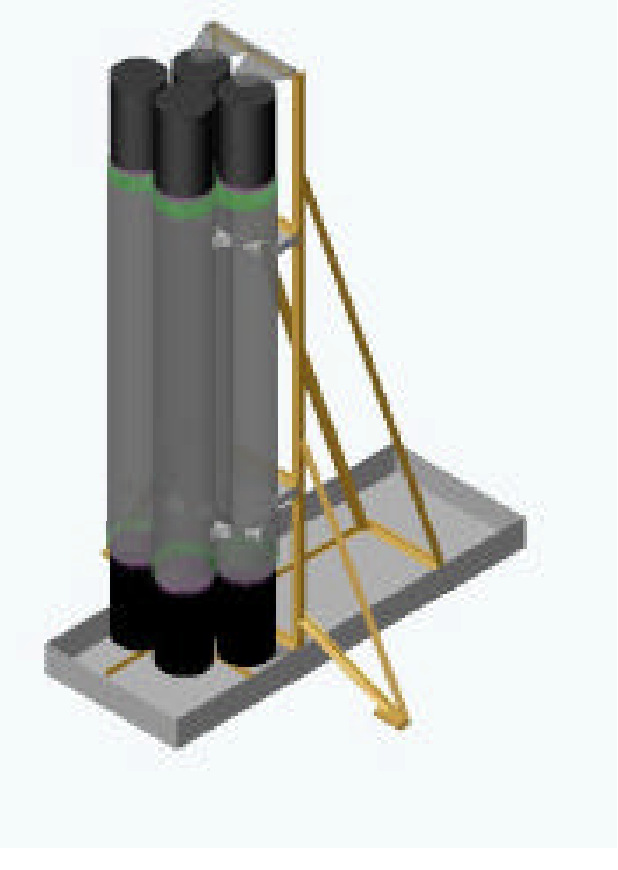

Figure 5.1 Detector array to detect signature SNM high-energy fission product $\gamma$-rays.

Pictures of two small cells are shown below as well as a picture of the small cell alongside an unfilled standard cell. 


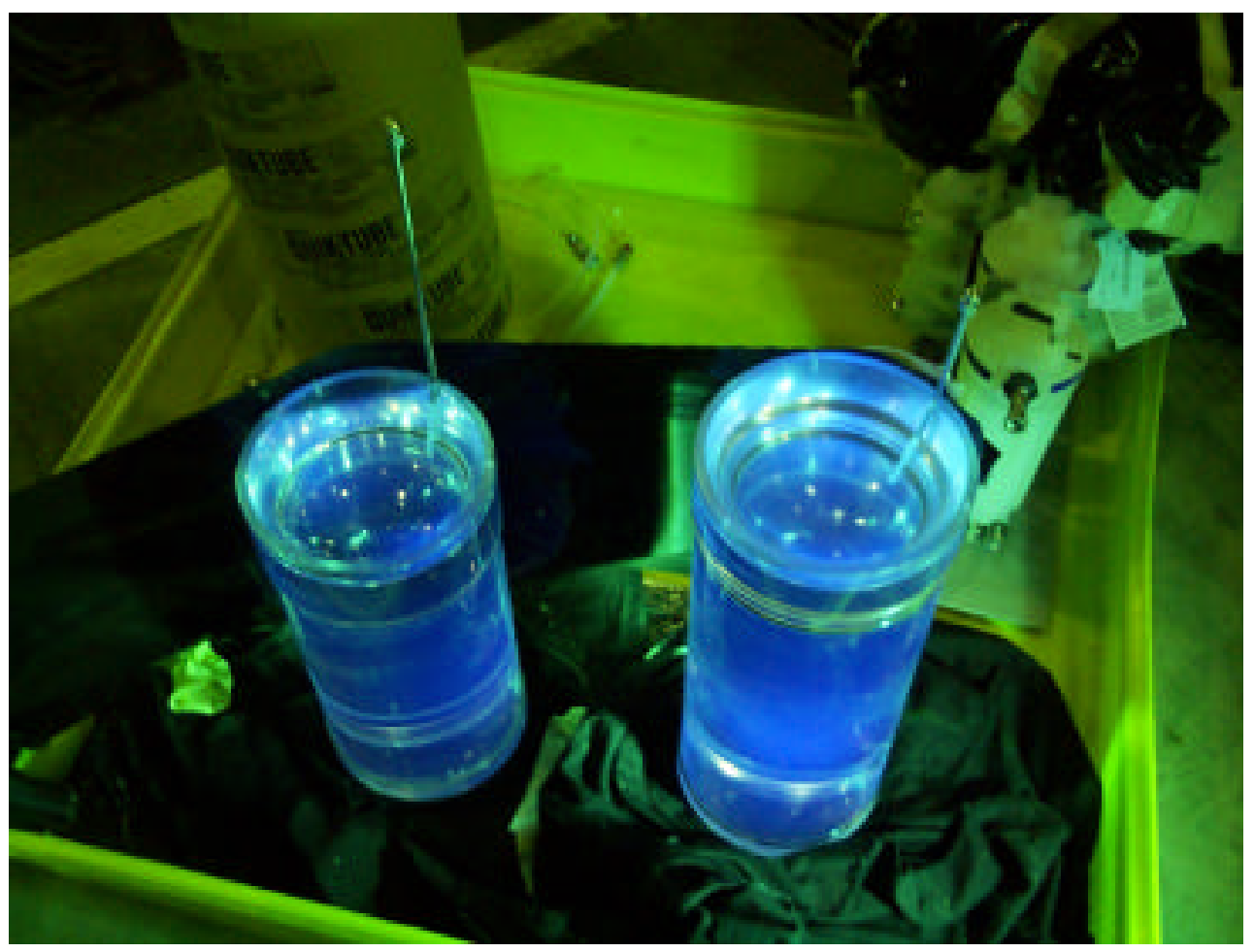

Figure 5.2 Two small cells of the liquid scintillation detector 


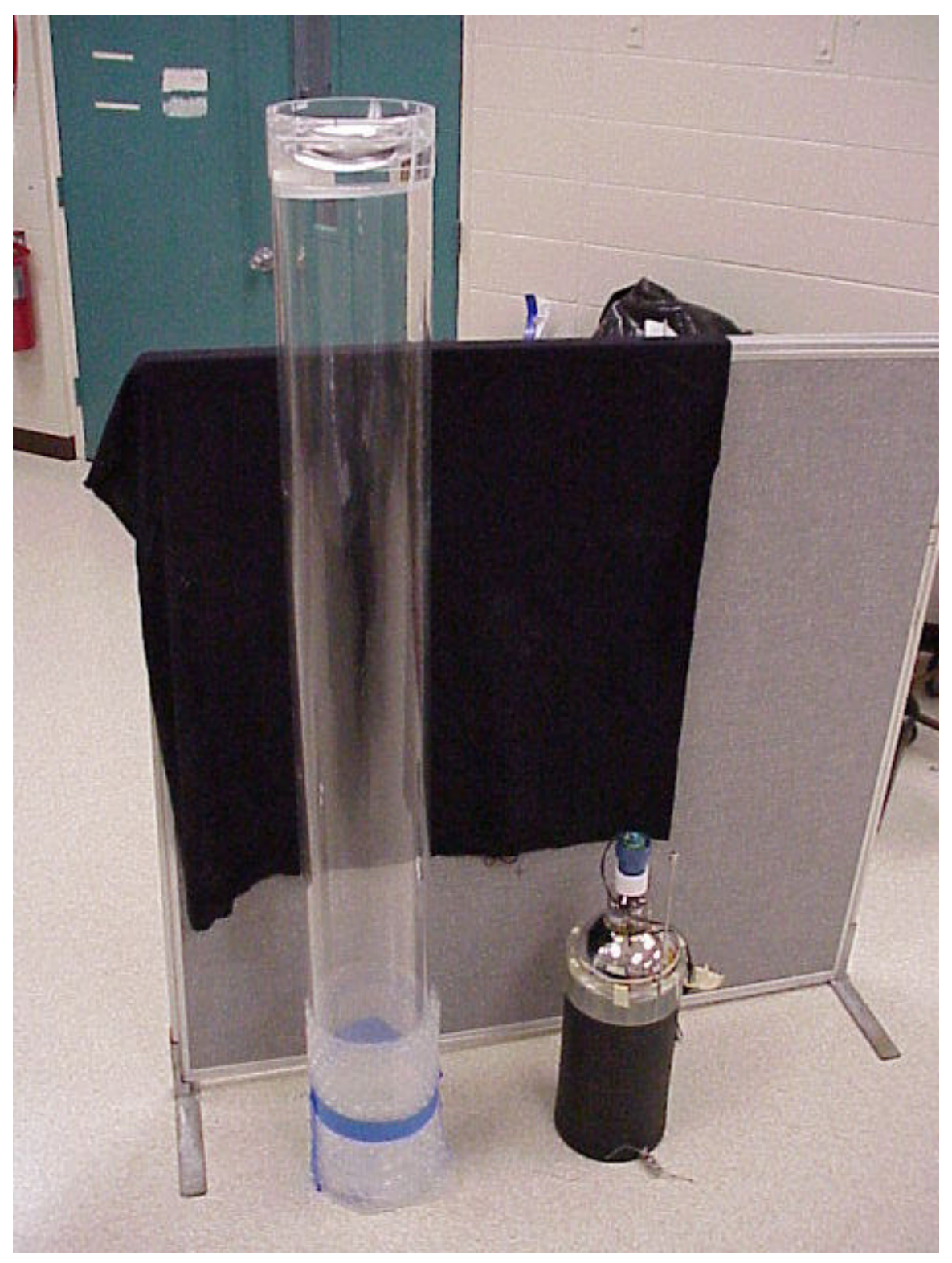

Figure 5.3 An unfilled standard scintillator cell alongside the small cell shown above

These detectors are estimated to have $\sim 50 \%$ detection efficiency as an incident $\gamma$-ray undergoes multiple Compton scattering events in the large detector volume depositing much of its energy. An energy discriminator will be set to suppress response to any events depositing less than $3 \mathrm{MeV}$ and that will reduce the detector efficiency to $\sim 10 \%$. A pulse height spectrum for one cell of this array is shown below where a ${ }^{60} \mathrm{Co}$ source illuminated the detector with its two $\gamma$-rays of equal intensity at 1.17 and $1.33 \mathrm{MeV}$. 


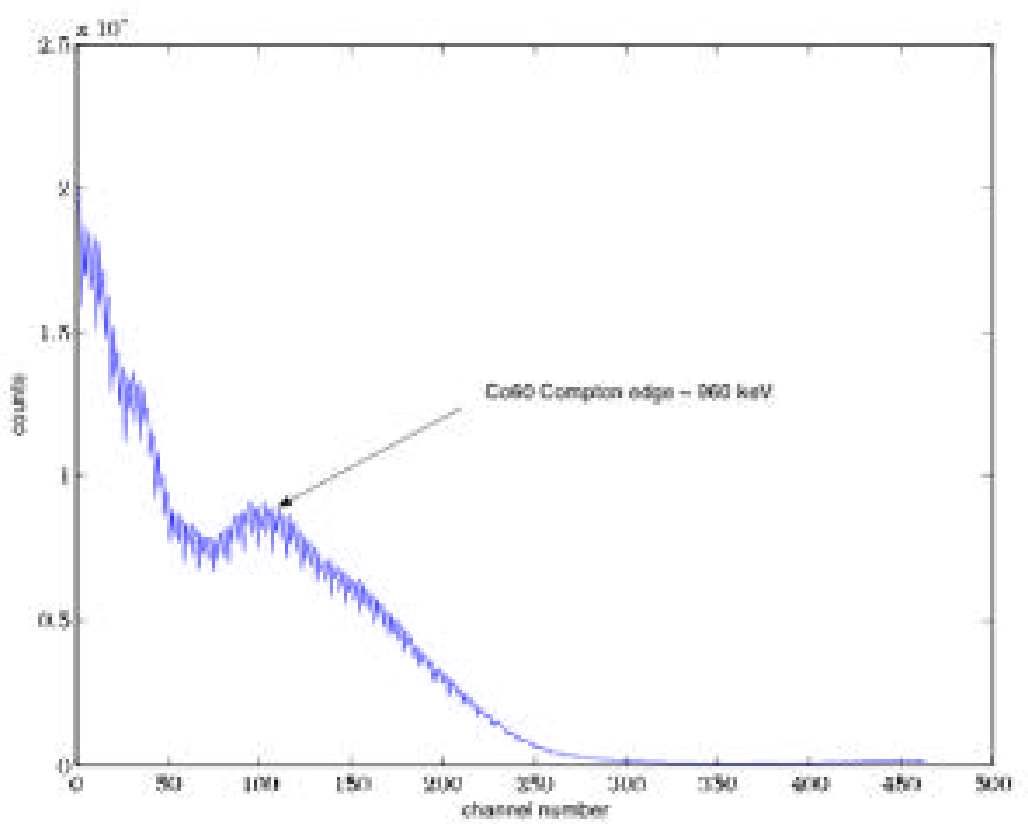

Figure 5.4 Pulse height spectrums from large liquid scintillator detector exposed to ${ }^{60} \mathrm{Co}$ $\gamma$-ray source.

Examination of the figure shows the resolution is very modest, but adequate to distinguish $\gamma$-rays separated by $\sim 20 \%$ in energy. That capability will be adequate to discriminate signature fission product $\gamma$-rays at $\mathrm{E}_{\gamma}=3-7 \mathrm{MeV}$ from the low energy interferences. More importantly, these detectors have sufficiently high efficiency that the predicted signal strength of $\sim 0.5 \mathrm{\gamma} / \mathrm{cm}^{2} / \mathrm{sec}$ at the container wall will translate to $10^{4} \mathrm{cps}$ at the detectors.

The detector array has a relatively fast time response, $\sim 100 \mathrm{~ns}$ or better, so that neutrons or $\gamma$-rays that are emitted as part of a fission chain can be identified from the multiplicity of events in the area at high count rates. This is an important capability that can detect significant neutron multiplication in an SNM assembly that would distinguish it clearly from legitimate cargo contents that may include natural uranium. The scintillators can detect fast neutrons from their scattering in the detector and also can detect thermal neutrons as they are captured in the Gd that is also loaded into the liquid scintillation material. The thermal neutron capture produces a very distinctive $\gamma$-ray cascade depositing a total of approximately $\sim 8 \mathrm{MeV}$ in the detector. Similarly, $\gamma$-rays emitted during fission chain events may lead to large multiplicity of $\gamma$-ray events in the array.

Since the array is subdivided into many elements forming pixels with dimensions $\sim 30 \mathrm{~cm}$, the acquired data contains information on the location of the target in the cargo container. As the induced radiation source scans along the detector array its position along the length of the container can be determined to within a few tens of $\mathrm{cm}$.

Finally, the detector array can be used even if active neutron interrogation of the cargo is not called for. It can be used without the neutron source to scan for large amounts of radioactive material present in a cargo. The neutron and $\gamma$-ray sensitivity is very high so that small amounts of radioactivity can be detected. In addition, the array is segmented so that some indication of the 
location or spatial extent of the radioactive material can be obtained from the count rates in multiple array elements. Establishing the geometrical extent of the radioactive material would help to distinguish a cargo with small amounts of uranium distributed throughout from the normal cargo with a small SNM component hidden in it.

\section{$6 \quad$ Advanced signal processing to suppress background}

The high-energy $\gamma$-ray signature produced by SNM has several principal characteristics that distinguish it from either natural background radiation sources or from the radioactivity produced during neutron interrogation of cargo. They are:

- High energy. Significant $\gamma$-ray intensity is produced at energies in the range 3-7 MeV, as has been discussed in Section 3. There is essentially no natural radioactivity that produces $\gamma$-radiation above approximately 2.5 $\mathrm{MeV}$. Neutron interrogation produces many high-energy $\gamma$-rays from $(n, \gamma)$ reactions with species in the cargo and the environment, but they are not produced in between beam pulses. Finally, a high-energy neutron beam can produce activation reactions such as $(n, 2 n),(n, p)$, and $(n, \alpha)$ on cargo and environmental nuclides that subsequently emit high-energy $\gamma$-rays but nearly all of these species are long-lived compared to the fission products, as seen in the table below. These reactions can produce interferences, but most interferences can be eliminated by reducing beam energy, as the table below shows. To first order the fission product $\gamma$-rays are unique in their high energies.

There are a number of short-lived background and/or activation products that could interfere with identifying the SNM signature radiation. Table 6.1 below summarizes the nuclides of greatest concern.

Table 6.1 Neutron activation products with short half-lives

\begin{tabular}{|c|c|c|c|c|c|c|c|}
\hline $\begin{array}{l}\text { Product } \\
\text { Nuclide }\end{array}$ & Reaction & $\begin{array}{l}\mathrm{E} \gamma \\
(\mathrm{MeV})\end{array}$ & $\begin{array}{l}\text { Half } \\
\text { Life } \\
\text { (sec) }\end{array}$ & $\begin{array}{l}\mathrm{I}_{\gamma_{-}} \\
(\mathrm{abs})\end{array}$ & $\begin{array}{l}\mathrm{I}_{\mathrm{g}}(>2.0 \\
\mathrm{MeV})\end{array}$ & $\begin{array}{l}\text { Thresh } \\
(\mathrm{MeV})\end{array}$ & $\begin{array}{l}\text { Target } \\
\% \\
\text { abund }\end{array}$ \\
\hline${ }^{15} \mathrm{C}$ & ${ }^{18} \mathrm{O}(\mathrm{n}, \mathrm{a})$ & 5.3 & 2.4 & 0.63 & & 5.29 & 0.2 \\
\hline \multirow[t]{2}{*}{${ }^{16} \mathrm{~N}$} & ${ }^{16} \mathrm{O}(\mathrm{n}, \mathrm{p})$ & 6.1 & 7.1 & 0.67 & & 10.25 & 99.8 \\
\hline & & 7.1 & & 0.049 & & & \\
\hline \multirow[t]{2}{*}{${ }^{26} \mathrm{Na}$} & ${ }^{26} \mathrm{Mg}(\mathrm{n}, \mathrm{p})$ & 2.52 & 1.1 & & $.070>2.0$ & 8.86 & 11 \\
\hline & & 2.54 & & & & & \\
\hline \multirow[t]{3}{*}{${ }^{30} \mathrm{Al}$} & ${ }^{30} \mathrm{Si}(\mathrm{n}, \mathrm{p})$ & 2.23 & 3.6 & & $1.05>2.0$ & 8.04 & 3.1 \\
\hline & & 2.6 & & & & & \\
\hline & & 3.5 & & & & & \\
\hline \multirow[t]{3}{*}{${ }^{44} \mathrm{~K}$} & ${ }^{44} \mathrm{Ca}(\mathrm{n}, \mathrm{p})$ & 2.15 & 1326 & & $>0.4$ & 4.99 & 2.09 \\
\hline & & 2.52 & & & & & \\
\hline & & 3.66 & & & & & \\
\hline \multirow[t]{2}{*}{${ }^{37} \mathrm{~S}$} & ${ }^{36} \operatorname{Ar}(\mathrm{n}, \gamma)$ & 3.1 & 300 & 0.94 & & 0 & 0.34 \\
\hline & ${ }^{40} \mathrm{Ar}(\mathrm{n}, \mathrm{a})$ & & & & & 2.56 & 99.6 \\
\hline
\end{tabular}


- Short and relatively unique decay times. There are a wide range of fission products produced and many of them have short half-lives, i.e. in the range 0.5-100 seconds. Natural backgrounds are necessarily constant and the activated materials produced by interrogation are mostly long-lived with half-lives of minutes to years. Here too the fission product $\gamma$-rays are distinct from most interfering sources by their short half-lives.

- Temporal nature of the scanning process. Physical scanning of an SNM target through a collimated neutron beam at a known velocity provides a unique temporal dependence in the "signature" radiation. The known temporal shape of this response is unique and can be used to distinguish it from background and other interfering sources.

In addition to the above it is anticipated that neutron events will be detected, including those due to delayed fission neutrons, and will be distinguished by the detector arrays deployed. This information can be used together with the $\gamma$-ray data to make decisions about the possible presence of SNM in a given cargo container. If a significant amount of SNM is present then there is a possibility of neutron multiplication that produces chains of fission events. Those chains will appear as chains of both neutron and $\gamma$-ray production, and the signature would be non-Poisson deviations in the normal counting statistics of both the $\gamma$-ray and the neutron detectors. So, there are many sources of information that can be combined coherently in an Expert System to provide a high degree of confidence in the system decision that might not be warranted from any one information source alone. These information sources are visualized in the figure below.

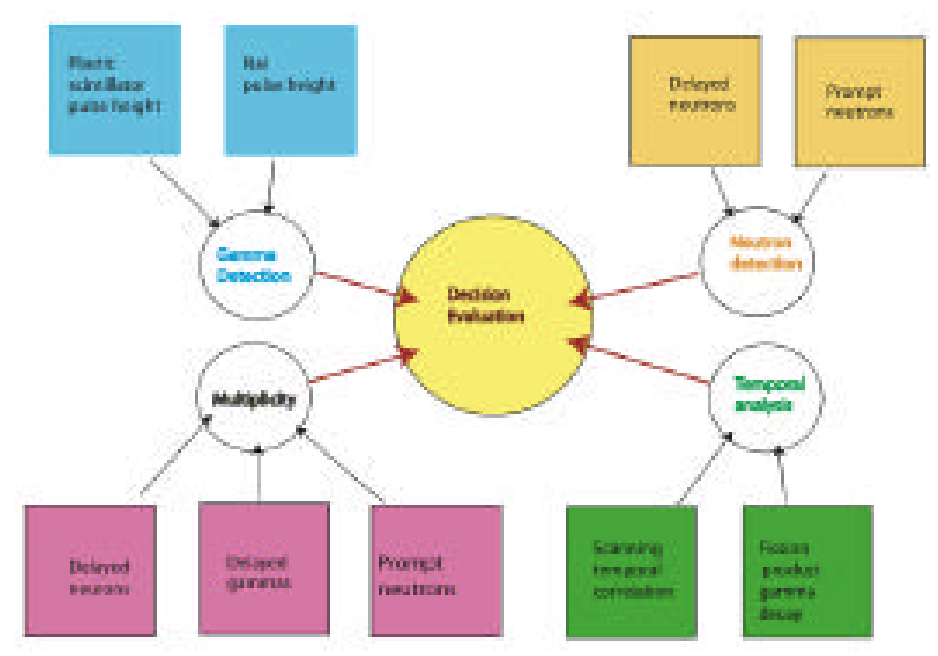

Figure 6.1 Information sources driving the decision process 
Decision functions are being developed that characterize each detected event regarding the probability that it is indicative of SNM presence. As events are detected a distribution function is developed that leads to a detection decision for each information channel with known, or predictable, error rates. A Receiver Operating Characteristic (ROC) curve plots the probability of detection vs. the probability of false alarm for different parameter values. Various methodologies for developing this function are currently under study. These information sources will then be combined to improve the confidence of decisions made using this information. They will optimally utilize the all the principal distinguishing characteristics above and will provide prediction of the error rates, i.e. false positives or false alarms, and false negatives or failure to detect.

\section{Neutron source design}

\subsection{Neutron beam energy}

Neutron interrogation is chosen primarily because the neutrons penetrate cargo reasonably well to reach a target of interest and then they produce a distinctive radiation signature that escapes the cargo for detection. Neutron penetration varies widely among materials. Neutron mean free path in several cargo types has been evaluated and a summary shown in the figure below. Note that the units on the ordinate are areal density, i.e. $\mathrm{MFP}=\rho \lambda$ where $\lambda$ is the ordinary mean free path in material of density $\rho$.

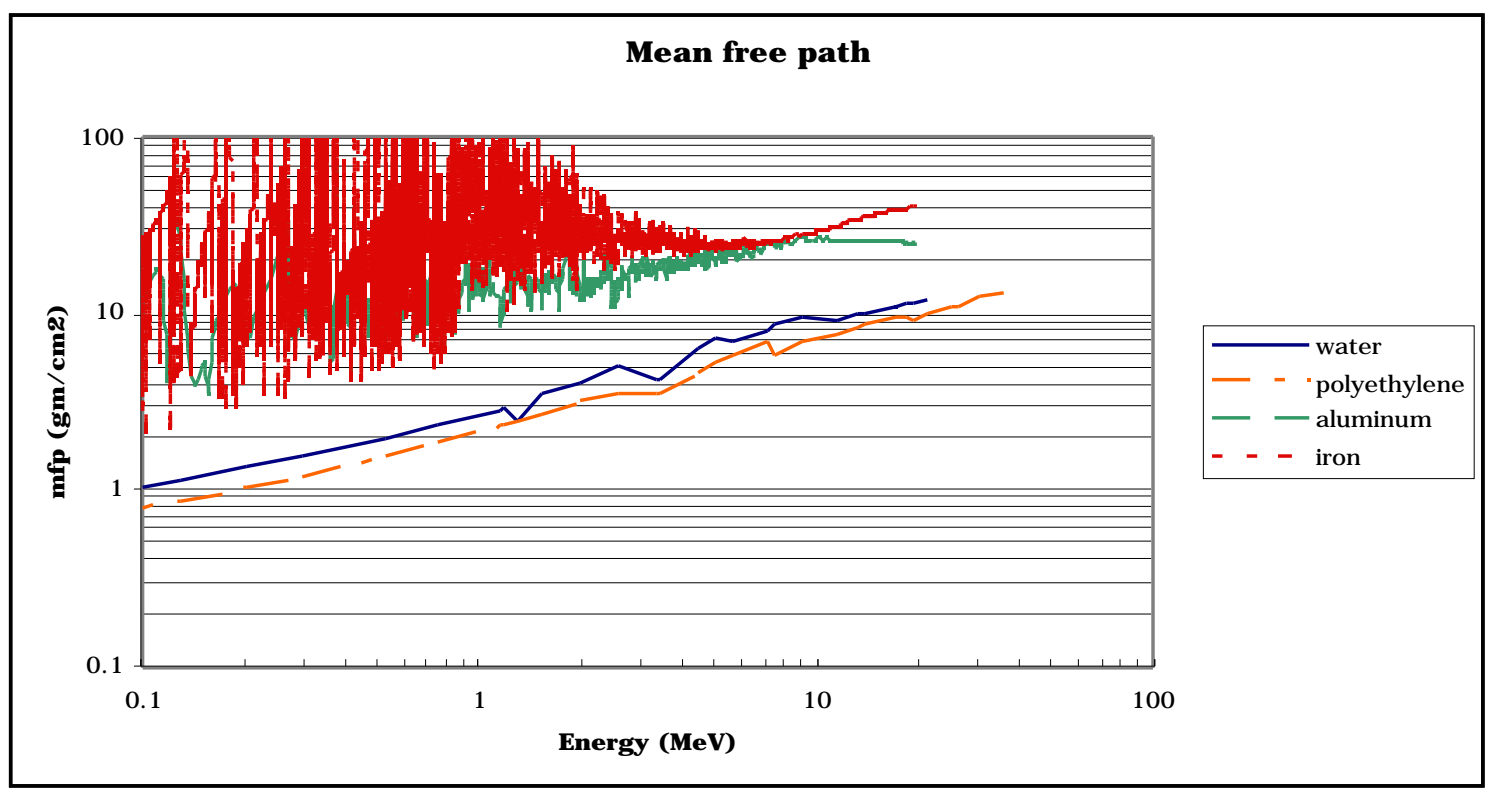

Figure 7.1.1 Neutron mean-free-path in several materials representative of cargo

Examination of the figure shows the advantage of interrogating at the highest neutron energy. Neutron sources at $E_{n}=14 \mathrm{MeV}$ have mean attenuation length roughly $3 \mathrm{X}$ larger than at $2.5 \mathrm{MeV}$, and are vastly superior to low energy sources, i.e. $5 \mathrm{X}$ more than $0.5 \mathrm{MeV}$ sources. However, they have the potential to damage cargo by activating it. It should be noted that simple analyses done so 
far and described later indicate this is not likely to be a significant problem. More importantly, neutrons at energies above $10 \mathrm{MeV}$ activate oxygen to produce a strong interference due to the short-lived $(7.1 \mathrm{sec}){ }^{16} \mathrm{~N}$ produced as described earlier. There are, of course other reactions producing ${ }^{16} \mathrm{~N}$ such as neutron capture in ${ }^{15} \mathrm{~N}$ and the ${ }^{19} \mathrm{~F}(\mathrm{n}, \alpha){ }^{16} \mathrm{~N}$ reactions. Mitigating the capture reactions is the low abundance of ${ }^{15} \mathrm{~N}$, only $0.34 \%$. Mitigating the $\mathrm{F}$ activation is its moderate energy threshold of $\sim 3.5 \mathrm{MeV}$, moderately low cross section of $\sim 0.15 \mathrm{~b}[14]$, and its low abundance in most cargos.

One solution to this problem is utilization of a small accelerator, based on a radio frequency quadrupole (RFQ) that produces neutrons by the $D-D$ reaction with accelerated beam energy of a few $\mathrm{MeV}$. The figure below shows the neutron beam energy as a function of incident deuteron energy.

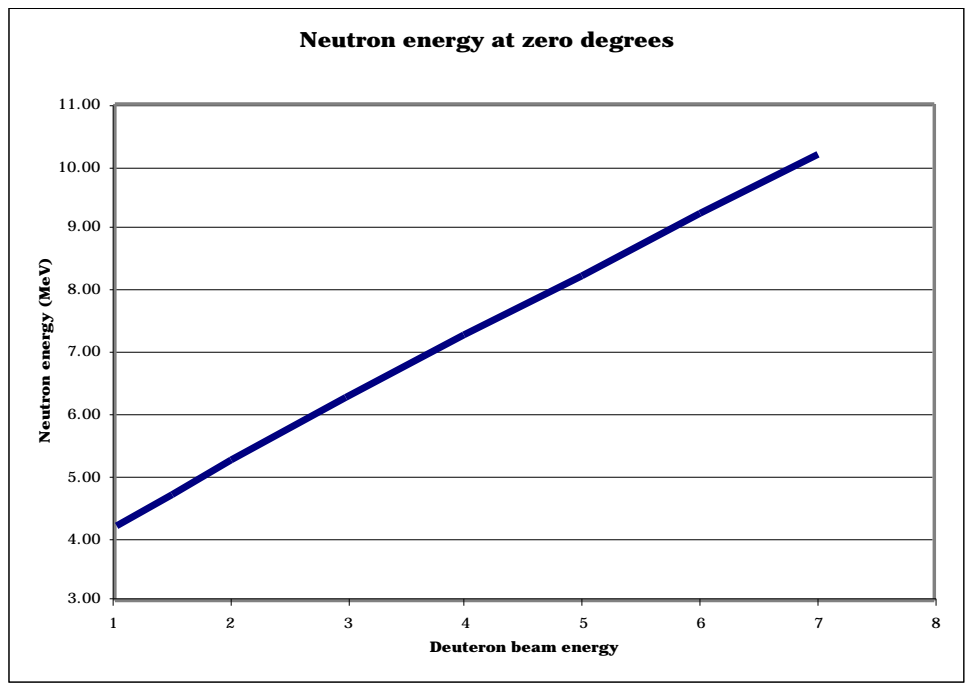

Figure 7.1.2 D-D neutron energy vs. D-beam energy

Neutron interrogation energy increases almost linearly with D-beam energy in the D-D reaction. Neutron energies in the most desirable range are achieved with D-beam energies in the range $2-5 \mathrm{MeV}$. This is a convenient range for simple RFQ's and they can be made very compact and inexpensive compared to larger accelerators. Useful beam currents up to $1 \mathrm{~mA}$ are readily obtained. As the beam energy increases the neutron output is increasingly peaked in the forward direction due to the kinematics of the reaction and to the forward peaking of the reaction in the center of mass coordinate system.

An estimate of the neutron flux at a target location can be made based on the beam energy, current, differential reaction cross-section and the amount of target deuterium. The neutron flux at the target is given by:

$$
\Phi=\frac{1}{R^{2}} \frac{d \Phi}{d \Omega}=\frac{I_{d} N_{o} \varepsilon \rho T}{e A_{o} R^{2}} \frac{d \sigma}{d \Omega}
$$

Where $I_{d}$ is the D-beam current, e the electron charge, $N_{o}$ Avogadro's number, $\mathrm{A}_{\mathrm{o}}$ the mass number of the material holding the deuterium (which slows the beam), $\varepsilon$ the number of target $\mathrm{D}$ atoms per atom of the base material, $\rho \mathrm{T}$ the 
density and thickness of the target, and $\mathrm{d} \sigma / \mathrm{d} \Omega$ the reaction differential cross section[47]. The target thickness, $\mathrm{T}$, is chosen so that the energy loss for the beam is limited to a value for which the dispersion in neutron energies is acceptable. Evaluation here utilizes the $\mathrm{dE} / \mathrm{dx}$ data from Northcliffe \& Schilling[48]. Since the low energy neutrons produced after the incident beam slows significantly in the target are broadly dispersed in angle and not very penetrating, we choose to limit the beam energy loss to $\sim 1 \mathrm{MeV}$ and choose target thickness with that in mind.

An evaluation of the above relation is plotted below for the case where $\mathrm{I}=1 \mathrm{~mA}$, and the target holder is Ti with $\varepsilon=2$. Two cases are shown: a) the target thickness is increased with beam energy so that in all cases the beam loses $1 \mathrm{MeV}$ traversing the target thickness, and b) a fixed target thickness of $10 \mathrm{mg} / \mathrm{cm}^{2}$. Just for comparison, the fast flux due to an isotropic source of $1 \times 10^{11} \mathrm{n} / \mathrm{s}$ is shown as well.

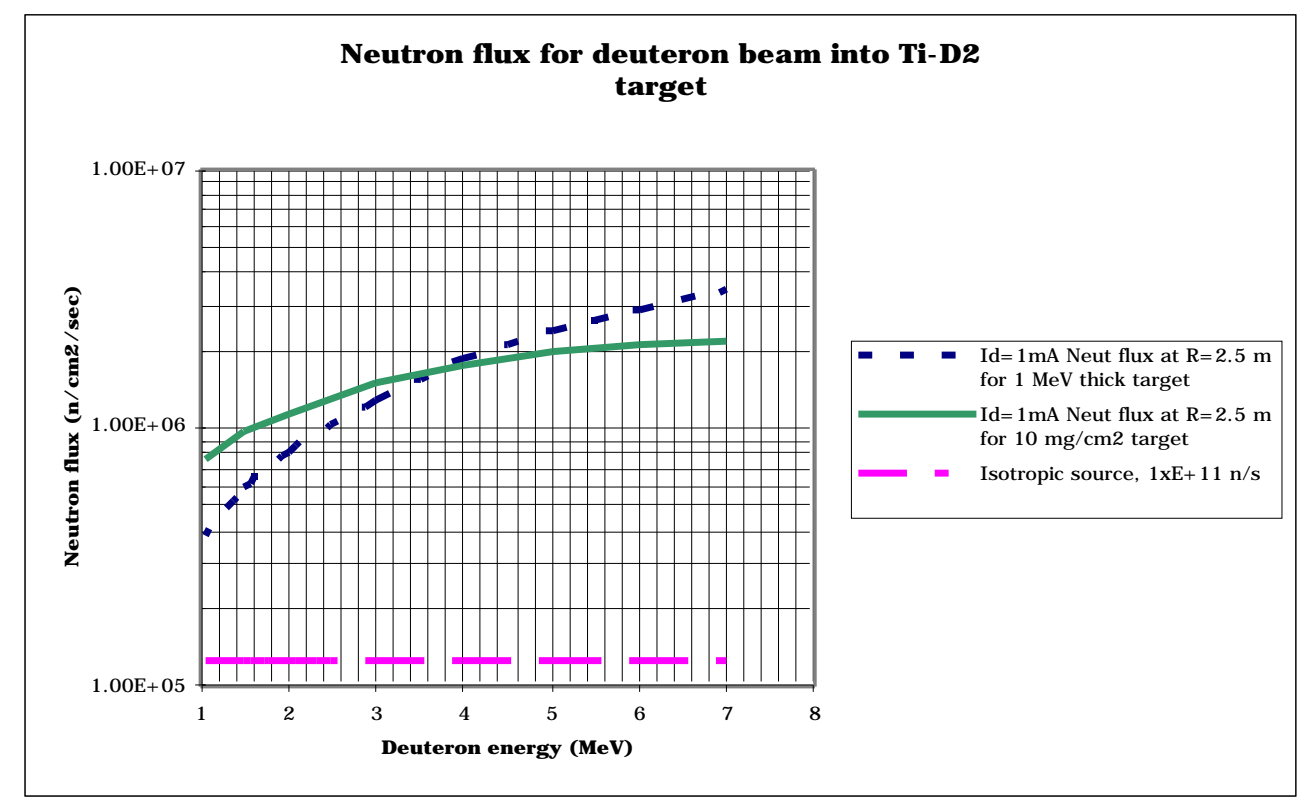

Figure 7.1.3 Neutron fast flux at target location for various beam energies and target thicknesses.

Examination of the figure shows that a $1 \mathrm{~mA}$ D-beam at $\mathrm{E}_{\mathrm{d}}=5 \mathrm{MeV}$ produces 20-25X higher flux at the target location than an isotropic $1 \times 10^{11} \mathrm{n} / \mathrm{s}$ source. In addition, the D-D neutron output is collimated kinematically in the forward direction so that shielding requirements and activation of the neutron source system components is greatly reduced compared to the isotropic source. Design work and cost estimation for such a source is just now beginning. Thus, it is clear that an RFQ accelerator can produce D-D neutrons with an intensity ontarget that meets the count rate requirements from section 3 while, at the same time, maintaining beam energy below the activation threshold for production of the interfering ${ }^{16} \mathrm{~N}$. This beam also produces an interrogating source with good cargo penetration as exhibited in Figure 7.1.1. 


\subsection{Optimal pulse structure}

Section 3 showed that there are many fission products with relatively high $\gamma$-ray yields at energies above $3 \mathrm{MeV}$. There are 40 or so fission products contributing to this signature and they have a wide range of decay times. If $P_{\mathrm{i}}$ is the production rate of one species, i.e. nuclide-i, during a neutron beam pulse of duration $\tau$, then the number of fission products, $\mathrm{N}_{\mathrm{i}}$, is given below.

$$
N_{i}=\frac{P_{i}}{\lambda_{i}}\left(1-e^{-\lambda_{i} \tau}\right)
$$

The total decay rate at time $t$ due to all nuclides is the summation over their individual decay rates.

$$
D(t)=\sum_{i} \lambda_{i} N_{i}=\sum_{i} P_{i}\left(1-e^{-\lambda_{i} \tau}\right) e^{-\lambda_{i} t}
$$

This sum has been carried out for the nuclides identified in the tables of Section 3 and the result is shown in the plot below.

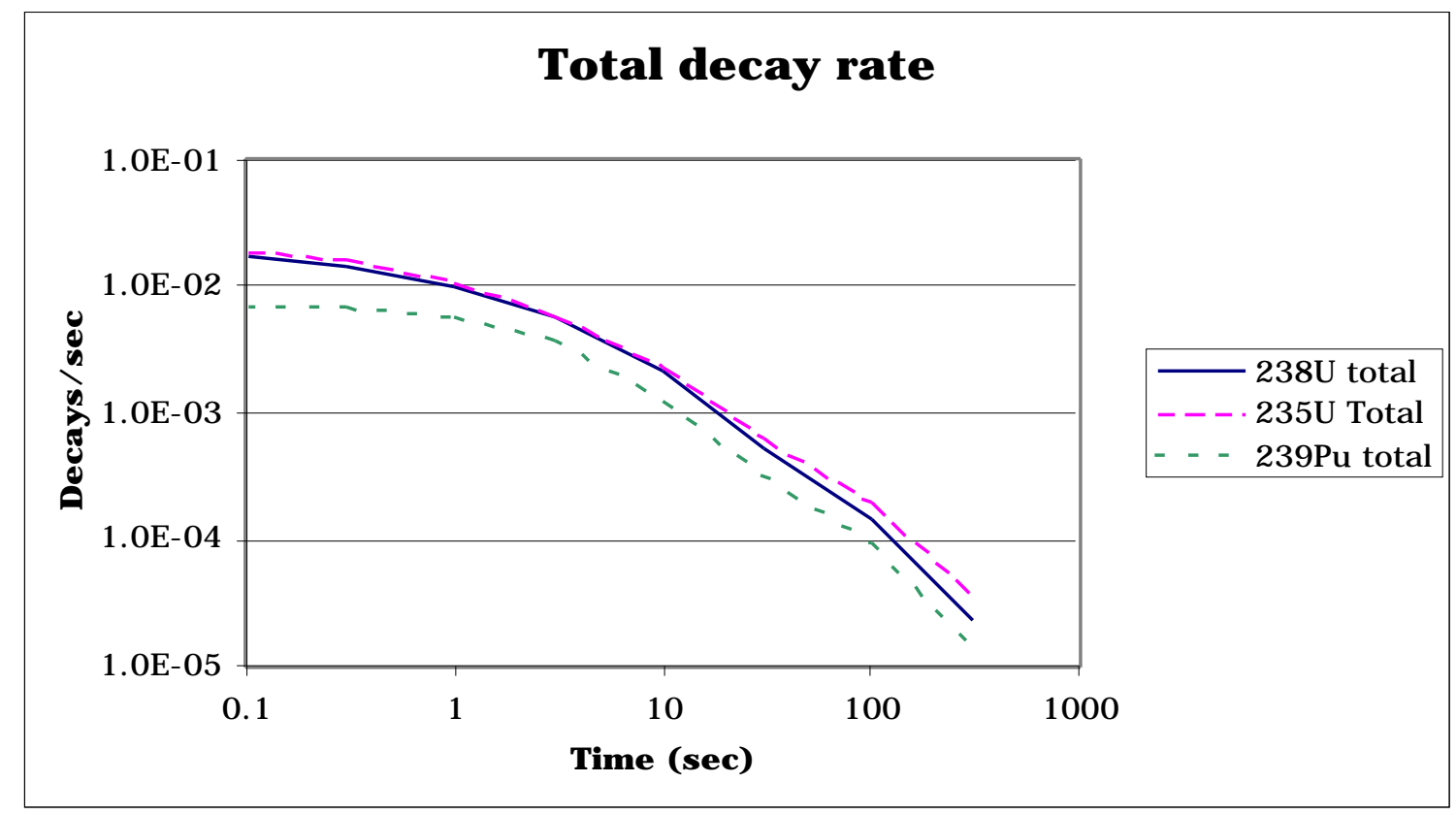

Figure 7.2.1 Decay rate of high-energy $\gamma$-rays

The decays illustrated in the figure may be analyzed to determine an effective half-life that varies with time as the species mix changes. The effective half-life is shown below. 


\section{Effective half-life}

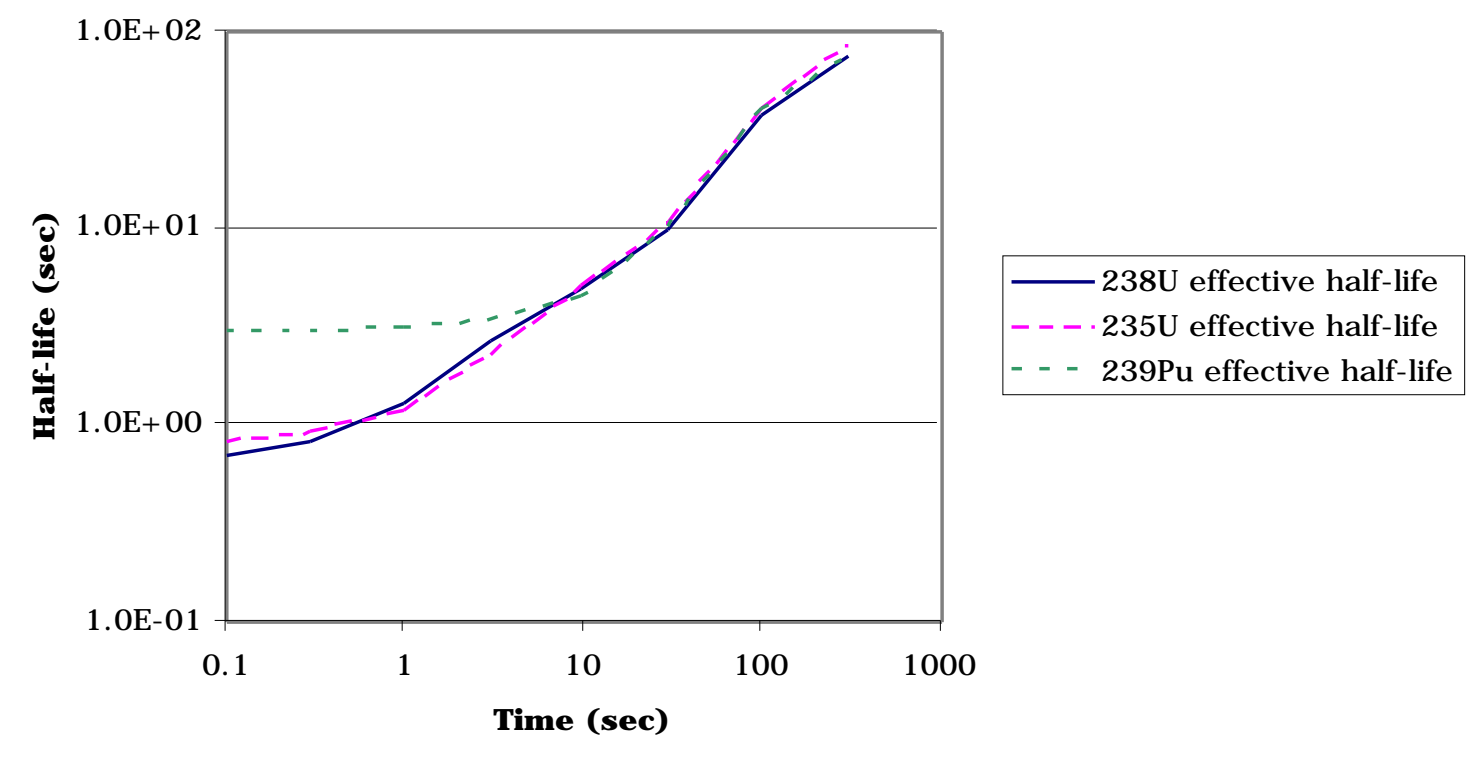

Figure 7.2.2 Effective half-life of total decays

Finally, the total decays may be integrated to determine the time required to observe $50 \%$ or $90 \%$ of all decays. That result is shown in the figure below.

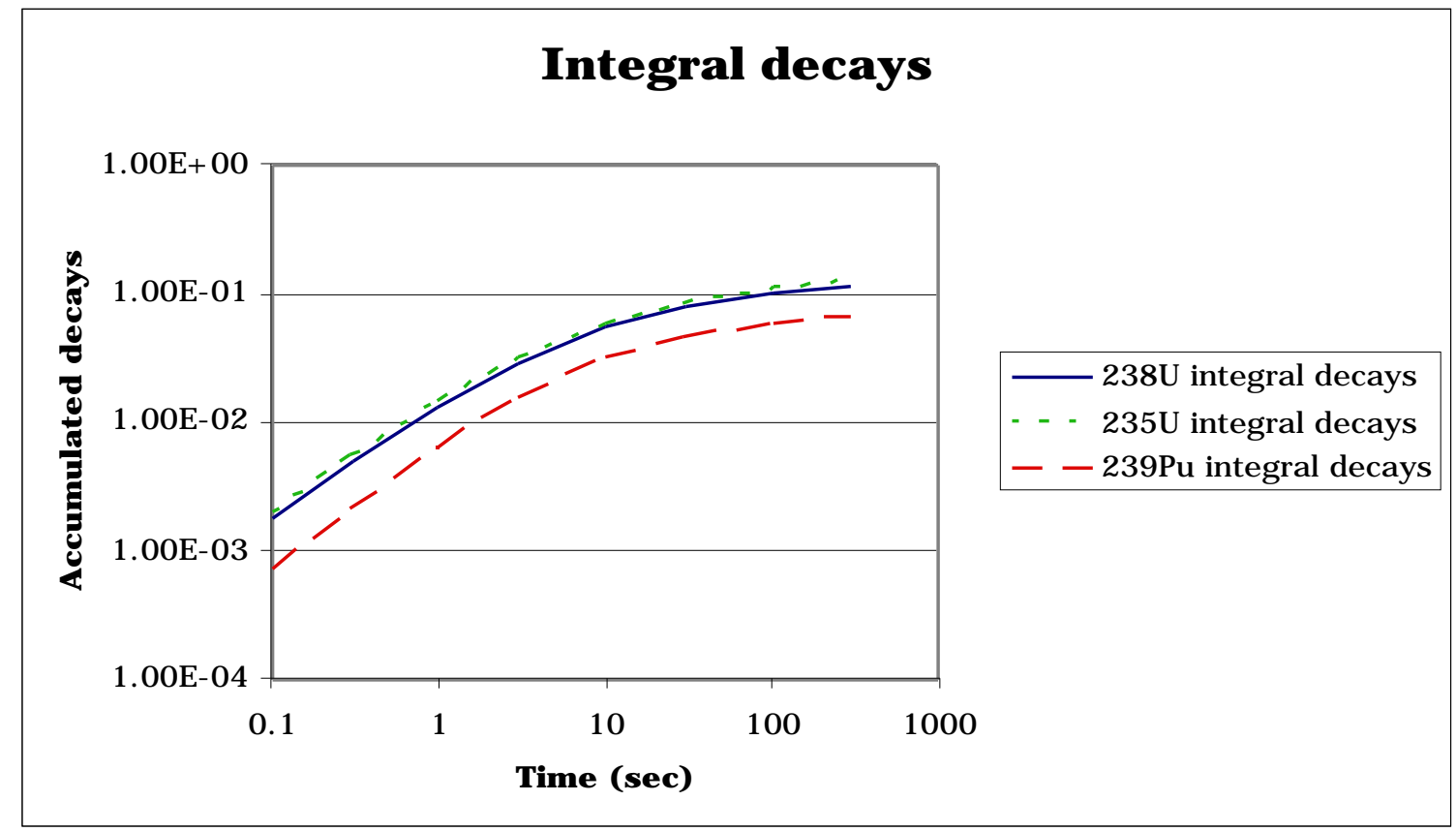

Figure 7.2.3 Accumulated decays per fission

Using the data shown above the estimated number of decays accumulated over long counting times can be determined and partial results are tabulated below. 
Table 7.2.1 Time required for a fixed fraction of decays to occur (sec)

\begin{tabular}{|c|c|c|}
\hline & $50 \%$ & $90 \%$ \\
\hline${ }^{235} \mathrm{U}$ thermal fission & 11 & 100 \\
\hline${ }^{239} \mathrm{Pu}$ thermal fission & 12 & 120 \\
\hline${ }^{238} \mathrm{U}$ fast fission & 10 & 100 \\
\hline
\end{tabular}

The pulse structure of an interrogating beam must be optimized for maximum reliability with minimum interrogation time. This requires the maximum count rate of detected "signature" events while minimizing the count rate due to interfering events. For detection of $\mathrm{CW}$ during the beam pulse the optimum is a continuous beam without beam-off intervals. However, that would not allow detection of the delayed SNM radiation from fission products. To address the optimization of delayed radiation detection we assume a train of pulses with duration $\tau$ and interval T where delayed radiation is counted only during the beam-off interval.

If there were only one pulse with duration $\tau$ and a single counting interval immediately following with duration $\mathrm{T}-\tau$, then the number of decays during the counting interval is given below, where $\mathrm{P}$ is the production rate of the nuclide of interest during the beam pulse and $\lambda$ is its decay constant.

$$
C_{1}=\frac{P}{\lambda}\left(1-e^{-\lambda \tau}\right)\left(1-e^{-\lambda(T-\tau)}\right)
$$

If there is a train of $\mathrm{N}$ pulses, beginning with no fission products, it can be shown that the total number of decays during the $\mathrm{N}$ subsequent counting intervals is given below.

$$
C_{N}=\frac{C_{1}}{\left(1-e^{-\lambda T}\right)^{2}}\left[N-(N+1) e^{-\lambda T}+e^{-(N+1) \lambda T}\right]
$$

Using the relation in Eq. 7.2.4 it is possible to optimize the beam duty factor, $\tau / \mathrm{T}$, to provide the maximum number of counts. This has been done and the result is shown in the figure below for the case $\mathrm{PNT}=1$. Three curves are included representing several pulse intervals, i.e. $\lambda \mathrm{T}=0.1,1.0$, and 5.0. 


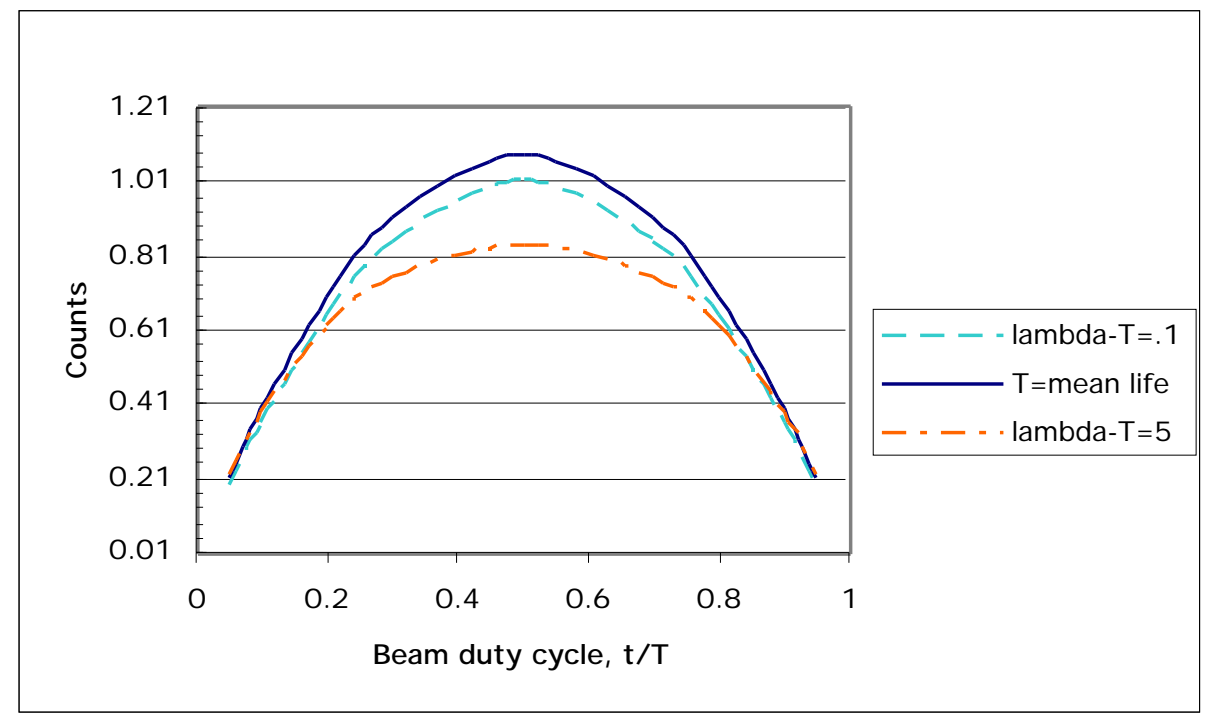

Figure 7.2.4 Optimizing the beam duty factor and repetition rate for maximum number of detected events. The three curves correspond to pulse intervals that are, respectively, $0.1,1.0$, and 5.0 times the mean life of the nuclide whose decays are being counted.

The principal conclusions are:

- The maximum number of detected events occurs when the duty factor is approximately $50 \%$

- The optimal pulse repetition rate corresponds to an interval of one meanlifetime of the nuclide being counted. However, it is important to note that the result is relatively insensitive to the pulse interval, $\mathrm{T}$, over the range 0.1-5.0 mean lifetimes.

Eq. 7.2.4 above can also be used to estimate the ratio of signal to background, S/B. Not surprisingly the maximum S/B occurs when the beam duty factor approaches $100 \%$. This is intuitively obvious because the number of background events approaches zero as the counting interval goes to zero. But in that limiting condition there are zero net signal counts.

\subsection{Overall neutron source requirements}

The preceding evaluations and experiments have established special requirements for the interrogating neutron source. It must meet the following requirements as a minimum:

- Thermal neutron flux at the target location $\geq 1 \times 10^{6} \mathrm{n} / \mathrm{cm}^{2} \mathrm{sec}$

- Beam pulse structure providing 10-30 sec on and 10-30 sec off

- Contrast, i.e. beam-on compared to beam-off between pulses $\geq 10^{9}$

- Collimated to confine principle neutron flux to a region approximately the size of a SNM target, i.e. a few feet across at cargo container centerline

- Energy spectrum with mean value $~ 5-8 \mathrm{MeV}$

- No significant intensity above the thresholds for short-lived activation of background species such as oxygen. 


\section{Limitations due to activation of cargo}

A neutron interrogation system utilizing $14 \mathrm{MeV}$ neutrons is intrusive. It will activate the environment and the cargos through fast neutron reactions such as $(n, p),(n, 2 n),(n, \alpha)$, and as those neutrons are thermalized they will produce neutron capture, i.e. $(n, \gamma)$ reactions. In the first group of reactions there are many target nuclides whose reaction threshold is below $14 \mathrm{MeV}$ and their cross sections are significant. This can produce an economic or political impact on scanning operations if cargos are activated significantly, affecting both the commercial value of the cargo and the personnel who must handle it. It can produce a radiation background in the environment of the scanner that could interfere with measurements and could even increase over time. So we need to understand the magnitude of the activation problem.

What follows is a very crude but understandable approach that provides a rough upper-bound estimate of activation in cargos and the scanner environment. In what follows it will be assumed that thermal neutrons activate the cargo in the normal case. If $14 \mathrm{MeV}$ neutrons are utilized they will be reduced to low or thermal energies after a few mean free paths, but a portion of the cargo will be exposed and activated additionally by the fast neutrons. In the worst case we set an upper bound on the activation by assuming the cargo does not moderate the $14 \mathrm{MeV}$ neutrons. In reality, thick cargos themselves will strongly moderate the neutron spectrum and reduce or eliminate many of the activation reactions considered below. The following discussion should be treated only as a guide to where the problems are and not used as a reliable or accurate representation of the actual radioactivity produced. It is presented in the knowledge that this simple analysis is likely to overestimate cargo activation by a decade or even a few decades and serves only as an interim guide pending completion of detailed simulation for a range of real cargo configurations. This is only an upper-bound estimate of the problem.

The interrogating beam can activate a nuclide of interest and its activity (decay rate per gram of cargo) is described as follows.

$$
\frac{A_{i}}{M}=\frac{\lambda_{i} N_{i}}{M}
$$

Where $\mathrm{Ni}$ is the number of radioactive atoms produced by neutron radiation in a medium of mass $M$, and is determined by neutron flux and cross sections.

$$
\frac{d N_{i}}{d t}=A \int_{0}^{L} \Sigma_{a}^{i} \Phi_{n}(x, t) d x
$$

$\Sigma_{\mathrm{a}}{ }^{\mathrm{i}}$ is the production cross section for nuclide-i, A the area illuminated and L its thickness. For a point source of neutrons, constant in time for duration $\mathrm{T}$ at intensity $I$ and distance $R_{s}$ the activation is given below.

$$
\left.N_{i}=A \Sigma_{a}^{i} \frac{I}{4 \pi R_{s}^{2}}\left[\frac{1-e^{-\mu_{n} L}}{\mu_{n}}\right] \frac{1-e^{-\lambda_{i} T}}{\lambda_{i}}\right]
$$


The cross section is a sum over all the target species in which activation is produced, and where their relative abundances are described by their atom fractions $\alpha_{i}$.

$$
\Sigma_{a}^{i}=\frac{N_{o} \rho \alpha_{i} \sigma_{a}^{i}}{M_{o}}=\frac{N_{0} m}{A L M_{0}} \alpha_{i} \sigma_{a}^{i}
$$

Of course $\mathrm{N}_{\mathrm{o}}$ is Avogadro and $\mathrm{M}_{\mathrm{o}}$ the mass number. Then the activity produced is given below.

$$
\frac{A_{i}}{M}=\frac{I}{4 \pi R_{s}^{2}}\left[\frac{1-e^{-\mu_{n} L}}{\mu_{n} L}\right]\left[1-e^{-\lambda_{i} T}\right] \frac{N_{0}}{M_{0}} \beta_{i} \sigma_{a}^{i}
$$

\subsection{Context and perspective}

Worst-case scenarios will be studied. For example, the slowest viable scanning speed is expected to be $\geq 2 \mathrm{ft} / \mathrm{min}$. This is derived from the notion that a $20 \mathrm{ft}$ container must be scanned in an interval no longer than $10 \mathrm{~min}$. Neutron beams are expected to be well collimated, with width $\leq 2 \mathrm{ft}$. Consequently, it will be assumed in the following analyses that any given cargo volume may be exposed to the interrogating beam for durations up to one minute, probably longer than actual scans will impose.

A second example of over-estimation is the approximation made where all $\gamma$-ray path lengths to the exit surface are assumed normal to the surface rather than the longer attenuation length for those directed oblique to the surface.

\subsection{Radioactive material}

Commercial cargos are limited by DOT regulations. Activity greater than $2 \mathrm{nCi} / \mathrm{gm}$ is classified as radioactive material. Food is restricted to a much lower level and the limits are just now being identified. This note will remain a rough draft while those limits are being determined.

\subsection{Radiation dose, a very rough thumb rule}

The activity estimates provided by Eq. 8.5 above can be used to arrive at very crude radiation dose rate estimates. Of course real cargos will provide selfshielding of the radiation and the actual contact dose rates will depend on the geometrical distribution of the radioactivity. It is also important to consider the number and spectra of $\gamma$-rays in each decay, as that too will determine radiation dose rates external to the cargo. Nevertheless, given all the caveats here it is possible to proceed with a thumb rule.

Radiation areas at LLNL set as a goal the reduction of dose rates to $\sim 2.5$ $\mathrm{mR} / \mathrm{hr}$ or lower for occupational exposures. This is derived from the $5,000-$ $\mathrm{mR} / \mathrm{yr}$ legal limits for radiation workers and assumes 2,000 working (and exposed) hours per year. The legal limit for the general public is $500 \mathrm{mR} / \mathrm{yr}$ and most guidelines recommend lower than 1/3 of this limit, i.e. $135 \mathrm{mR} / \mathrm{yr}$ or 10 $\mu \mathrm{R} / \mathrm{hr}$ dose rate. The NCRP has recommended radiation dose limits to cargos and especially to people who may be concealed in cargo that are consistent with 
radiation exposures allowed for the public. Their recommended limits are 100 $\mathrm{mR}$ for normal scanning and can be increased to $500 \mathrm{mR}$ where national security is allowed[49].

Environmental dose rates in the US are typically $\sim 300 \mathrm{mR} / \mathrm{yr}$, or $34 \mu \mathrm{R} / \mathrm{hr}$. Radiation levels from cargos and the scanning environment should be compared to these numbers. In the estimates that follow the radiation levels can usefully be compared to a $10 \mu \mathrm{R} / \mathrm{hr}$ guideline for the general public, i.e. nonradiation workers.

Assume the radioactivity given by Eq. 8.5 is distributed throughout a plate. The plate has a very large surface area and half of the unattenuated $\gamma$-rays escape each side. We neglect the longer path lengths for escape when the trajectory is oblique to the surface, and so we will over-estimate the dose.

$$
\Phi_{\gamma}=\frac{1}{2} \int_{0}^{T_{i}} Y_{i} \lambda_{i} N_{i}(x) e^{-\mu_{\gamma} x} d x
$$

If the flux to dose conversion factor for these $\gamma$-rays is $D_{o}$ and the $\gamma$-ray yield per decay is $Y$, then the surface radiation dose rate is given below.

$$
D_{\gamma}=\frac{1}{2 D_{o}}\left(\frac{A_{i}}{M}\right) Y\left[\left(\frac{\mu_{n}}{\mu_{n}+\mu_{\gamma}}\right)\left(\frac{1-e^{-\left(\mu_{\gamma}+\mu_{n}\right) L}}{1-e^{-\mu_{n} L}}\right)\right]
$$

The dose conversion factor for $\gamma$-rays at $300 \mathrm{keV}$ is $\mathrm{D}_{\mathrm{o}}=2 \gamma$-rays $/ \mathrm{cm}^{2} / \mathrm{sec}$ for each $1.0 \mu \mathrm{Rem} / \mathrm{hr}$. In an earlier section it was assumed that $\mu_{\mathrm{n}} \mathrm{L}=1$. Eq. 8.7 can then be evaluated from the ratios of the attenuation coefficients and an estimate of $Y$.

$$
D_{\gamma} \sim \alpha\left(\frac{A_{i}}{M}\right)
$$

Where

$$
\left.\alpha \equiv \frac{\rho Y_{i}}{2 D_{0}}\left[\frac{\mu_{n}}{\mu_{n}+\mu_{\gamma}}\right] \frac{1-e^{-\left(\mu_{n}+\mu_{\gamma}\right) L}}{1-e^{-\mu_{n} L}}\right]
$$

and

$$
D_{o}=2.0 \frac{\gamma-\mathrm{rays} / \mathrm{cm}^{2} \mathrm{sec}}{\mu R / \mathrm{hr}}
$$


The coefficient $\alpha$ is estimated in the table below.

Table 8.3.1 Dose coefficients for cargo materials

\begin{tabular}{|c|c|c|c|}
\hline Material & $\mathrm{Y}(\gamma /$ decay $)[8]$ & $\mu_{\gamma} / \mu_{\mathrm{n}}[14,46]$ & $\begin{array}{c}\alpha(\mu \mathrm{R} / \mathrm{hr} \text { per } \\
\mathrm{pCi} / \mathrm{gm})\end{array}$ \\
\hline Copper & 3 & 4.8 & 1.8 \\
\hline Aluminum & 1 & 2.8 & 0.28 \\
\hline Steel & 1.5 & 4 & 0.83 \\
\hline
\end{tabular}

In the following sections three media will be considered in some detail, they are aluminum, steel, and agricultural products. In all cases it will be assumed that there is a $\mathrm{I}=1 \times 10^{11} \mathrm{n} / \mathrm{s}$ source of $14 \mathrm{MeV}$ neutrons at $\mathrm{R}_{\mathrm{s}}=2 \mathrm{~m}$, and the thickness of the medium in each case is taken to be one neutron mean free path, i.e. $\mu_{\mathrm{n}} \mathrm{L}=1$ at $14 \mathrm{MeV}$. It will also be assumed that the thermal flux is equal to the fast flux, and the irradiation times assumed will be $\mathrm{T}=1$ minute.

\subsection{Activation of aluminum}

Below is a table showing the principal activities produced in aluminum, based on the same analysis as used above.

Table 8.4.1 Aluminum activation in a 1-minute irradiation

\begin{tabular}{|l|l|l|l|l|l|l|l|l|}
\hline Target & $\begin{array}{l}\text { Mix } \\
(\%)\end{array}$ & Reaction & $\begin{array}{l}\text { Threshold } \\
{[14](\mathrm{MeV})}\end{array}$ & $\begin{array}{l}\mathrm{T}_{1 / 2} \\
{[14]} \\
(\mathrm{hr})\end{array}$ & $\begin{array}{l}\sigma \\
{[14]} \\
(\mathrm{b})\end{array}$ & \multicolumn{3}{|c|}{$\begin{array}{l}\mathrm{A}_{\mathrm{i}} / \mathrm{M} \\
(\mathrm{pCi} / \mathrm{gm}\end{array}$} \\
\hline & & & & & & $\mathrm{t}=0$ & $\mathrm{t}=1 \mathrm{hr}$ & $\mathrm{t}=10 \mathrm{hr}$ \\
\hline${ }^{27} \mathrm{Al}$ & 100 & $(\mathrm{n}, \gamma)^{28} \mathrm{Al}$ & 0.0 & 0.0375 & 0.23 & 4620 & 0 & 0 \\
\hline${ }^{\prime \prime}$ & & $(\mathrm{n}, 2 \mathrm{n})^{26} \mathrm{Al}$ & 13.8 & 0.0018 & 0.046 & 3480 & 0 & 0 \\
\hline${ }^{\prime \prime}$ & & $(\mathrm{n}, \mathrm{p})^{27} \mathrm{Mg}$ & 3.6 & 0.158 & 0.074 & 396 & 4.9 & 0 \\
\hline $\begin{array}{l}\text { Total } \\
\text { activity }\end{array}$ & & $(\mathrm{n}, \mathrm{\alpha})^{24} \mathrm{Na}$ & 6.5 & 15 & 0.13 & 7.6 & 7.3 & 4.8 \\
\hline
\end{tabular}




\subsection{Activation in steel}

Below is a table showing the principal activities produced in steel, based on the same analysis as used above.

Table 8.5.1 Steel composition and its activation in a 1-minute irradiation

\begin{tabular}{|c|c|c|c|c|c|c|c|c|}
\hline Target & $\begin{array}{l}\text { Mix } \\
(\%)\end{array}$ & Reaction & $\begin{array}{l}\text { Threshold } \\
\text { [14] }(\mathrm{MeV}\end{array}$ & $\begin{array}{l}\mathrm{T}_{1 / 2}[8] \\
(\mathrm{hr})\end{array}$ & $\begin{array}{l}\sigma[14] \\
\text { (b) }\end{array}$ & \multicolumn{3}{|c|}{$\begin{array}{l}\mathrm{Ai} / \mathrm{M} \\
(\mathrm{pCi} / \mathrm{g})\end{array}$} \\
\hline & & & & & & $\mathrm{t}=0$ & $\mathrm{t}=1 \mathrm{hr}$ & $\mathrm{t}=10 \mathrm{hr}$ \\
\hline${ }^{63} \mathrm{Cu}$ & 2.1 & $(\mathrm{n}, \gamma)^{64} \mathrm{Cu}$ & 0.0 & 12.7 & 4.5 & 3.1 & 3.0 & 1.8 \\
\hline & & $(n, 2 n)^{63} \mathrm{Cu}$ & 11.1 & 0.16 & 0.47 & 25 & 0.33 & $\overline{0}$ \\
\hline & & $(n, p)^{63} \mathrm{Ni}$ & 0.9 & $8.8 \times 10^{5}$ & 0.043 & $4.3 \times 10^{-7}$ & $4.3 \times 10^{-7}$ & $4.3 \times 10^{-7}$ \\
\hline & & $(\mathrm{n}, \alpha)^{60} \mathrm{Co}$ & 3.0 & $4.6 \times 10^{4}$ & 0.043 & $8.3 \times 10^{-6}$ & $8.3 \times 10^{-6}$ & $8.3 \times 10^{-6}$ \\
\hline${ }^{65} \mathrm{Cu}$ & 0.9 & $(\mathrm{n}, \gamma)^{66} \mathrm{Cu}$ & 0.0 & 0.085 & 2.1 & 88 & 0.025 & 0 \\
\hline " & & $(n, 2 n)^{64} \mathrm{Cu}$ & 11.0 & 12.7 & 0.90 & 0.27 & 0.26 & 0.16 \\
\hline " & & $(n, p)^{65} \mathrm{Ni}$ & 2.5 & 2.5 & 0.025 & 0.038 & 0.029 & 0.0024 \\
\hline 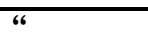 & & $(\mathrm{n}, \alpha)^{62} \mathrm{Co}$ & 5.0 & 0.23 & 0.011 & 0.18 & 0.0087 & 0 \\
\hline${ }^{55} \mathrm{Mn}$ & 2.0 & $(\mathrm{n}, \gamma)^{56} \mathrm{Mn}$ & 0.0 & 2.6 & 13. & 43.4 & 33.3 & 3.0 \\
\hline & & $(n, 2 n)^{54} \mathrm{Mn}$ & 11.0 & 7488 & 0.72 & $8.1 \times 10^{-4}$ & $8.1 \times 10^{-4}$ & $8.1 \times 10^{-4}$ \\
\hline & & $(n, p)^{55} \mathrm{Cr}$ & 4.5 & 0.058 & 0.037 & 4.9 & 0 & 0 \\
\hline " & & $(n, \alpha)^{52} V$ & $\overline{7.0}$ & 0.063 & 0.028 & 3.4 & $\overline{0}$ & $\overline{0}$ \\
\hline${ }^{50} \mathrm{Cr}$ & 0.72 & $(\mathrm{n}, \gamma)^{51} \mathrm{Cr}$ & 0.0 & 665 & 15.9 & 0.073 & 0.073 & 0.072 \\
\hline 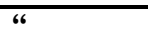 & & $(\mathrm{n}, 2 \mathrm{n})^{49} \mathrm{Cr}$ & 13.7 & 0.71 & 0.023 & 0.098 & 0.037 & $\overline{0}$ \\
\hline${ }^{52} \mathrm{Cr}$ & 15.1 & $(\mathrm{n}, 2 \mathrm{n})^{51} \mathrm{Cr}$ & 13.0 & 665 & 0.26 & 0.025 & 0.025 & 0.025 \\
\hline${ }^{53} \mathrm{Cr}$ & 1.7 & $(n, p)^{53} V$ & 6.5 & 0.03 & 0.04 & 8.0 & $\overline{0}$ & 0 \\
\hline${ }^{54} \mathrm{Cr}$ & 0.36 & $(\mathrm{n}, \gamma)^{55} \mathrm{Cr}$ & $\overline{0.0}$ & 0.058 & 0.36 & 8.6 & 0 & 0 \\
\hline & & $(n, p)^{54} V$ & 12.0 & 0.0136 & 0.01 & 0.75 & 0 & 0 \\
\hline${ }^{58} \mathrm{Ni}$ & 6.0 & $(\mathrm{n}, 2 \mathrm{n})^{57} \mathrm{Ni}$ & 13.0 & 35.6 & 0.023 & 0.016 & 0.016 & 0.013 \\
\hline “ & & $(n, p)^{58} \mathrm{Co}$ & 2.0 & 9.1 & 0.5 & 1.4 & 1.3 & 0.65 \\
\hline${ }^{60} \mathrm{Ni}$ & 2.6 & $(n, p)^{60} \mathrm{Co}$ & 5.0 & $4.6 \times 10^{4}$ & 0.15 & $3.6 \times 10^{-5}$ & $3.6 \times 10^{-5}$ & $3.6 \times 10^{-5}$ \\
\hline & & $(n, \alpha)^{57} \mathrm{Mn}$ & 4.0 & 0.024 & 0.06 & 22. & 0 & 0 \\
\hline${ }^{62} \mathrm{Ni}$ & 0.46 & $(\mathrm{n}, \alpha)^{59} \mathrm{Fe}$ & 11.0 & 2670 & 0.014 & $1.0 \times 10^{-5}$ & $1.0 \times 10^{-5}$ & $1.0 \times 10^{-5}$ \\
\hline${ }^{54} \mathrm{Fe}$ & 5.3 & $(n, 2 n)^{53} \mathrm{Fe}$ & 14.5 & 0.14 & 0.006 & 0.92 & .0065 & $\overline{0}$ \\
\hline "1 & & $(\mathrm{n}, \alpha)^{51} \mathrm{Cr}$ & 5.5 & 665 & 0.086 & 0.0029 & 0.0029 & 0.0029 \\
\hline${ }^{56} \mathrm{Fe}$ & 83 & $(n, p)^{56} M n$ & 5.5 & 2.6 & 0.11 & 14.8 & 11.3 & 1.03 \\
\hline${ }^{57} \mathrm{Fe}$ & 1.9 & $(n, p)^{57} \mathrm{Mn}$ & 5.5 & 0.025 & 0.058 & 14.9 & 0 & 0 \\
\hline $\begin{array}{l}\text { Total } \\
\text { activity }\end{array}$ & & & & & & 240 & 49.7 & 6.8 \\
\hline
\end{tabular}

\subsection{Activation summary}

Utilizing the analysis of Section 8.3 and the data from Tables 8.4 and 8.5 the total activation level of prospective cargos can be estimated roughly. This has been done thermal neutron flux derived from the $1 \times 10^{11} \mathrm{n} / \mathrm{s}$ source 
described in the analysis and for 1-minute irradiation. Summary plots for the predicted activation and radiation dose rate at contact are plotted below.

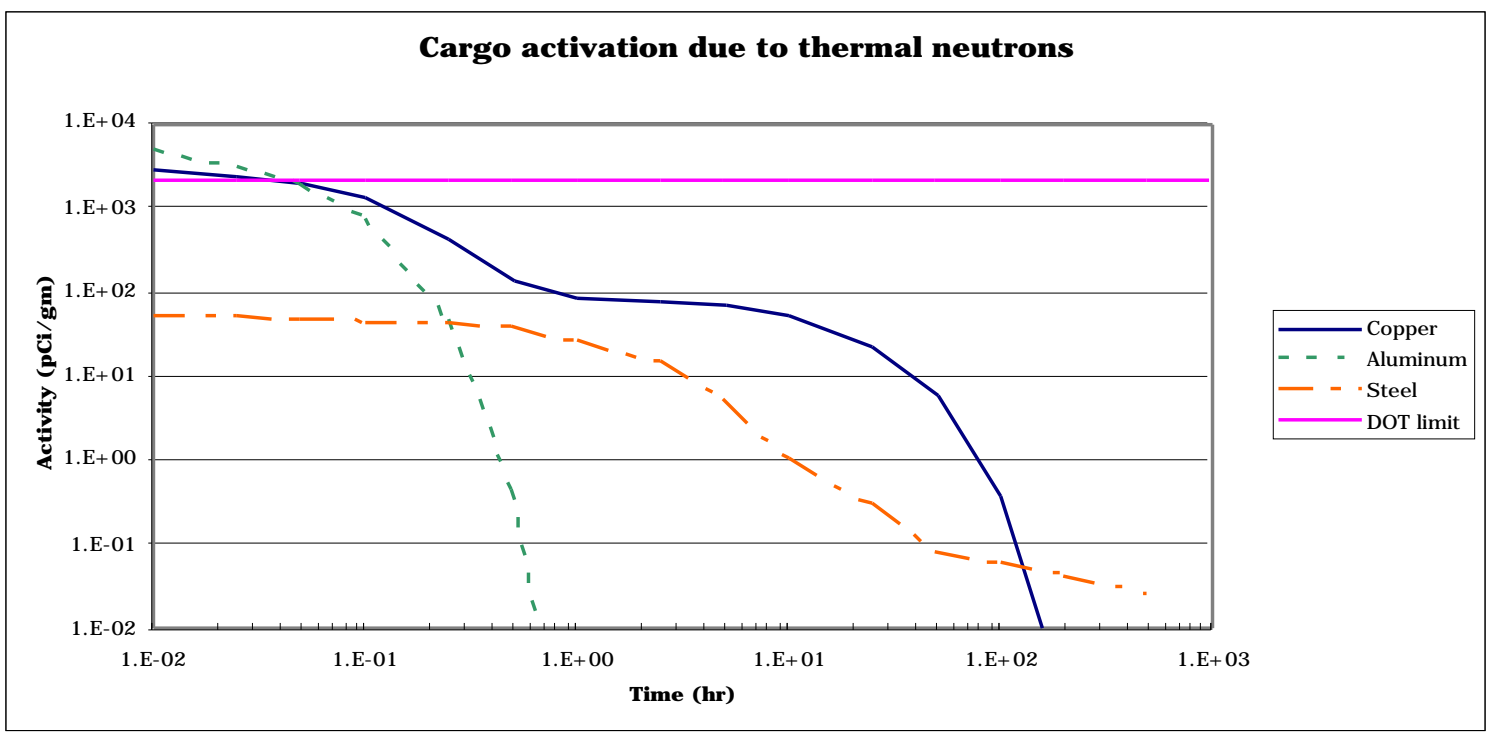

Figure 8.6.1 Total activation of various cargos following 1-minute irradiation by thermal neutrons generated by a $1 \times 10^{11} \mathrm{n} / \mathrm{s}$ source at $R=2 \mathrm{~m}$.

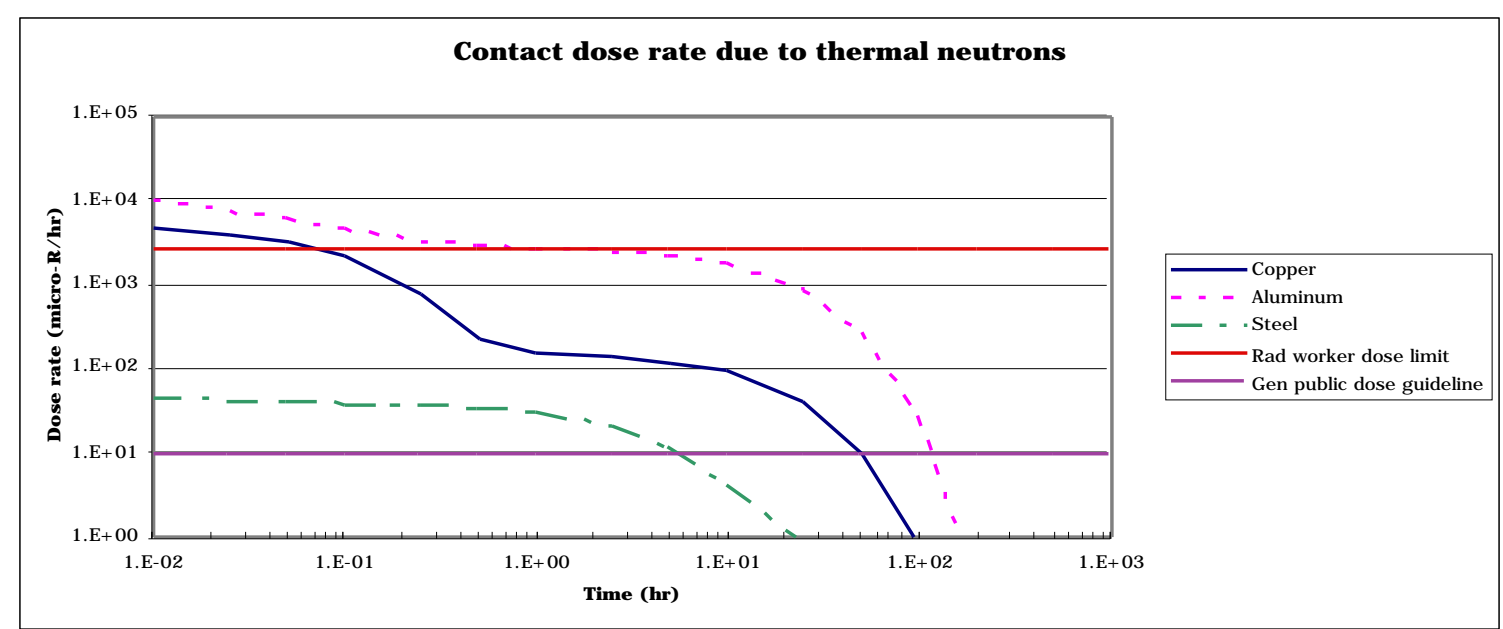

Figure 8.6.2 Contact dose rate following 1-minute irradiation by thermal neutrons generated by $1 \times 10^{10} \mathrm{n} / \mathrm{s}$ source at $R=2 \mathrm{~m}$.

Examination of the figure shows that activation and dose rates fall rapidly during the first hour after irradiation. Solid straight lines indicate guideline levels for activation determined by the DOT standard for non-radioactive shipments. Similarly, solid straight lines indicate the DoE radiation dose limits for radiation workers and for the general public. In all of the cargos considered here the activation levels drop below DOT limits within the first few minutes. Contact radiation dose rates also drop below limits for radiation workers within an hour 
following interrogation. However, some additional cooling is required before exposure of the general public.

If one considers the very worst possible case where some portions of the cargo are exposed to unmoderated $14 \mathrm{MeV}$ neutrons then the activation and dose rates are slightly higher. The upper bound rates for activation are shown in the figure below.

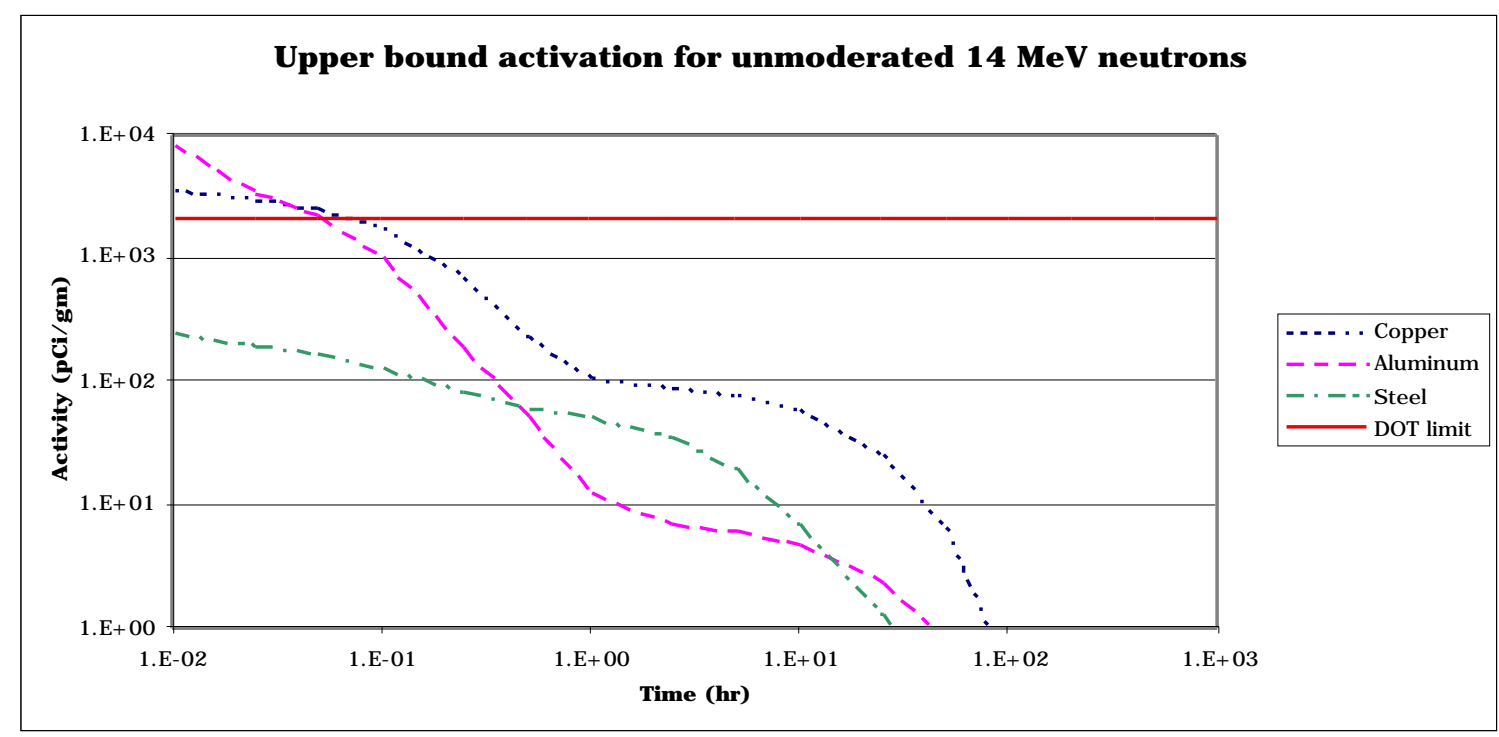

Figure 8.6.3 Upper bound activation estimate

Examination of the figure shows that the activity drops below the DOT standard within minutes even for this worst-case scenario.

\subsection{Activation of agricultural products}

FDA regulations limit the radiation dose when sterilizing or scanning food cargo. The regulations currently speak only to $\gamma$-ray irradiation and ${ }^{252} \mathrm{Cf}$ neutron sources. For purposes of food sterilization the regulations only address isotopic sources of ${ }^{60} \mathrm{Co}$ or ${ }^{137} \mathrm{Cs}$, X-ray machines with output below $5 \mathrm{MeV}$, and electron beam sources with endpoint below $5 \mathrm{MeV}$. With these sources in mind the dose limits depend on the food and the purpose of the sterilization, and limits vary in the range $1-10 \mathrm{kGy}$ (100 $\mathrm{kRad}$ to $1 \mathrm{Mrad})$ depending on the type of food $[50,51]$. On the other hand, scanning food cargo using $\gamma$-radiation is limited to a maximum electron beam energy of $10 \mathrm{MeV}$ and maximum dose of $0.5 \mathrm{~Gy}$ (50 Rad)[52-54]. The NCRP recommends that neutron scanning for security purposes be limited to total dose that is reduced by the relative weighting factors for neutrons and $\gamma$-rays. In the case of $14 \mathrm{MeV}$ neutron radiation scanning the weighting factor is 20[55], so that the allowable neutron dose is limited to 2.5 $\mathrm{Rad}$, or $50 \mathrm{Rem}$. If a neutron source of ${ }^{252} \mathrm{Cf}$ is used the dose limit is $2 \mathrm{mGy}(0.2$ $\mathrm{Rad})$. The limit is increased to $10 \mathrm{~Gy}(1.0 \mathrm{kRad})$ for the case where photon energies are limited to $0.5 \mathrm{MeV}$ or sources limited to the isotope ${ }^{241} \mathrm{Am},{ }^{137} \mathrm{Cs}$, ${ }^{125} \mathrm{I},{ }^{85} \mathrm{Kr},{ }^{226} \mathrm{Ra}$, and ${ }^{90} \mathrm{Sr}[52-54]$.

Most agricultural and food products contain a low level of natural radioactivity acquired from unstable species in the soil and cosmic ray generated 
species in the air. One example of natural radioactivity present in all vegetation and in the animals that consume vegetable matter is ${ }^{40} \mathrm{~K}$. The ${ }^{40} \mathrm{~K}$ isotope has a natural abundance in potassium of $0.01 \%$ and a half-life of $1.3 \times 10^{9} \mathrm{y}$. The table below shows the natural radioactivity level of a variety of foods.

Table 8.6.1 Natural ${ }^{40} \mathrm{~K}$ radioactivity in foods

\begin{tabular}{|lc|}
\hline Food product & ${ }^{40} \mathbf{K}$ activity $(\mathbf{p C i} / \mathbf{g m})$ \\
\hline Banana & 3.2 \\
Lean beef & 2.8 \\
Dry cocoa powder & 13.0 \\
Milk & 1.29 \\
Average of many green vegetables & 2.4 \\
\hline
\end{tabular}

Examination of the above table shows that there are many foods containing radioactive ${ }^{40} \mathrm{~K}$ at a level of a few $\mathrm{pCi} / \mathrm{gm}$. There are many other foods containing similar amounts of other radioactive species.

Radioactivity in food will be increased by neutron activation during a neutron scan of a cargo container. The levels reached may be predicted by the same analysis as was used for activation of other cargos once the elemental composition is known. The FDA publishes the elemental composition of many agricultural products (hundreds). Using such a the mean composition is estimated approximately as follows, given that individual foods will vary $\pm \mathrm{X} 2$ from the values assumed, but few will vary a factor of $\pm \mathrm{X} 3$ from these values. Below is a randomly selected list of the trace element concentrations in various foods. The primary constituents are, of course, $\mathrm{H}, \mathrm{C}, \mathrm{O}$, and $\mathrm{N}$.

\section{Table 8.6.2 Trace-elemental composition of raw foods, $\mathrm{mg} / 100 \mathrm{gm}$}

\begin{tabular}{|l|r|r|r|r|r|r|r|r|r}
\hline Food & $\mathrm{Ca}$ & $\mathrm{Fe}$ & $\mathrm{Mg}$ & $\mathrm{P}$ & $\mathrm{K}$ & $\mathrm{Na}$ & $\mathrm{Zn}$ & $\mathrm{Cu}$ & $\mathrm{Mn}$ \\
\hline & & & & & & & & & \\
\hline Artichoke & 44 & 1.28 & 60 & 90 & 370 & 94 & 0.49 & 0.23 & 0.26 \\
\hline Brussel sprouts & 42 & 1.4 & 23 & 69 & 389 & 25 & 0.42 & 0.07 & 0.34 \\
\hline Cabbage & 51 & 0.49 & 15 & 42 & 206 & 11 & 0.21 & 0.097 & 0.14 \\
\hline Carrots & 27 & 0.5 & 15 & 44 & 323 & 35 & 0.2 & 0.047 & 0.16 \\
\hline Cauliflower & 22 & 0.44 & 15 & 44 & 303 & 30 & 0.28 & 0.042 & 0.16 \\
\hline Lettuce & 68 & 1.4 & 11 & 25 & 264 & 9 & 0.29 & 0.044 & 0.75 \\
\hline Mushroom & 5 & 1.24 & 10 & 104 & 370 & 4 & 0.73 & 0.49 & 0.11 \\
\hline Potato & 7 & 0.76 & 21 & 46 & 543 & 6 & 0.39 & 0.26 & 0.26 \\
\hline Pumpkin & 21 & 0.8 & 12 & 44 & 340 & 1 & 0.32 & 0.13 & 0.13 \\
\hline Squash & 15 & 0.42 & 22 & 40 & 253 & 3 & 0.18 & 0.086 & 0.18 \\
\hline & & & & & & & & 0.1496 & 0.249 \\
\hline mean= & 30.2 & 0.873 & 20.4 & 54.8 & 336.1 & 21.8 & 0.351 & 0.1496 &
\end{tabular}

The mean composition given above may be used with Eq. 8.5 to estimate the activity of this cargo. For completeness $10 \%$ nitrogen has been added. There is no appreciable activity due to $\mathrm{H}, \mathrm{C}$, or $\mathrm{O}$. 
Table 8.6.3 Radioactivity in agricultural products

\begin{tabular}{|c|c|c|c|c|c|c|c|c|}
\hline Target & $\begin{array}{l}\text { Mix } \\
(\%)\end{array}$ & Reaction & $\begin{array}{l}\text { Threshold } \\
{[14]} \\
(\mathrm{MeV})\end{array}$ & $\begin{array}{l}\mathrm{T}_{1 / 2} \\
{[8]} \\
\text { (hr) }\end{array}$ & $\begin{array}{l}\sigma \\
{[14]} \\
\text { (b) }\end{array}$ & \multicolumn{3}{|c|}{$\begin{array}{l}\mathrm{Ai} / \mathrm{M} \\
(\mathrm{pCi} / \mathrm{gm})\end{array}$} \\
\hline & & & & & & $t=0$ & $t=1 \mathrm{hr}$ & $t=10 \mathrm{hr}$ \\
\hline${ }^{14} \mathrm{~N}$ & 10 & $(n, 2 n)^{13} N$ & 12.0 & 0.17 & 0.0065 & 6.9 & 1.1 & 0 \\
\hline${ }^{40} \mathrm{Ca}$ & 0.029 & $(\mathrm{n}, \alpha)^{37} \mathrm{Ar}$ & 4.0 & 840 & 0.14 & $9.6 \times 10^{-5}$ & $9.6 \times 10^{-5}$ & $9.6 \times 10^{-5}$ \\
\hline${ }^{44} \mathrm{Ca}$ & & $(n, p)^{44} K$ & 2.6 & 0.37 & 0.17 & 0.0086 & 0 & 0 \\
\hline & & $(n, \alpha)^{41} \mathrm{Ar}$ & 2.0 & 1.8 & 0.17 & $2.8 \times 10^{-4}$ & $1.9 \times 10^{-4}$ & $5.8 \times 10^{-6}$ \\
\hline${ }^{54} \mathrm{Fe}$ & $5.2 \times 10^{-5}$ & $(n, 2 n)^{53} \mathrm{Fe}$ & 14.5 & 0.14 & 0.006 & $4.1 \times 10^{-5}$ & $\overline{0}$ & 0 \\
\hline${ }^{24} \mathrm{Mg}$ & 0.016 & $(n, p)^{24} \mathrm{Na}$ & 7.0 & 15 & 0.17 & 0.0036 & .0034 & 0 \\
\hline${ }^{25} \mathrm{Mg}$ & 0.0022 & $(n, p)^{25} \mathrm{Na}$ & 4.6 & 0.016 & 0.055 & 0.097 & 0 & 0 \\
\hline${ }^{26} \mathrm{Mg}$ & 0.0022 & $(n, \alpha)^{23} \mathrm{Ne}$ & 10 & $\overline{0.010}$ & 0.09 & 0.23 & $\overline{0}$ & $\overline{0}$ \\
\hline${ }^{31} \mathrm{P}$ & 0.055 & $(\mathrm{n}, \gamma)^{32} \mathrm{P}$ & $\overline{0.0}$ & 343 & $\overline{0.2}$ & $6.3 \times 10^{-4}$ & $6.3 \times 10^{-4}$ & $6.3 \times 10^{-4}$ \\
\hline " & & $(n, 2 n)^{30} P$ & 14 & 0.042 & 0.01 & 0.23 & $\overline{0}$ & $\overline{0}$ \\
\hline $\bar{~}$ & & $(n, p)^{31} S$ & 2.8 & 2.6 & 0.1 & 0.041 & 0.032 & 0.003 \\
\hline & & $(\mathrm{n}, \alpha)^{28} \mathrm{Al}$ & 6.0 & 0.038 & 0.12 & 3.0 & 0 & 0 \\
\hline${ }^{39} \mathrm{~K}$ & 0.31 & $(n, 2 n)^{38} K$ & 14 & 0.13 & 0.0015 & 0.070 & $3.0 \times 10^{-4}$ & 0 \\
\hline${ }^{41} \mathrm{~K}$ & 0.023 & $(\mathrm{n}, \gamma)^{42} \mathrm{~K}$ & $\overline{0.0}$ & 12.4 & 1.5 & 0.054 & 0.051 & 0.031 \\
\hline " & & $(n, p)^{41} \mathrm{Ar}$ & 5.5 & 1.83 & $\overline{0.08}$ & 0.019 & 0.013 & 0.0004 \\
\hline “ & & $(\mathrm{n}, \alpha)^{38} \mathrm{Cl}$ & 7.5 & 0.62 & 0.035 & 0.025 & 0.008 & 0 \\
\hline${ }^{23} \mathrm{Na}$ & 0.022 & $(\mathrm{n}, \gamma)^{24} \mathrm{Na}$ & 0.0 & 15 & 0.53 & 0.015 & 0.015 & 0.010 \\
\hline & & $(\mathrm{n}, \mathrm{p}) 23 \mathrm{Ne}$ & 6.0 & 0.010 & 0.06 & 1.5 & 0 & 0 \\
\hline & & $(n, \alpha)^{20} \mathrm{~F}$ & 7.0 & 0.0031 & 0.13 & 4.7 & 0 & 0 \\
\hline${ }^{64} \mathrm{Zn}$ & $1.7 \times 10^{-4}$ & $(n, 2 n)^{63} Z n$ & 12.7 & 0.64 & 0.13 & $6.8 \times 10^{-4}$ & 0 & 0 \\
\hline I & & $(n, p)^{64} \mathrm{Cu}$ & 2.1 & 12.7 & 0.21 & $5.6 \times 10^{-5}$ & $5.3 \times 10^{-5}$ & $3.2 \times 10^{-5}$ \\
\hline${ }^{66} \mathrm{Zn}$ & $9.3 \times 10^{-5}$ & $(n, p)^{66} \mathrm{Cu}$ & 6.5 & 0.085 & 0.05 & 0.0011 & 0 & 0 \\
\hline${ }^{68} \mathrm{Zn}$ & $6.6 \times 10^{-5}$ & $(n, p)^{68} \mathrm{Cu}$ & 8.7 & 0.063 & 0.025 & $4.7 \times 10^{-4}$ & 0 & 0 \\
\hline${ }^{63} \mathrm{Cu}$ & $1.0 \times 10^{-6}$ & $(\mathrm{n}, \gamma)^{64} \mathrm{Cu}$ & $\overline{0.0}$ & 12.7 & 4.5 & $7.2 \times 10^{-4}$ & $6.8 \times 10^{-4}$ & $4.2 \times 10^{-4}$ \\
\hline " & & $(n, 2 n)^{62} \mathrm{Cu}$ & 11.7 & 0.16 & 0.35 & 0.0042 & $5.9 \times 10^{-5}$ & 0 \\
\hline${ }^{65} \mathrm{Cu}$ & $4.6 \times 10^{-5}$ & $(\mathrm{n}, \gamma)^{66} \mathrm{Cu}$ & 0.0 & 0.085 & 2.1 & 0.021 & 0 & 0 \\
\hline " & & $(n, 2 n)^{64} \mathrm{Cu}$ & 11.0 & 12.7 & 0.90 & $6.3 \times 10^{-5}$ & $5.8 \times 10^{-5}$ & $3.7 \times 10^{-5}$ \\
\hline u & & $(n, \alpha)^{62} \mathrm{Co}$ & 10.0 & 0.23 & 0.008 & $3.1 \times 10^{-5}$ & 0 & 0 \\
\hline${ }^{55} \mathrm{Mn}$ & $2.5 \times 10^{-4}$ & $(\mathrm{n}, \gamma)^{56} \mathrm{Mn}$ & 0.0 & 2.6 & 13.4 & 0.026 & 0.020 & 0.0018 \\
\hline & & $(n, p)^{55} \mathrm{Cr}$ & 6.0 & 0.058 & 0.037 & 0.0028 & 0 & 0 \\
\hline “ & & $(n, \alpha)^{52} V$ & 7.0 & 0.063 & 0.028 & 0.0020 & 0 & 0 \\
\hline Total & & & & & & 16.9 & 0.25 & 0.049 \\
\hline
\end{tabular}

The plot below shows the activity levels in agricultural products assuming the composition cited in the table above. 


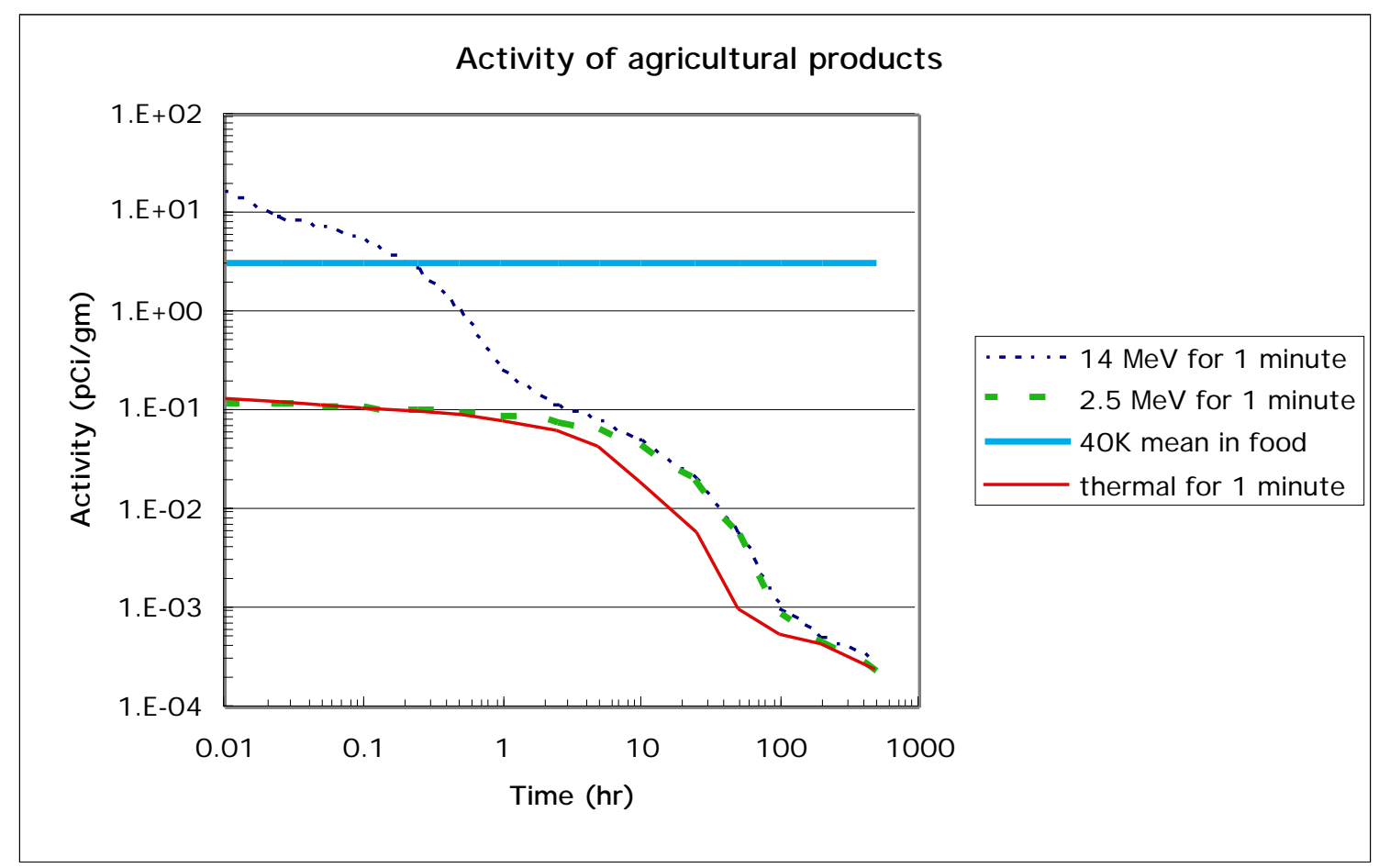

Figure 8.6.1 Upper bound activation of agricultural products due to 1-minute irradiation at $1 \times 10^{11} \mathrm{n} / \mathrm{s}$.

Activation levels for $2.5 \mathrm{MeV}$ and thermal neutrons are essentially identical and the curves cannot be distinguished. Examining the plot we find that the activation due to thermal or $2.5 \mathrm{MeV}$ neutrons is 100X less than the naturally present ${ }^{40} \mathrm{~K}$ content of many foods. Even in the presence of high fluxes of 14 $\mathrm{MeV}$ neutrons the activation drops below the natural radioactivity level within minutes. The above activities will be compared with FDA and EPA guidelines to determine whether any specific activities generate a particular concern.

\section{Conclusions and prospects}

The goal of the work reported here is to develop a concept for a neutron interrogation system that would detect small targets of SNM, specifically $5 \mathrm{~kg}$ HEU or $1 \mathrm{~kg} \mathrm{Pu}$, even when well shielded by a thick cargo. It is essential that the concept be reliable and has low false-positive and false-negative error rates. It also must be rapid to avoid interruption of commerce.

The context for this system was presented in Section 2. A new radiation signature unique to SNM has been identified that utilizes high-energy $\left(\mathrm{E}_{\gamma}=3-7 \mathrm{MeV}\right)$ fission product $\gamma$-radiation. Estimates of its characteristic spectrum and intensity were presented in Section 3. Fortunately, this highenergy $\gamma$-ray signature is robust in that it is very distinct compared to normal background radiation where there is no comparable high-energy $\gamma$-ray radiation. Equally important, this high-energy $\gamma$-ray signature has a factor of 10 higher yield than the classical delayed neutron technique and penetrates low- $Z$ and high- $Z$ cargos readily even at the greatest thickness expected. Consequently, the signature flux is at least 2-4 decades more intense than delayed neutron signals 
and facilitates the detection of SNM even when shielded by thick cargos or when shielded intentionally.

Characteristics of the new signature were predicted in Section 3 and confirmed experimentally in Section 4 . These experiments revealed an important interference, namely the activation of ${ }^{16} \mathrm{O}$ to produce ${ }^{16} \mathrm{~N}$ (by the ${ }^{16} \mathrm{O}(\mathrm{n}, \mathrm{p}){ }^{16} \mathrm{~N}$ reaction) to produce ${ }^{16} \mathrm{~N}$ whose 7 -sec $\beta$-decay produces a $6 \mathrm{MeV}$ $\gamma$-ray. That interference is important when irradiating with $14 \mathrm{MeV}$ neutrons but is eliminated when lower energy neutron sources are utilized, as its reaction threshold is $10 \mathrm{MeV}$. The predicted signature $\gamma$-ray fluxes exiting a thick cargo are relatively small as presented in Section 3; of order $1 \mathrm{\gamma} / \mathrm{cm}^{2} / \mathrm{sec}$. However, inexpensive and large arrays of scintillation detectors (described in Section 5) are relatively simple to deploy and these low fluxes then produce useful signal count rates of $2-4 \times 10^{4} \mathrm{cps}$. That is high enough to quickly identify SNM by its characteristic high-energy $\gamma$-radiation and characteristic short decay time, though the backgrounds in those detectors have not yet been determined. Experimental characterization of the $\gamma$-ray flux exiting thick cargos has not yet been undertaken. But the signature is expected to be robust and the $\gamma$-radiation only moderately attenuated in even the thickest cargos. The nominally 20 sec decay time of the SNM signature observed in the experiments is well matched to the 1 minute goal for the time to scan a container.

The work reported here leads to definite requirements for the interrogation neutron source. In Section 7 it was shown that good signal strength requires neutron fluxes on-target of order $1-10 \times 10^{5} \mathrm{n} / \mathrm{cm}^{2} / \mathrm{sec}$. It was shown there that neutron penetration increases with energy, by a factor of $\sim 3$ when the energy is raised from 0.5 to $2.5 \mathrm{MeV}$, and another factor of 3 going from 2.5 to $14 \mathrm{MeV}$. However, it was shown that the neutron energy must be below the ${ }^{16} \mathrm{O}(\mathrm{n}, \mathrm{p})$ threshold of $10 \mathrm{MeV}$ to avoid the only interference detected in the experiments. A small deuteron accelerator producing approximately $\sim 1 \mathrm{~mA}$, 2-5 MeV deuteron beam on a deuterium or beryllium target meets the above requirements. Commercially available technology can produce such an accelerator at affordable cost ( $\sim 500 \mathrm{k})$. Such an accelerator produces neutrons that are kinematically collimated in the forward direction so that shielding requirements are reduced while beam flux on-target is increased. In addition, this technology provides a very penetrating beam in the energy range $4-8 \mathrm{MeV}$ while remaining below the oxygen activation threshold. Maximum counting statistics and lowest error rates in the identification occur when the beam is pulsed with a $50 \%$ duty cycle (See section 7). The period for this pulsing is optimal when matched to the half-life of the species that make up the signature, i.e. 10-60 sec. This is readily achieved with commercially available equipment and is well suited to rapid scanning of cargo containers.

Finally, unwanted collateral effects of the interrogation such as neutron activation of the cargo have been analyzed in Section 8. In all cases the predicted activation levels are low. Cargo radioactivity is far below the levels at which they are considered non-radioactive by DOT shipping standards. In the case of agricultural cargos the neutron-induced radioactivity is far below the normal ${ }^{40} \mathrm{~K}$ radioactivity present in many foods commonly found in the human food supply. Even in the worst case when $14 \mathrm{MeV}$ neutrons are used and not moderated the dose rates resulting from activation are well within limits for radiation workers within minutes and in most cases drop to levels acceptable for exposure of the 
general public within minutes or hours. In all cases studied the activation levels of cargo, even under the worst-case assumptions used in Section 8.

A viable concept for cargo interrogation has been presented and its components have been evaluated experimentally. Utilization of the new $\gamma$-ray signature for SNM appears to promise a dramatic improvement in sensitivity for those cases where thick intervening cargo shields a target of interest or where the material is shielded with intentionally placed high-Z materials. Experiments and simulations are in progress to quantitatively determine the effects of cargo or intentional shielding to reduce and/or interfere with the SNM signature. Those experiments will then be used to establish the scanning intervals required to reduce the error rates, i.e. false positive and false negative, to acceptable levels.

\section{References}

1. C. E. Grassley, M. Baucus, B. Thomas, C. B. Rangel, "Container security: Expansion of key customs programs will require greater attention to critical success factors ", General Accounting Office, US Congress, GAO-03-770, July 25, 2003, www.gao.gov/cgi-bin/getrpt?GAO-030770.

2. Maritime_Transport_Committee, "Security in maritime transport: Risk facators and economic impact ", Organization for Economic Co-operation and Development (OECD); Directorate for Science, Technology and Industry, July, 2003, http://www.oecd.org/dataoecd/63/13/4375896.pdf.

3. M. M. May, D. Wilkening, T. L. Putnam, "Container security report", 2003, Center for International Security and Cooperation, http://cisac.stanford.edu/nuclearterrorism/index.html\#3

4. PNL, "Nuclear and radiological threat detection for vehicle cargo ", Pacific Northwest National Laboratory, PIET-43741-QR-005, February 28, 2002,

5. S. Fetter, V. A. Frolov, M. Miller, R. Mozley, O. F. Prilutsky, S. N. Rodionov, R. Z. Sagdeev, "Detecting nuclear warheads", Science \& Global Security, $\underline{1}$, 1990, pp. 225-302.

6. J. Medalia, "Terrorist nuclear attacks on seaports: Threat and response", October 8, 2002, Personal communication.

7. NRC, Making the Nation Safer: The Role of Science and Technology in Countering Terrorism, The National Academies Press, Washington, DC (2002), pp.

8. LBNL_Nuclear_Science_Division, "Isotope Explorer", 2003, http://ie.lbl.gov/ensdf/

9. LBNL_Nuclear_Science_Division, "Table of Isotopes", 2003, Lawrence Berkeley National Laboratory, website, http://ie.lbl.gov/toi/ 
10. J. L. Jones, K. J. Haskell, J. M. Hoggan, D. R. Norman, W. Y. Yoon, "Photonuclear-based detection of nuclear smuggling in cargo containers", Conference on Accelerator Applications in Research and Industry, 12 November, 2002, Denton, TX,

11. J. L. Jones, W. Y. Toon, Y. D. Harker, J. M. Hoggan, K. J. Haskell, L. A. VanAusdein, "Proof-of-concept assessment of a photofission-based interrogation system for the detection of shielded nuclear material ", Idaho Nuclear Engineering Laboratory, INEEL/EXT-2000-01523, 2000,

12. G. R. Keepin, "Nuclear safeguards research and development ", Los Alamos National Laboratory, LA-4368-MS, October-December, 1969,

13. G. R. Keepin, "Nuclear safeguards research and development ", Los Alamos National Laboratory, LA--4457-MS, January-April, 1970,

14. LLNL_Nuclear_Data_Group, "Nuclear Data System 2000", 2003, http://www-ndg.llnl.gov/llnl/nds.cgi

15. H. Franz, W. Rudolph, H. Ohm, K. Kratz, G. Herrmann, F. Nuh, D.

Slaughter, S. Prussin, "Delayed neutron spectroscopy with ${ }^{3} \mathrm{He}$ spectrometers", Nuc. Inst. Meth. 144, 253-261 (1977).

16. F. Nuh, D. Slaughter, S. Prussin, H. Ohm, W. Rudolph, K. Kratz, "Delayed neutrons and high energy $\gamma$-rays from decay of ${ }^{87} \mathrm{Br}^{\prime \prime}$, Nuc. Phys. $\underline{\mathbf{A 2 9 3}}, 410-424$ (1977).

17. M. P. Snell, "Gamma-ray technology: The practical container inspection alternative", 2001, SAIC, http://www.portechnology.org/,

18. R. D. Richardson, V. V. Verbinski, V. J. Orphan, "New cargo inspection and transportation technology applications", 2002, Port technology International, http://www.porttechnology.org/, May,

19. R. D. Richardson, V. V. Verbinski, V. J. Orphan, "New cargo inspection and transportation technology applications", 2001, SAIC, http://www.portechnology.org/,

20. C. J. McBee, D. W. Bowlin, V. J. Orphan, "Mobile cargo inspection provides improved throughput efficiency and flexibility", 2001, SAIC, http://www.portechnology.org/,

21. J. L. Jones, Y. D. Harker, W. Y. Yoon, L. O. Johnson, R. S. Lawrence, "Pulsed photon interrogation with neutron-induced gamma-ray spectrometry for cargo inspections", Cargo Inspection Technologies, 2276, 326-338, 25-27 July, 1994, San Diego, CA, SPIE.

22. C. E. Moss, C. A. Goulding, C. L. Hollas, W. L. Myers, "Linear acceleratorbased active interrogation for detection of highly enriched uranium", Conference 
on Accelerator Applications in Research and Industry, 12 November, 2002, Denton, TX,

23. J. Moss, D. Geesaman, L. Schroeder, J. Simon-Gillo, B. Keister, "Report on the workshop on the role of the nuclear physics research community in combating terrorism ", Department of Energy, DoE/SC-0062, 11-12 july, 2002,

24. E. B. Norman, S. G. Prussin, R.-M. Larimer, H. Shugart, E. Browne, A. R. Smith, R. J. McDonald, H. Nitsche, P. Gupta, M. I. Frank, T. B. Gosnell, "Signatures of special nuclear material: High-energy $\gamma$-rays following fission ", Lawrence Livermore National Laboratory, UCRL-JC-153259, May, 2003,

25. R. A. Alvarez, A. D. Dougan, M. R. Rowland, T. F. Wang, "Neutron interrogation to identify chemical elements with an ion-tube neutron source (INS)", J. Radioanal. Nucl. Chem 192, 73-80 (1995).

26. W. C. Lee, D. B. Mahood, P. Ryge, P. Shea, T. Gozani, "Thermal neutron analysis (TNA) explosive detection based on electronic neutron generators", Nuc. Inst. Meth. B $\underline{99}, 739-742$ (1995).

27. A. P. Barzilov, P. C. Womble, G. Vourvopoulos, "NELIS - A neutron elemental inspection sysstem of commodities pallets", 2001 Office of National Drug Control Policy International Technology Symposium, 2001,

28. D. R. Brown, T. Gozani, "Cargo inspection system based on pulsed fast neutron analysis", Nuc. Inst. Meth. B 99, 753-756 (1995).

29. D. R. Brown, "Cargo inspection system based on pulsed fast neutron analysis: an update", Cargo Inspection Technologies, 2276, 449-456, 25-27 July, 1994, San Diego, CA, SPIE.

30. T. Gozani, "Understanding the physics limitations of PFNA - the nanosecond pulsed fast neutron analysis", Nuc. Inst. Meth. B $\underline{99}$, 743-747 (1995).

31. R. C. Smith, M. J. Hurwitz, K.-C. Tran, "System to detect contraband in cargo containers using fast and slow neutron irradition and collimated gamma detectors", Nuc. Inst. Meth. B 99, 733-735 (1995).

32. G. Vourvopoulos, P. C. Womble, "Pulsed fast/thermal neutron analysis: A technique for explosives detection", TALANTA 또, 459-468 (2001).

33. P. C. Womble, F. J. Schultz, G. Vourvopoulos, "Non-destructive characterization using pulsed fast-thermal neutrons", Nuc. Inst. Meth. B 99, 757760 (1995).

34. P. Lebrun, P. Le Tourneur, B. Poumarede, H. Moller, P. Bach, "On-line analysis of bulk materials using pulsed neutron interrogation", Application of Accelerators in Research and Industry, 475, 695-698, November, 1998, Denton, TX, American Institute of Physics. 
35. P. C. Womble, C. Campbell, G. Vourvopoulos, J. Paschal, Z. Gacsi, S. Hui, "Detection of explosives with the PELAN system", CP576, Application of Accelerators in Research and Industry-Sixteenth International Conference, 07354-0015, 2001, American Institute of Physics.

36. P. C. Womble, G. Vourvopoulos, I. Novikov, J. Paschal, "PELAN 2001:

Current status of the PELAN explosives detection system", SPIE Conference on Hard X-ray and Gamma-ray Detector Physics, July 29-August 3, 2001, San Diego, CA, Society of Photo-Optical Instrumentation Engineers.

37. P. C. Womble, G. Vourvopoulos, I. Novikov, J. Paschal, "PELAN 2001: Current status of the PELAN explosives detection system", Hard X-ray and Gamma Ray Detector Physics, 7/29-8/3, 2001, San Diego, CA, Society of PhotoOptical Instrumentation Engineers.

38. D. R. Brown, "Cargo inspection system based on pulsed fast neutron analysis", SPIE 2092, 254-262 (1993).

39. R. Loveman, J. Bendahan, T. Gozani, J. Stevenson, "Time of flight fast neutron radiography", Nuc. Inst. Meth. B 99, 765-768 (1995).

40. B. J. Micklich, C. L. Fink, T. J. Yule, "Key research issues in the pulsed fastneutron analysis technique for cargo inspection", Cargo Inspection Technologies, 2276, 310-320, 25-27 July, 1994, San Diego, CA, SPIE.

41. J. Bendahan, L. Feinstein, D. Keeley, R. Loveman, "Image reconstruction from pulsed fast neutron analysis", Application of Accelerators in Research and Industry, 475, 726-730, November, 1998, Denton, TX, American Institute of Physics.

42. H. Martz, P. Griffin, "Assessment of cargo inspection technologies for the detection of explosives and drugs ", Lawrence Livermore National Laboratory, FAA-191, 2001,

43. S. M. Khan, "Review of neutron-based technologies for the inspection of cargo containers", Cargo Inspection Technologies, 2276, 294-309, 25-27 July, 1994, San Diego, CA, SPIE.

44. M. Gmar, J. M. Capdevila, "Use of delayed gamma spectra for detection of actinides (U,Pu) by photofission", Nuc. Inst. Meth. A $\underline{\mathbf{4 2 2}}, 841-845$ (2002).

45. LBNL_Nuclear_Science_Division, "Fission Home Page", 2003, http://ie.lbl.gov/fission.html

46. T. Rockwell III, Reactor Shielding Design Manual, D. Van Nostrand Co., New York (1956), pp. 
47. H. Liskien, A. Paulsen, "Neutron production cross sections and energies for the reactions $\mathrm{T}(\mathrm{p}, \mathrm{n})^{3} \mathrm{He}, \mathrm{D}(\mathrm{d}, \mathrm{n})^{3} \mathrm{He}$ and $\mathrm{T}(\mathrm{d}, \mathrm{n})^{4} \mathrm{He}$ ", Nuclear Data Tables $\underline{\mathbf{1 1}}$, 569-619 (1973).

48. L. C. Northcliffe, R. F. Schilling, "Range and stopping power tables for heavy ions", Nuclear Data Tables 프, 233-463 (1970).

49. T. S. Tenforde, L. L. Braby, L. Greenwood, C. B. Meinhold, S. D. Wiltshire, "Letter report on radiation protection advice for pulsed fast neutron analysis system used in security surveillance ", National Council on Radiation Protection and Measurements, letter-September 20, 2002,

50. Code of Federal Regulations, 21 CFR 179.26, (2003)

51. G. H. Pauli, "U. S. regulatory requirements for irradiating foods", 2001, Office of Premarket Approval, HFS-205, Center for Food Safety and Applied Nutrition, Food and Drug Administration, website, http://www.foodsafety.gov/ dms/opa-rdtk.html

52. Federal Register, 21 CFR 179, 62 FR 64108, (1997)

53. Code of Federal Regulations, 21 CFR 179, 66 FR 18537, (2001)

54. Code of Federal Regulations, 21 CFR 179.21, 440 (2003)

55. "Limitation of exposure to ionizing radiation ", National Council on Radiation Protection, NCRP Report-116, 1993, 